\title{
Development of a Fuel Cell Hybrid Low-Speed Electric Vehicle Testing Facility
}

\author{
by \\ Sezer Tezcan \\ B. Eng., Kocaeli University, 2001
}

A Thesis Submitted in Partial fulfillment of the Requirements for the Degree of MASTER OF APPLIED SCIENCE

in the Department of Mechanical Engineering 


\section{ABSTRACT}

Low-speed electric vehicles, powered by an electric motor, produce no emissions and travel at speeds below $40 \mathrm{~km} / \mathrm{h}$. These vehicles are designed to complement primary vehicles for local neighborhood transportation.

The fuel cell hybrid electric system has the ideal characteristics needed to power these low-speed vehicles. This type of system can attain a much longer range and a shorter recharge/refuel time when compared with electric vehicles powered solely by batteries.

To optimize these modem vehicles and the fuel cell power system for a given driving environment, the hybrid power system and vehicle must be tested under specific road cycles developed from realistic traffic patterns before mass-production begins. A testing apparatus known as a "dynamometer" is usually chosen for testing purposes.

Dynamometers are used to isolate and quantify a vehicle torque, power output, and dynamics from overall vehicle performance. When combined with drive cycle simulations, dynamometer testing can serve as an effective evaluation tool in vehicle design and optimization. The results from dynamometer testing provide useful information for the theoretical models and guide the design of the vehicle and the fuel cell power system.

A dynamometer system for testing fuel cell hybrid low-speed electric vehicles (FCHLSEVs) is under development at the Institute for Integrated Energy Systems (IESVic) and at the Department of Mechanical Engineering at the University of Victoria. The system is designed to assist in the analysis and development of FCHLSEVs as well as in the validation of current vehicle performance modeling methods. It will be used as a design and evaluation tool for fuel cell - powered vehicles.

The system consists of: roller units, eddy-current absorber and controller, a custom platform for housing, custom connection and adjustment parts, data acquisition electronics and software, and research software developed at UVic. A larger roller unit is considered as a future addition to test larger fuel cell vehicles. 
The thesis work describes the dynamometer system design, including the spatial and structural analyses carried out on the dynamometer. This report gives a background study of fuel cell systems, low-speed vehicles and their testing methods, the configurations of the designed platform structure, its potential variations, and its capacity for testing of various FCHLSEVs, including a fuel cell - powered electric scooter and a utility vehicle. 


\section{ACKNOWLEDGEMENTS}

It gives me a great pleasure for me to thank Dr. Zuomin Dong and Dr. Afzal Suleman for the opportunity they gave me to work on this research area and their invaluable guidance over the course of my work. I also would like to express my gratitude for the assistance of Jeff Wishart, Ph.D. Candidate, Matthew Guenther, M.A.Sc., and the workshop staff Rodney Katz and Ken Begley for their help in manufacturing process. Finally, I would like to thank my parents Sevgi Tura and Dr. Safak Tezcan for their moral and financial supports during my studies in Canada. 


\section{TABLE OF CONTENTS}

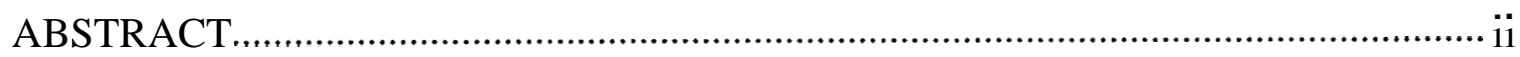

ACKNOWLEDGEMENTS...................................................................................

TABLE OF CONTENTS .................................................................................. v

LIST OF FIGURES …......................................................................................... vii

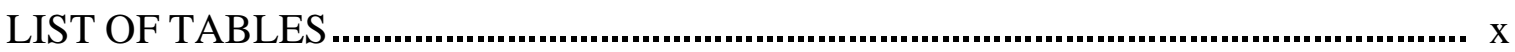

LIST OF ABBREVIATIONS.............................................................................

1 INTRODUCTION .......................................................................................... 1

1.1 Environmental Concerns and Clean Energy Sources ............................................. 1

1.2 Development of Fuel Cell Technology .................................................................. 2

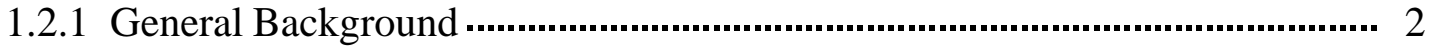

1.2.2 Fuel Cell System Development ............................................................. 5

1.3 Development of Low-Speed Vehicles (LSVs) ………......................................... 6

1.3.1 Low-Speed Hybrid Electric Vehicles (LSHEV) ................................................ 9

1.3.2 Fuel Cell Hybrid Low-Speed Electric Vehicles (FCHLSEVs)........................ 10

1.4 Performance Testing of Low-Speed Electric Vehicles.......................................... 12

1.5 Outline of the Thesis ……............................................................................. 14

2 MODELING OF LOW SPEED ELECTRIC VEHICLEs............................................. 16

2.1 Objective of the Vehicle Model......................................................................... 16

2.2 Power at Wheels of a Scooter ........................................................................ 16

2.3 Powerplant Power of a Scooter....................................................................... 21

3 LOW SPEED ELECTRIC VEHICLE (LSEV) PERFORMANCE TESTING............. 23

3.1 Objective and Scope of Vehicle Performance Testing ......................................... 23

3.2 Methods of Vehicle Performance Testing ........................................................ 26

3.3 Dynamometer for Vehicle Performance Testing ............................................... 27

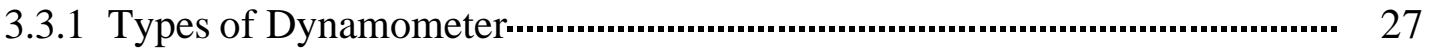

3.3.2 Components of a Dynamometer.......................................................... 28

3.3.3 Data Acquisition from Dynamometers...................................................... 29

4 DESIGN OF THE LOW SPEED ELECTRIC VEHICLE TEST BED........................ 32

4.1 Purposes of the LSHEV Testing Facility at UVic ...................................................... 33

4.2 Key Components and System Configuration - an Overview …….......................... 33

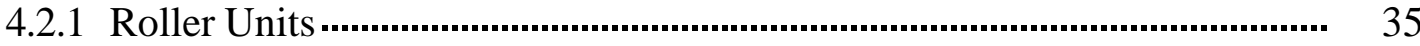

4.2.2 Dynamic Load Absorber and its Controller..................................................... 37

4.2.3 Data Acquisition Electronics, Analysis and Load Control ............................ 40

4.3 Dynamometer Load Calculation ……………………........................................ 43

4.3.1 Inertial Load Calculation of the Roller .................................................. 43

4.3.2 Static Load Calculation from the Eddy Current Absorber................................ 44

4.3.3 Combined Load from the Roller and the Eddy Current Absorber.................. 45 
5.1 LSEV Test Bed Platform Design for Housing Dynamometer Components............. 47

5.1.1 Design to Accommodate Two Different Roller Units ........................................ 48

5.1.2 Conceptual Design of fuel cell powered E-Gator ...........................................52

5.1.3 FCHLSEVs settings on the Dynamometer Platform .........................................54

5.2 Vehicle Test Bed Design for Motion Transmission and Load Applications............ 55

5.2.1 Eddy-Current Absorber (ECA) Configuration.................................................... 58

5.2.2 Belt Connection ............................................................................................. 59

5.3 Vehicle Test Bed Design for Data Acquisition........................................................... 61

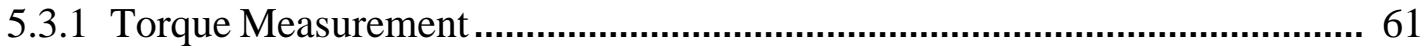

5.3.2 Load Cell Mount and Adjustment Design .......................................................... 62

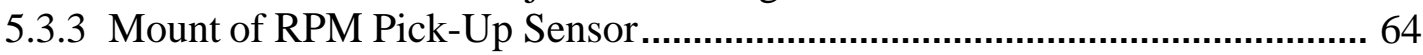

5.4 The Interferences in the Interior Mechanism Design .................................................. 65

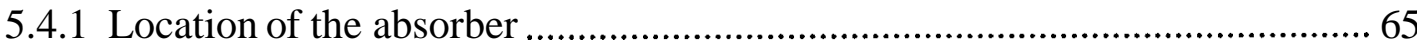

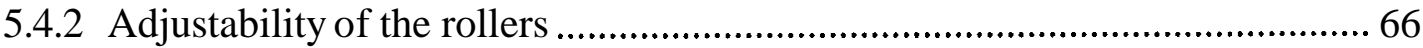

6 OPERATION OF LOW-SPEED ELECTRIC VEHICLE TEST BED (LSEVTB) ..... 69

6.1 General Procedures for Vehicle Testing ............................................................ 69

6.2 System Calibration and Initialization.................................................................... 70

6.3 Operation of Test Fuel Cell _ Battery Hybrid Electric Scooter ................................... 74

6.3.1 Hydrogen Fuel Supply ............................................................................ 75

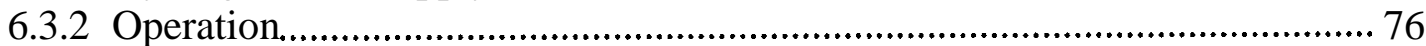

6.3.3 Basic Maintenance .............................................................................. 76

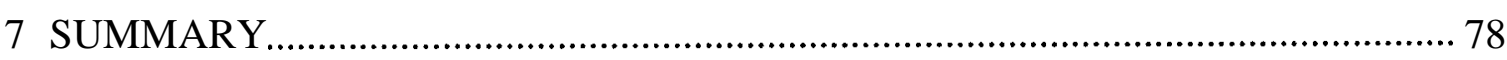

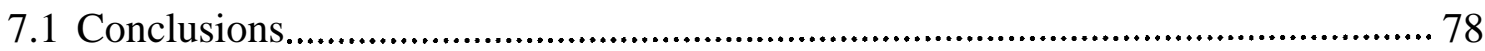

7.2 Future Work and Potential Improvements ............................................................ 78

REFERENCES ........................................................................................... 80

APPENDIX A: Technical Specifications of Various Low-Speed Electric Vehicles .... 82

APPENDIX B： Sample Power Calculation …………………………..................... 88

APPENDIX C: The Brushless DC Motor............................................................... 90

APPENDIX D: Technical Drawings ……………………................................... 91

APPENDIX E: Software Instructions........................................................................ 101 


\section{LIST OF FIGURES}

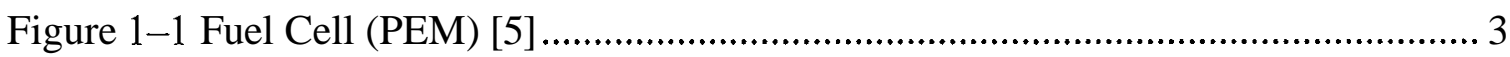

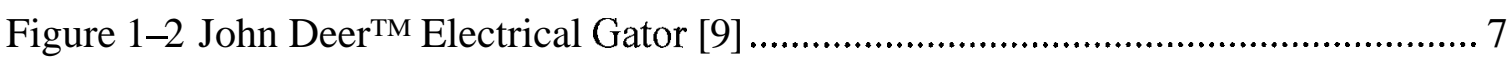

Figure 1-3 AGILTYTM Electrical Scooter and Yamaha G-Max ${ }^{\mathrm{TM}}$ Golf Cart [10] ............. 7

Figure 14 FCHLSEV power system details [9] ............................................................. 11

Figure 1-5 Fuel cell operated CWV by John Deere-Hydrogenics [9]............................... 11

Figure 1-6 Palcan-Celco fuel cell powered scooter [13]............................................... 12

Figure 1-7 Palcan_ UVic fuel cell powered scooter ........................................................... 12

Figure 1-8 Neighborhood Electric Vehicles [15] ........................................................... 14

Figure 2-1 Free-body diagram of a scooter ..................................................................... 17

Figure 3-1 Taipei Motorcycle Driving Cycle _ New York City Cycle [16]......................2 25

Figure 3-2 An Engine Dynamometer (left) - A Chassis Dynamometer (right) [18]....... 27

Figure 3-3 Chassis / Steady state dynamometers [18] ..................................................... 29

Figure 34 Typical Torque-Speed Curves for an ICE [19] and DC motor [20]............... 31

Figure 3-5 Power-torque curve for DC motors (right) [20] ............................................. 31

Figure 4-1 Control Flow Chart of UVic's dynamometer system........................................ 34

Figure 4-2 Go-Kart testing on DYNOmite ${ }^{\mathrm{TM}}$ 5" Roller Unit [18] .................................... 35

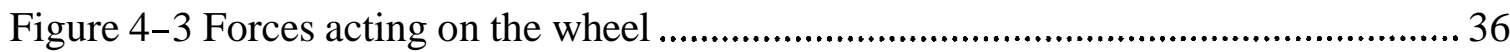

Figure 4-4 12" Dynomite Chassis Roller [18]..................................................... 37

Figure 4-5 Eddy-current absorber (right) and the control unit (left) [18] ...................... 37

Figure 4-6 Eddy Current Absorber details [18] ............................................................... 38

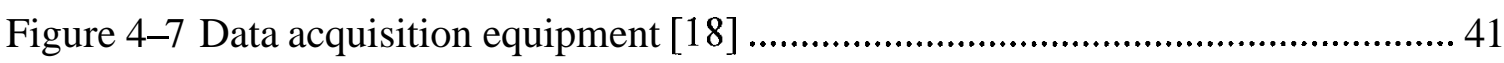

Figure 4-8 The Strain gage and the Load Cell ............................................................ 42

Figure 4-9 Static and Dynamic Load Simulations ............................................................ 46

Figure 5-1 12" (left) and 5" (right) Roller Units............................................................... 48

Figure 5-2 Steel square tubing of the platform frame ................................................... 49

Figure 5-3 The Dynamometer Platform Frame............................................................ 50

Figure 54 The assembly of 5 " roller unit inside the dynamometer platform.................. 51

Figure 5-5 The assembly of 12 " roller unit and the dynamometer platform................... 51

Figure 5-6 Concept fuel cell powered utility vehicle E-Gator ...................................... 53 
Figure 5-7 Fuel cell scooter setting on the dynamometer platform with 5" roller unit ... 54

Figure 5-8 Fuel cell gator setting on the dynamometer platform with 12 " roller unit..... 55

Figure 5-9 The assembly of the dynamometer interior mechanism.................................. 56

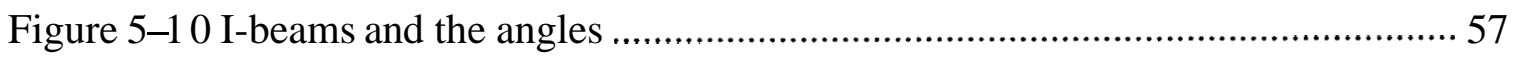

Figure 5-11 The assembly of the ECA system.......................................................... 58

Figure 5-12 The alignment plate ............................................................................... 59

Figure 5-13 The assembly of the belt mechanism with ECA and the roller .................... 60

Figure 5-14 The bushing flange and the pulley............................................................... 60

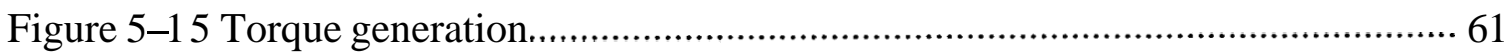

Figure 5-16 F force acting on the load cell. $\mathrm{d}$ distance from the ECA's shaft axis ......... 62

Figure 5-1 7 Load cell and its support plate configurations.............................................. 63

Figure 5-1 8 Load Cell and the related hardware.......................................................... 64

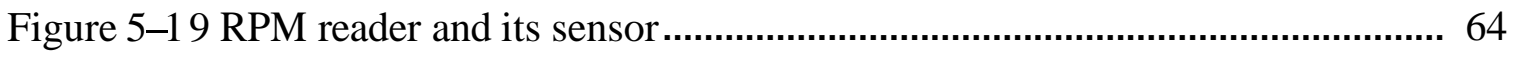

Figure 5-20 The relevance with the belt length.............................................................. 65

Figure 5-21 The distance limitations causing the I-beam cut ....................................... 66

Figure 5-22 The wide and narrow positions of the rollers ............................................ 67

Figure 5-23 Rollers in wide position and the additional raising part ............................... 68

Figure 6-1 Constructed test bed at UVic..................................................................... 69

Figure 6-2 The proper wheel setting on the rollers ................................................... 70

Figure 6-3 Coast-down test ...................................................................................... 71

Figure 64 Maximum speed test............................................................................ 72

Figure 6-5 Random cruising test ............................................................................ 72

Figure 6-6 Sweep test .......................................................................................... 73

Figure 67 Software Console (left - original, right - modified) ......................................... 74

Figure 6-8 UVic fuel cell scooter....................................................................... 74

Figure 6-9 Glove box (left), fuel cell stack and metal hydride canisters (right).............. 75

Figure 7-1 Speed control flow diagram............................................................................ 79

Figure A-2 ZES IV Fuel Cell Scooter...................................................................... 84

Figure A-3 John Deere ${ }^{\mathrm{TM}}$ E-Gator................................................................... 86

Figure C-1 The operation of brushless DC motor ...................................................... 90

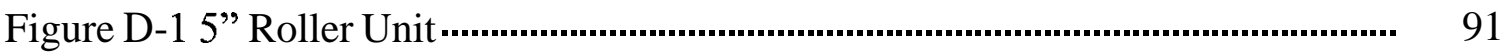




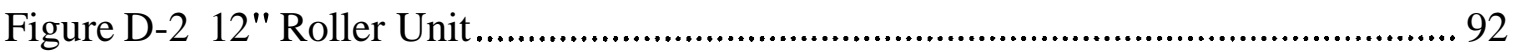

Figure D-3 Dynamometer Platform Main Frame .................................................... 93

Figure D-4 Concept fuel cell powered E-Gator .................................................... 94

Figure D-5 The Alignment Plate for the Eddy Current Absorber .................................. 95

Figure D-6 The Bushing Flange for the Roller-Belt Connection ................................. 95

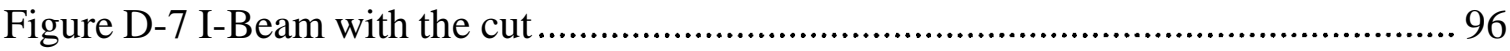

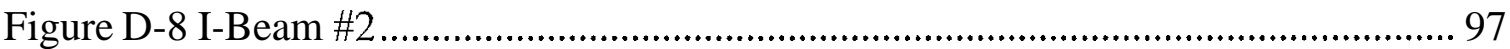

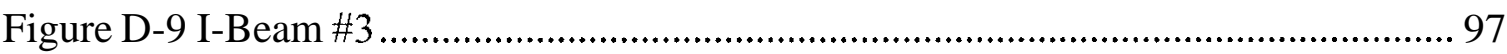

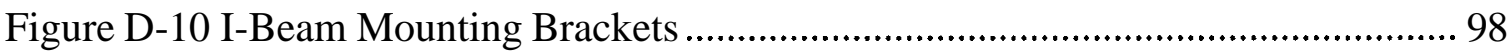

Figure D-11 I-Beam Mounting Brackets ..................................................................... 98

Figure D-12 The Support Plate for the Load Cell....................................................... 99

Figure D-13 The Metal Block for ECA raise............................................................ 99

Figure D-14 The study of raising ECA for rollers wide positions................................ 100 


\section{LIST OF TABLES}

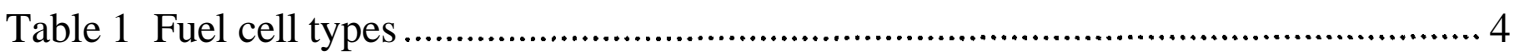

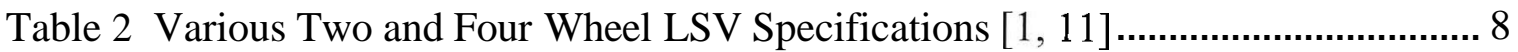

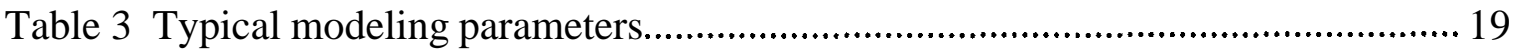

Table 4 Modeling parameters of UVic's electric scooters.......................................... 20

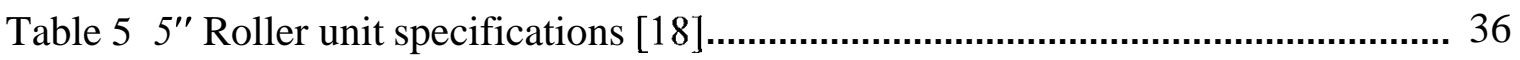

Table 6 Max Low-Speed Vehicle Specifications........................................................ 47

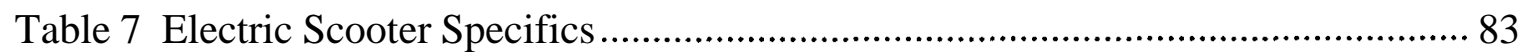




\section{LIST OF ABBREVIATIONS}

\begin{tabular}{|c|c|}
\hline APU & Auxiliary Power Unit \\
\hline $\mathrm{BOP}$ & Balance of Plant \\
\hline $\mathrm{ECA}$ & Eddy-Current Absorber \\
\hline Emf & Electro-magnetic field \\
\hline FCHLSEV & Fuel Cell Hybrid Low-Speed Electric Vehicle \\
\hline GHG & Greenhouse Gasses \\
\hline $\mathrm{HEV}$ & Hybrid Electric Vehicle \\
\hline ICE & Internal Combustion Engine \\
\hline IESVic & Institute for Integrated Energy Systems \\
\hline LSEV & Low-Speed Electric Vehicle \\
\hline LSHEV & Low-Speed Hybrid Electric Vehicle \\
\hline LSV & Low-Speed Vehicle \\
\hline mFUDS & Modified Federal Urban Driving Schedule - used for motorcycles \\
\hline $\mathrm{NEV}$ & Neighborhood Electric Vehicle \\
\hline NYCC & New York City Cycle \\
\hline PEM & Proton Exchange Membrane \\
\hline PPU & Primary Power Unit \\
\hline TMDC & Taipei Motorcycle Driving Cycle \\
\hline UVic & University of Victoria \\
\hline $\mathrm{ZEV}$ & Zero-Emission Vehicle \\
\hline
\end{tabular}




\section{INTRODUCTION}

\section{Environmental Concerns and Clean Energy Sources}

The constant need for energy in every aspect of modern life, together with the growing concern for environmental pollution and greenhouse gasses (GHGs) has sparked interest in new, cleaner and more efficient energy sources. Gasoline-powered vehicles are an essential part of many people's lives and this dependence has caused a significant increase in air pollution over the last several decades. It is believed that the pollutants emitted from fossil fuel-burning internal combustion engines (ICEs) is one of the major contributors to global warming and is also linked to severe human illnesses such as: leukemia, lung cancer, and respiratory disease [1]. Many governments and automobile manufacturers have recognized this problem and a push for the development of cleanerrunning vehicles has been initiated.

Many automobile manufacturers are currently developing zero-emission vehicles (ZEVs) to accommodate, and in some cases replace, heavily polluting internal combustionpowered vehicles. The primary component in replacing the IC-powered vehicles, for most developers, is the electric drive train [2]. Electric drive trains are usually powered by batteries; however, electric vehicles powered solely by batteries have not been widely accepted by the consumer market due to the perceived limitations, such as the limited number of recharging stations, the inadequate driving range between recharging, and the prolonged recharging time for the batteries [3]. Due to those limitations, vehicles that incorporate fuel cell systems are becoming an attractive design option to many developers.

Fuel cell technology is one of the major techniques to reduce the GHGs emitted to the atmosphere and can be applied to just about every process that requires energy. Transportation, portable power, residential, and stationary (power plants, hospitals, public facilities, etc.) applications are some of the many categories in which fuels cells can replace conventional methods. Fuel cells are flexible in their application and they have many advantages over other energy-generation techniques. They significantly reduce air 
pollution, for instance, according to a recent study at University of Victoria (UVic), the $\mathrm{CO}_{2}$ emission of a small utility vehicle - the "Gator", which is a low-speed utility vehicle, is found to be approximately $4 \mathrm{~kg} / \mathrm{h}$ [4]. On the other hand, by using fuel cell systems, zero or low GHG emissions can be obtained. Although noise pollution does not receive significant publicity as a public nuisance, it may become one in the future; fuel cells are extremely quiet and would drastically lower the decibel level of urban areas. One of the waste products of fuel cell operation is heat, and this waste heat can be harnessed to provide space heating and hot water. Since fuel cells are more efficient power conversion devices, they are therefore theoretically capable of higher performance; furthermore, because the fuel cell contains no moving parts, they promise a lower level of required maintenance than current fossil fuel - burning technologies.

\subsection{Development of Fuel Cell Technology}

\subsubsection{General Background}

A fuel cell is a device that converts chemical energy from hydrogen and oxygen into electrical energy, producing an electrical current. It is similar to a battery in that it has an anode and a cathode. However, a battery is only capable of storing power, whereas the fuel cell can generate power, so long as fuel is being continuously supplied. As such, the fuel cell system is more similar to an engine, except that it operates very efficiently at low temperatures and with minimal moving parts. In the process of electrochemical conversion to create electricity, the only by-products of the fuel cell are water and heat. The illustration of a fuel cell, the proton exchange membrane (PEM) type which is discussed in the following paragraphs, is given in Figure 1-1.

To produce a usable amount of electricity, multiple fuel cells are combined into a fuel cell stack. The stack is essentially an assembly of multiple fuel cells, designed to produce a sufficient quantity of electricity and sufficiently high voltage to power an appliance of the application. The fuel cell stacks are modular, and the electricity generated can be increased or decreased by altering the number of cells in the stack. 


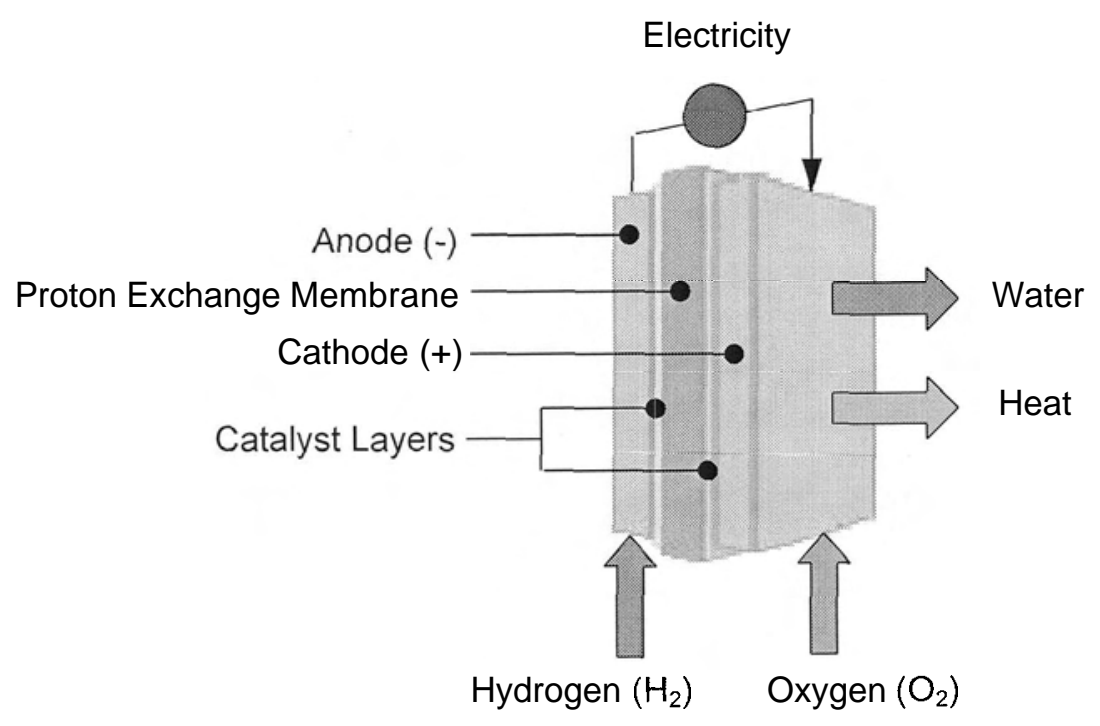

Figure 1-1 Fuel Cell (PEM) [5]

Producing electrical power for a working application, such as an engine or an appliance, requires much more than just the fuel cell stack. In addition to the stack, a fuel cell system includes many components, and demands considerations on a number of related issues, for instance the Balance of Plant (BOP), injection of fuel and oxidant gases, management of a critical water balance, conditioning of the output power, and monitoring and control of all the required system parameters such as temperatures and pressures. Without this supportive operating system, the fuel cell stack cannot produce usable power. The successful integration of an entire fuel cell system is critical to achieving the desired power performance. Over the past decades, fuel cells of several different types have been developed. Each one has its idiosyncratic advantages and disadvantages as described in Table 1 [6].

Among these fuel cells, PEM fuel cell is the most viable candidate for automobiles and low-speed vehicle applications due to its low operating temperature and resulting quick start time [7]. These PEM fuel cells operate at relatively low temperatures $\left(60-80^{\circ} \mathrm{C}\right)$, have a high power density, can vary their output quickly to meet shifts in power demand, and are suited for applications, such as in automobiles and in low-speed vehicles, where a quick startup is required. 
Table 1 Fuel cell types

\begin{tabular}{|c|c|}
\hline $\begin{array}{r}\text { Solid Oxide } \\
\text { (SOFC) }\end{array}$ & $\begin{array}{l}\text { - } 40-60 \% \text { efficient or higher with cogeneration } \\
\text { (a thermodynamic process that simultaneously produces heat } \\
\text { and power) } \\
\text { - Operation around } 1000^{\circ} \mathrm{C} \\
\text { - Output of } 220 \mathrm{~kW} \\
\text { - Positive potential for high power applications } \\
\text { - Close to commercialization. }\end{array}$ \\
\hline Alkaline & $\begin{array}{l}\text { - } 70 \% \text { efficient } \\
\text { - Operation at } 150-200^{\circ} \mathrm{C} \\
\text { - } \quad \text { Ustput of } 300 \mathrm{~W}-5 \mathrm{~kW} \\
\text { - } \quad \text { Close to commercialization. }\end{array}$ \\
\hline $\begin{array}{r}\text { Proton } \\
\text { Exchange } \\
\text { Membrane } \\
\text { (PEM) }\end{array}$ & $\begin{array}{ll}- & 40-50 \% \text { efficient } \\
- & \text { operation around } 80 \cdot \mathrm{C} \\
\text { - } & \text { Output of } 50-250 \mathrm{~kW} \\
\text { - } & \text { High power density } \\
\text { - } & \text { Already commercialized because it can vary output quickly, but } \\
& \text { is sensitive to fuel impurities. }\end{array}$ \\
\hline $\begin{array}{r}\text { Molten } \\
\text { Carbonate } \\
\text { (MCFC) }\end{array}$ & $\begin{array}{l}\text { - } 50-60 \% \text { efficient or higher with cogeneration } \\
\text { - Operation around } 650^{\circ} \mathrm{C} \\
\text { - } \quad \text { Output of } 10 \mathrm{~kW}-2 \mathrm{MW} \text {, } \\
\text { - } \quad \text { Can use a wide variety of fuels and inexpensive catalysts. } \\
\text { - Corrosion and breakdown of cell component are problems. }\end{array}$ \\
\hline $\begin{array}{r}\text { Phosphoric Acid } \\
\text { (PAFC) }\end{array}$ & $\begin{array}{ll}\text { - } & 40-50 \% \text { efficient } \\
\text { - } & \text { Operation at } 150-200{ }^{\circ} \mathrm{C} \\
\text { - } & \text { Already commercialized } \\
\text { - } & \text { Has an expensive platinum catalyst; low power and current } \\
\text { outputs compared to other fuel cells, and the machines are } \\
\text { bulky and heavy. }\end{array}$ \\
\hline $\begin{array}{c}\text { Regenerative } \\
\text { Fuel Cells }\end{array}$ & $\begin{array}{l}\text { "Closed-loop" power generation; currently being studied; uses } \\
\text { solar-powered electrolysis to convert water into oxygen and } \\
\text { hydrogen. } \\
\text { - The hydrogen then passes through the fuel cell to form water, } \\
\text { which will be electrolyzed into reusable fuel. }\end{array}$ \\
\hline
\end{tabular}

PEM serves as the electrolyte of this particular type of fuel cell. Its material is sulphonated fluoropolymer a thin sheet that allows hydrogen ions $\left(\mathrm{H}^{+}\right)$to pass through it while remaining impermeable to elections. The solid electrolyte is an advantage because it can be made very thin, reduces corrosion of the electrodes, and it allows for a lower operating temperature since the electrolyte does not require a high temperature to keep it in liquid state. Hydrogen is fed to the anode side of the fuel cell where the catalyst "encourages" the hydrogen atoms to release electrons and become hydrogen ions (protons). The electrons travel in the form of an electric current through an external 
circuit before they return to the cathode side of the fuel cell where oxygen has been fed. At the same time, the protons diffuse through the membrane (electrolyte) to the cathode, where the hydrogen atom is recombined and reacted with oxygen to produce water, thus completing the overall process. This type of fuel cell is, however, sensitive to fuel impurities and so the hydrogen fuel and oxidant air must be made free from contaminants. The power output of a PEM fuel cell system for vehicular applications generally ranges from 50 to $250 \mathrm{~kW}$. Below are the electrochemical reactions that take place inside the fuel cell.

$$
\begin{aligned}
& \text { Anode: } \mathrm{H}_{2}(\mathrm{~g}) \leftrightarrow 2 \mathrm{H}+(\mathrm{aq})+2 \mathrm{e}- \\
& \text { Cathode: } 1 / 2 \mathrm{O}_{2}(\mathrm{~g})+2 \mathrm{H}+(\mathrm{aq})+2 \mathrm{e}-\leftrightarrow \mathrm{H}_{2} \mathrm{O}(\mathrm{l}) \\
& \text { Overall: } \mathrm{H}_{2}(\mathrm{~g})+1 / 2 \mathrm{O}_{2}(\mathrm{~g}) \leftrightarrow \mathrm{H}_{2} \mathrm{O}(\mathrm{l})+\text { heat }
\end{aligned}
$$

\subsubsection{Fuel Cell System Development}

Fuel cell systems are currently under development and have ideal characteristics for use in low-speed vehicles. They can attain longer ranges and are much more convenient then vehicles powered solely by batteries.

The power demand and system response characteristics knowledge assist in simultaneous sizing of fuel cell and storage device, and in the design of the control strategy. The fuel cell and storage components are sized with the control strategy in mind because it determines the output from each power source. When the power demand and the response characteristics are both based on particular driving cycles, it is possible to design the most efficient system.

In order to optimize fuel cell systems and vehicles, it is valuable to test those vehicles by developing realistic road cycles that can be used to model and test the fuel cell systems before they are produced. Performance testing considers the power demand and system response characteristics for fuel cell vehicles under particular driving patterns or cycles. The main intent is to develop load cycles that represent power demands based on realworld simulations. Once load cycles have been developed, they can be applied to 
computer models and physical testing apparatus to simulate and test the performance of the fuel cell power system that is used to drive the vehicle. Testing and system modeling is an effective way to reduce development costs and is an important part of the design process. Once confidence in the fuel cell system has been achieved; the fuel cell vehicle can be designed. One effective way to observe and compile accurate data pertaining to the real-world system response of a fuel cell vehicle is by dynamometer testing. Dynamometer testing well duplicates the driving cycles of vehicle use in a laboratory setting. It allows different driving conditions from ordinary use to extremes to be quickly tested, serving as an ideal evaluation tool in fuel cell vehicle design and optimization.

Fuel cell vehicle performance testing can also be observed in diagnostics. Often, the data from several performance tests can be analyzed in order to isolate and diagnose a specific problem or attribute within the vehicles' mechanics. Once the source has been identified, the component, or setting can be changed and the vehicle is retested to verify that the change has alleviated the problem.

\subsection{Development of Low-Speed Vehicles (LSVs)}

Under current Canadian federal regulations, LSVs are four-wheeled electric vehicles that have a minimum attainable speed of $32 \mathrm{~km} / \mathrm{h}$ and a maximum of $40 \mathrm{~km} / \mathrm{h}$, on a paved level surface [8]. These vehicles are designed to complement primary vehicles for local neighborhood transportation and also for applications such as warehouse and mining

mechanical support. The Canada Gazette Part II is currently being finalized and this will amend the Motor Vehicle Safety Regulations to introduce LSVs as a new vehicle class in Canada. The Canadian definition of LSVs generally reflects those of other countries; however slightly different definitions also exist. In this thesis, the definition of LSV is broadened to include two, three or four wheel vehicles such as: scooters, ATVs, motorbikes, golf carts, and small utility vehicles (e.g. Gators) illustrated in Figure 1-2 and Figure 1-3.

Due to the smaller size and the reduced mass of LSVs, there is a potential for significant reduction in energy consumption in the area of personal transportation when an LSV is 
used in lieu of a passenger car. At present the trend of LSV development is to have an electrical drive train, as a zero emission vehicle with significantly reduced noise levels.

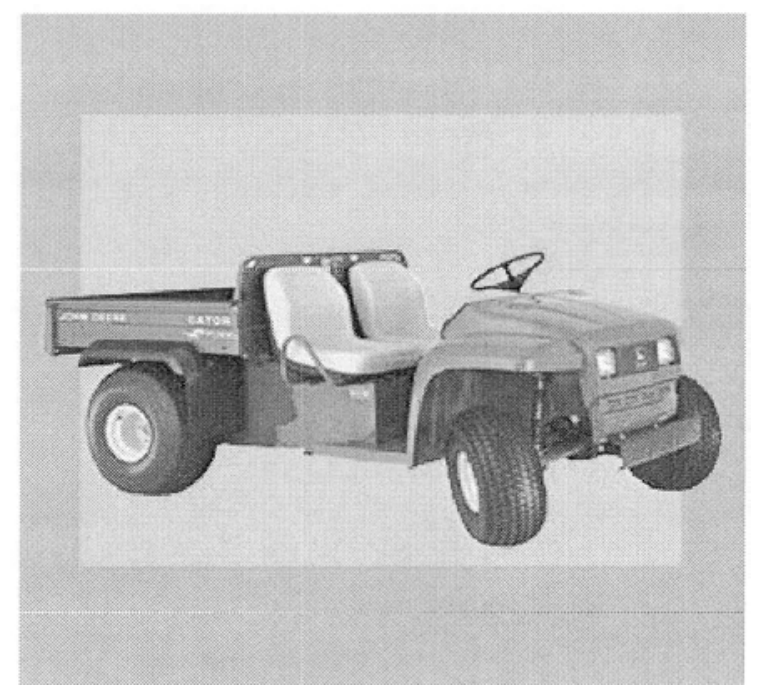

Figure 1-2 John Deer ${ }^{\text {TM }}$ Electrical Gator [9]
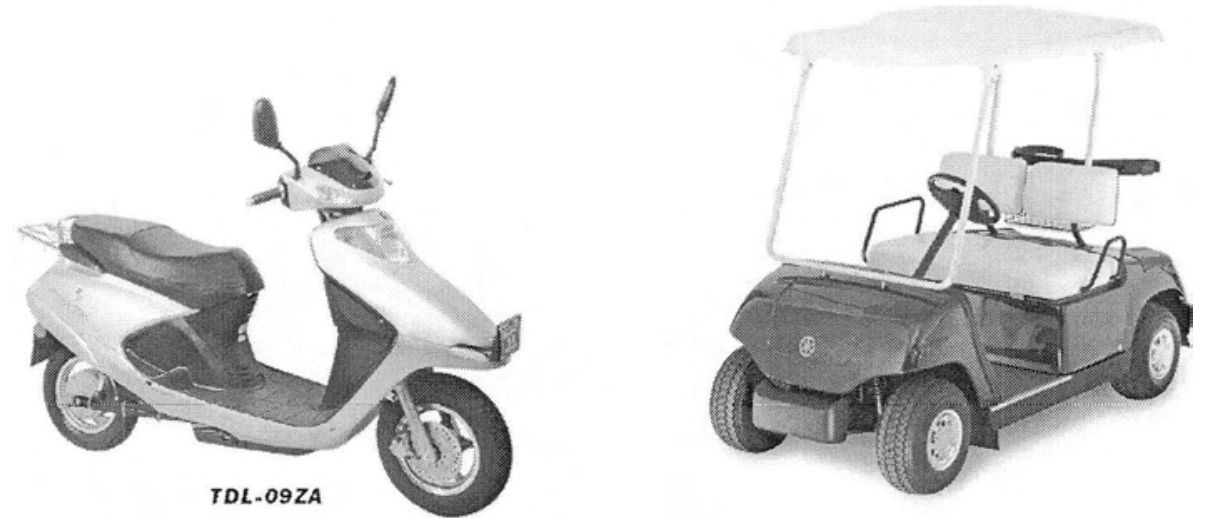

Figure 1-3 AGILTYTM Electrical Scooter and Yamaha G-Max ${ }^{\mathrm{TM}}$ Golf Cart [10]

LSVs are relatively new to the North American market and there remains a great deal of room for development. Ideally, LSVs would be less expensive to purchase, operate and maintain than ICE automobiles.

Some technical information for several LSVs is presented in Table 2. The vehicle types range from ordinary gasoline scooters to prototype electric scooters to a much heavier demonstration fuel cell - powered golf cart which is included because it is virtually the 
only PEM fuel cell vehicle designed at the 4-6 kW power output level. The power specification given is the mechanical/continuous power at the wheels. The power source (battery, fuel cell, ICE) typically produces $30 \%$ more energy than is actually measured at the wheels. This power loss occurs through the drive train and also due to the auxiliary components of lights, compressors, water pumps, and other electrical devices. This table was also used as a guide to design the LSV testing platform at UVic in the following chapters.

Table 2 Various Two and Four Wheel LSV Specifications [1, 11]

\begin{tabular}{|c|c|c|c|c|c|c|}
\hline Vehicle & Name & $\begin{array}{c}\text { Maximum } \\
\text { Motor } \\
\text { Power } \\
(\mathrm{kW}) \\
\end{array}$ & $\begin{array}{c}\text { Range } \\
(\mathrm{km})\end{array}$ & $\begin{array}{l}\text { Top } \\
\text { Speed } \\
\text { (kmlh) }\end{array}$ & $\begin{array}{c}\text { Curb } \\
\text { Weight } \\
\text { (kg) }\end{array}$ & $\begin{array}{l}\text { Wheel } \\
\text { Track } \\
(\mathbf{m m})\end{array}$ \\
\hline $\begin{array}{r}\text { E-Gator Electric } \\
\text { Utility Vehicle }\end{array}$ & John Deere & 2.8 & & 25 & 600 & 1500 \\
\hline $\begin{array}{r}\text { Electric } \\
\text { Motorcar }\end{array}$ & GEM E580 & & & 37 & 380 & 1335 \\
\hline $\begin{array}{l}\text { Neighborhood } \\
\text { Electric Vehicle }\end{array}$ & GEM $^{4}$ & & 50 & 40 & 564 & 1335 \\
\hline $\begin{array}{r}\text { Fuel Cell } \\
\text { Electric Golf } \\
\text { Cart }\end{array}$ & Schatz & $\begin{array}{l}1.5(4 \mathrm{~kW} \\
\text { fuel cell) }\end{array}$ & 24 & 20 & 380 & 1300 \\
\hline $\begin{array}{r}\text { Ni-Cd Battery } \\
\text { Powered } \\
\text { Electric Sronter }\end{array}$ & Honda $\underset{E S}{ }$ CUV & 3.2 & 35 & 60 & 130 & $n / a$ \\
\hline $\begin{array}{l}\text { Lead-Acid } \\
\text { Battery Powered } \\
\text { Electric Scooter }\end{array}$ & $\begin{array}{l}\text { Taiwan ITRI } \\
\text { ZES-2000 } \\
\end{array}$ & 3.4 & 60 & 50 & 105 & $\mathrm{n} / \mathrm{a}$ \\
\hline $\begin{array}{r}\text { Two Stroke ICE } \\
\text { Scooter }\end{array}$ & Honda Dia & 5 & 240 & 70 & 68 & $\mathrm{n} / \mathrm{a}$ \\
\hline Electric Bicycle & Zap & 0.3 & 19.3 & 25.7 & 26.8 & $\mathrm{n} / \mathrm{a}$ \\
\hline Electric Bicycle & $\begin{array}{l}\text { Puwerbike } \\
\text { Suzhou Small } \\
\text { Antelo e }\end{array}$ & 0.23 & 60 & 20.9 & 34.9 & $\mathrm{n} / \mathrm{a}$ \\
\hline
\end{tabular}

When compared to other LSVs, the 3-5 kW power requirement for a scooter that has small dimensions and lightweight, is a relatively high. However, this high power output is necessary due to the way in which scooters are driven under typical urban conditions [11]. Rapid acceleration is required to dodge in-between larger vehicles in congested traffic, and is useful for quick starting from a stopped position. For most LSVs, the average speeds and average power are low, but peak power can be high. 


\subsection{Low-Speed Hybrid Electric Vehicles (LSHEV)}

LSHEVs have two or more sources of onboard power, such as an ICE and a battery, or a fuel cell and a battery. The battery serves as an energy reservoir to provide the necessary power during, for example, acceleration or hill-climbing, as a means to store the surplus power at lower speeds and stops, and as a means to collect the recovered power from regenerative braking. Alternatively, an ultra-capacitor, a flywheel and a number other devices can also be used.

By integrating the power plant with various energy reservoirs, different types of LSHEVs can be produced; nevertheless, in order to direct the flow of power and to maintain adequate reserves of energy in the storage devices, a power control strategy is needed. This control strategy allows the components to work together in an optimal manner to achieve multiple design tasks, such as high fuel economy [12]. Detailed specifications and images of several LSHEVs are illustrated in Appendix A.

Various LSHEVs can be distinguished according to the series or parallel connections or a combination of both from the multiple sources of onboard power to the wheels of the vehicle [12].

- In a LSHEV with a series power train, the primary power unit (PPU), an ICE or a fuel cell, only generates electricity to be stored in the battery, and the motor draw electrical power from the battery to drive the wheels.

- In a LSHEV with a parallel power train, the auxiliary power unit (APU), such as battery and the PPU have their power outputs merged to the drive the wheels. The APU does not receive power from the PPU.

- The combination of series and parallel designs combines the best aspects of both, not only allowing the PPU to directly drive the wheels but also allowing it the ability to charge the energy storage device, the APU.

Regenerative braking, which converts wheel motion into electrical energy through the use of a generator, is another advantage of LSHEVs. Regenerative braking is the process by which some of the kinetic energy stored in the vehicle's moving mass is converted to 
potential energy through charging of the energy storage device during braking. In most electric vehicles and LSHEVs on the road today, this is accomplished by operating the traction motor as a generator, providing braking torque to the wheels and recharging the traction batteries. The energy provided by regenerative braking can then be used for propulsion or to power vehicle accessories.

Despite the attraction they offer in the form of zero emissions, battery-powered electric vehicles have failed to capture significant market shares due to their present drawbacks, including limited range, long battery recharge time, and the failure to match the performance of existing alternatives.

\subsubsection{Fuel Cell Hybrid Low-Speed Electric Vehicles (FCHLSEVs)}

FCHLSEVs are by definition, the vehicles with a combination of a fuel cell and an energy storage device. In these systems, the storage device is charged during operation, electrical energy can be stored during braking (regenerative braking), the driving range is greater than the vehicles powered solely by batteries [1], and the hydrogen refueling time takes dramatically less time when compared to the time required to recharge a battery. The low weight of the system is another advantage considering the large weight of the equivalent battery-powered system with the same efficiency. However, due to the complexity of the involved technologies and the lack of substantial prior experiences, the design and development of FCHLSEVs is a much more difficult task with many technical challenges.

Examples of LSFCHEVs include a small utility vehicle developed by Hydogenics Corp. and a fuel cell scooter developed by Palcan Ltd.

The fuel cell stack (HyPM20) shown in Figure 1-4 is built by Hydogenics for commercial work vehicles (CWV) and it delivers $20 \mathrm{~kW}$ of power. Due to its superior characteristic for the LSVs, the PEM fuel cell type is used in the system. The integration of this fuel cell stack in CWV was performed by John Deere (Figure 1-5). 


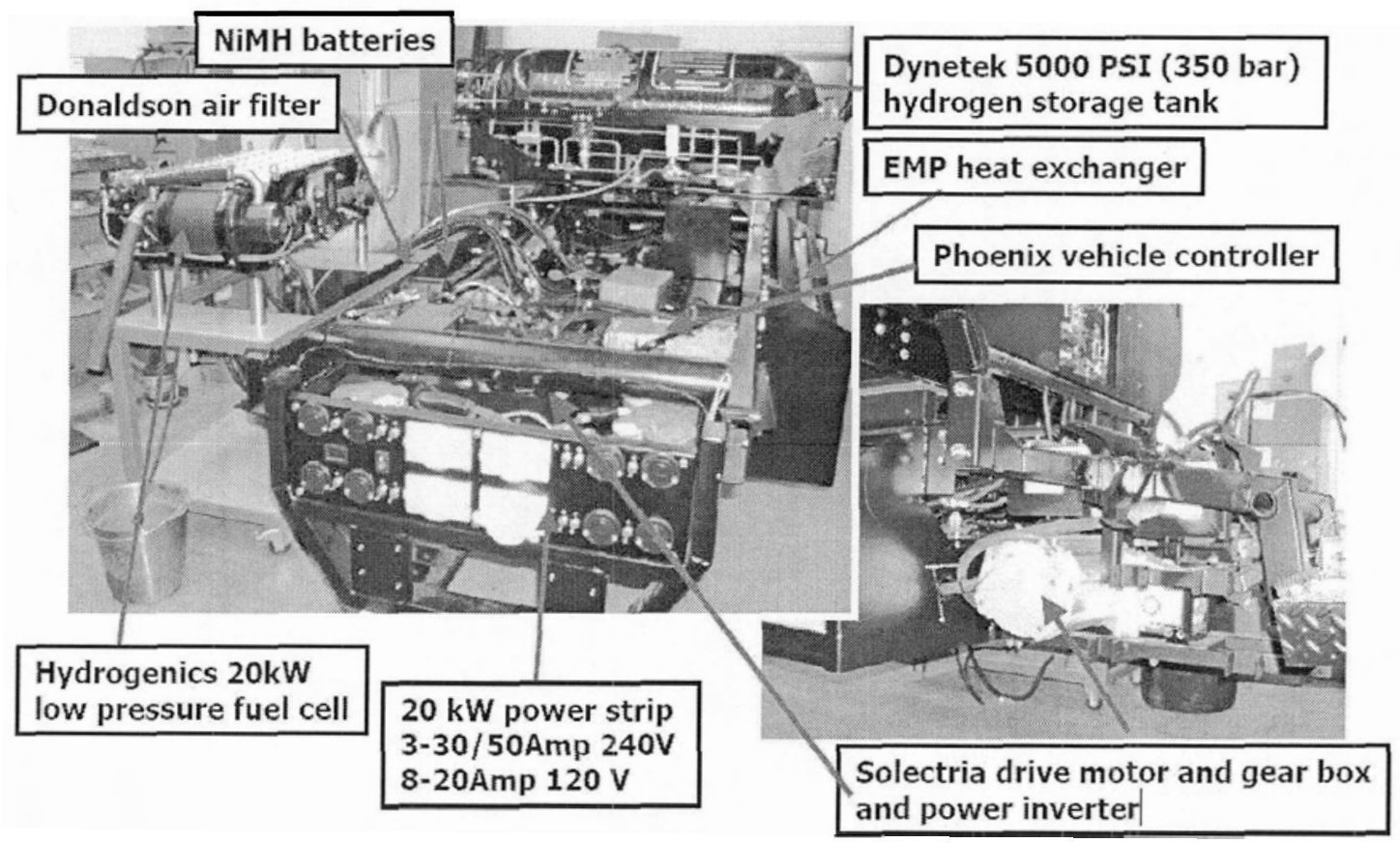

Figure 1-4 FCHLSEV power system details [9]
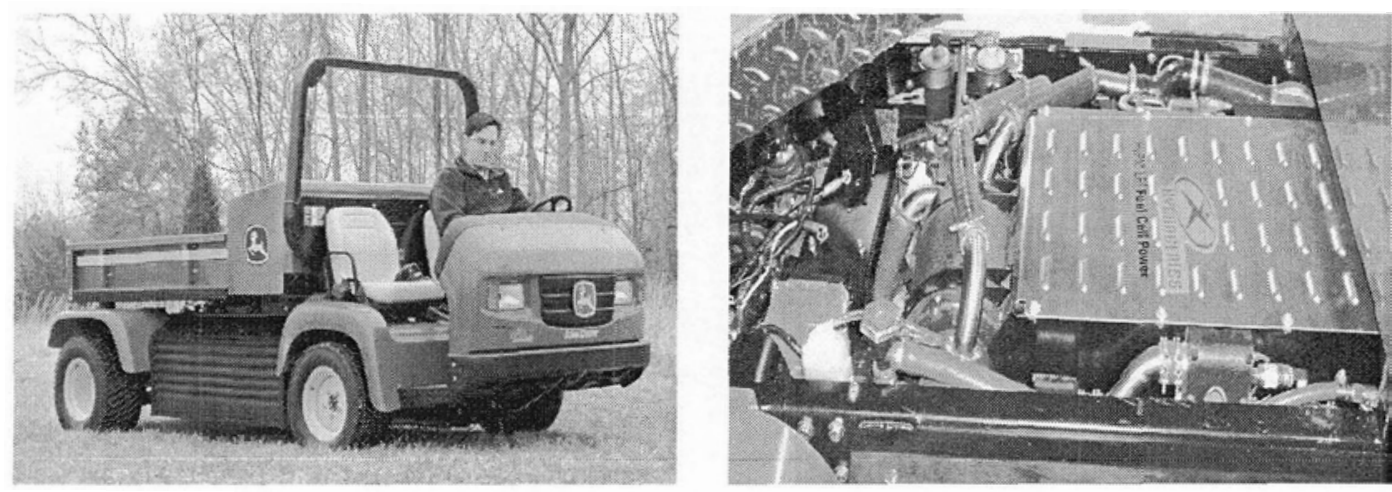

Figure 1-5 Fuel cell operated CWV by John Deere-Hydrogenics [9]

Over the past years, Palcan has formed strategic partnerships with LSEV developers and researchers in British Columbia and around the world, and carried out extensive research and development on fuel cell - battery hybrid electrical scooters and bicycles [13]. The first prototype fuel cell powered electrical scooter was developed using in-house PEM fuel cells metal hydride hydrogen storage, and power electronics technologies, with the Italian electric scooter manufacturer, Celco, in 2002-2003. In 2004, the second generation, fuel cell - battery hybrid electrical scooter was jointly developed by Palcan and IESVic of UVic for the FCHLSEV testing facility at UVic. The vehicle was 
designed using an improved vehicle design and simulation software package, ADvanced Vehicle SimulatOR (ADVISOR). Palcan's advanced PEM fuel cell, metal hydride hydrogen storage, and power electronics technologies are incorporated into this new development.

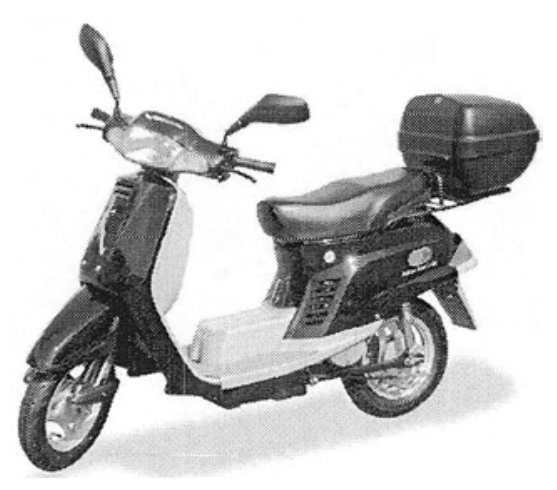

Figure 1-6 Palcan-Celco fuel cell powered scooter [13]
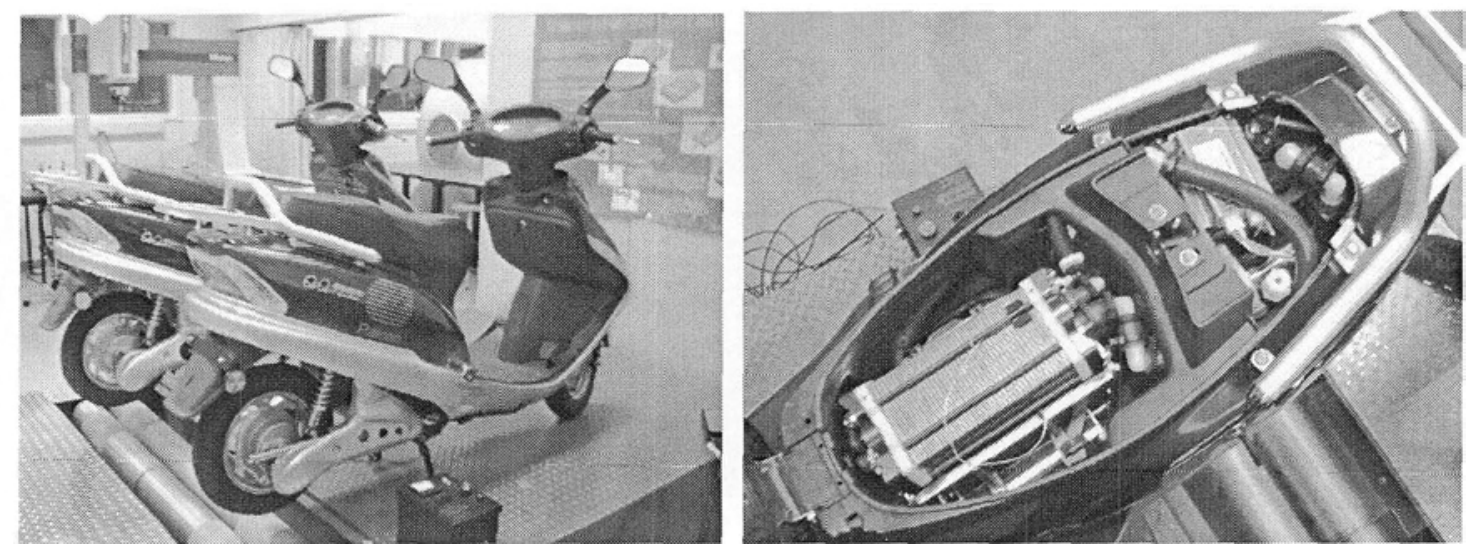

Figure 1-7 Palcan - UVic fuel cell powered scooter

\subsection{Performance Testing of Low-Speed Electric Vehicles}

Over the past several years, much effort has been devoted to test various LSEV as part of the development, and as part of the vehicle certification process. The primary purpose for these tests is road safety and functionality. 
To provide for independent assessment of Neighborhood Electric Vehicles (NEVs), which are considered to be pure electric vehicles intended for on-road use as LSEVs, the NEV America Program is sponsored by the U.S. Department of Energy Office of Transportation Technology [14]. Vehicles tested under this program are evaluated against specific qualitative and quantitative metrics. The results provide potential users a method for comparing various NEVs against consistent standards. For a vehicle to be considered as qualified for testing under the NEV America Program, it must comply with the program's minimum criteria. Vehicles that do not or cannot comply with all of the minimum requirements will be considered prototypes, and will not be considered as having successfully completed the program. All of the following requirements must be met by any vehicle before it can receive consideration under the NEV America Program [15]. The program tests can be briefly outlined as:

1. Rough road course test to accumulate standardized test mileage on each vehicle over a test track that includes rough road, water hazard and smooth track, to test the vehicles' ability to endure extreme conditions in a short time frame, and to collect energy use data for the determination of charging efficiency.

2. Braking test to subjectively evaluate the controllability of a vehicle during braking on wet and dry surfaces (both the stopping distance and the ability to maintain the vehicle in control, defined as staying in the course lane).

3. Road course handling test, to determine the minimum time required for a vehicle to perform a qualitative assessment of its stability and handling capabilities; battery charging, to provide guidance on charging traction batteries during the time the vehicle is being subjected to the program.

4. Measurement and evaluation of battery charger performance, and vehicle verification, to provide a traceable, quantifiable methodology for the collection and evaluation of electric vehicle charger data which is meant to quantify results obtained from operation of the battery charger when charging the battery from a complete discharge and when operating in the float mode.

5. Electric vehicle acceleration, gradeability, deceleration, and constant speed range tests. In those tests, although the dynamometers are an option for most other 
vehicle types, the NEVs are not dynamometer tested for a couple of reasons such as; the inexistence of a drive cycle that they are even remotely able to achieve due to their low top speeds, and they are really only driven one way - either stopped or the "gas" pedal is on the floor. Therefore, they do the "brick" test - they drive the NEV with the pedal to the floor until the vehicle is no longer able to maintain their maximum speed of $18 \mathrm{mph}$. Experience suggests this is a fairly good indicator of a NEV's real-world range. [15]

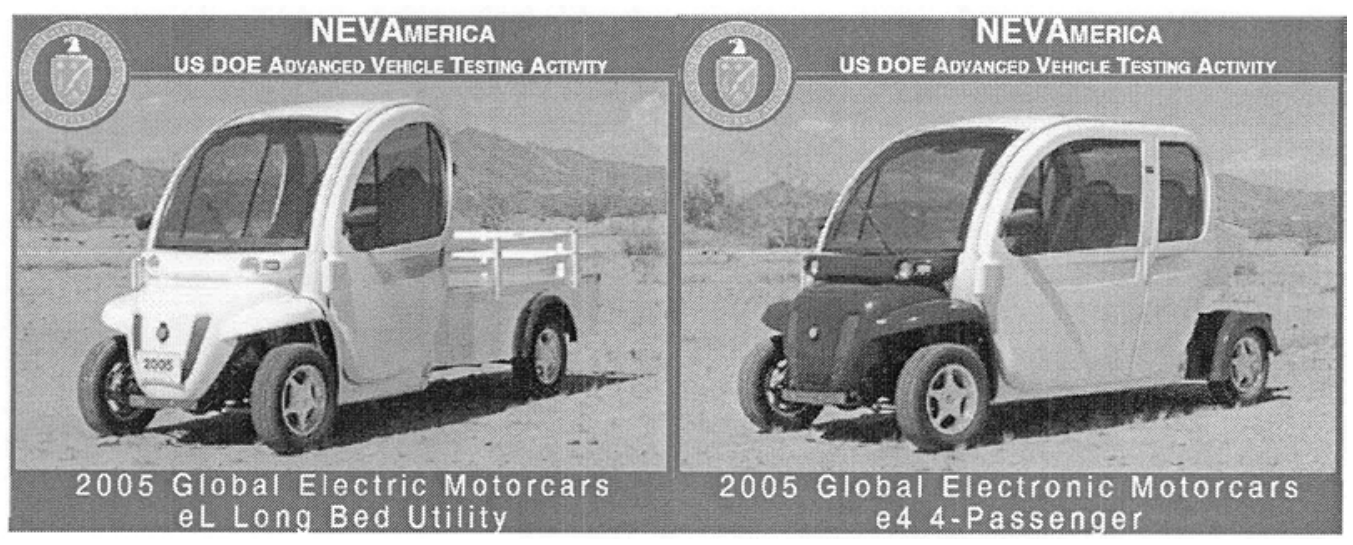

Figure 1-8 Neighborhood Electric Vehicles [15]

In this work, the main purpose for LSEV testing is to better understand the power plant requirements of these vehicles and how a fuel cell power system can be better designed to serve as the power plant to operate these LSEVs. The load cycles of the fuel cell system are to be derived from the vehicle tests under typical driving cycles.

\subsection{Outline of the Thesis}

Chapter 1 gave the background information about environmental concerns and clean energy sources, supports and introduces the fuel cell technology as one of the ways to overcome these problems particularly in the LSVs area, and the testing basics for their improvement.

Chapter 2 presents the mathematical model for an electric scooter. The model will be used to determine the key parameters used in the vehicle simulation and testing. 
Chapter 3 gives the objectives and the methods of testing LSEVs. Background information about dynamometers, which are arguably the best method for vehicular testing, is given including the basics of data acquisition and evaluation from dynamometers.

In Chapter 4, the purpose of the LSEV testing facility at UVic, key components of the dynamometer testing bed and system configuration, as well as the dynamometer load calculation are introduced.

In Chapter 5, the design of the dynamometer system with the configurations of the designed platform structure, its potential variations, and its ability for testing of various FCHLSEVs, including the fuel cell powered electric scooter and utility vehicle are carried out, using the Pro/ENGINEER (Version Wildfire2) CAD System.

Chapter 6 describes the operations of the LSEV test bed and the test fuel cell - battery hybrid electric scooter. The dynamometer system set up, initialization, and the procedures for vehicle testing are discussed.

Chapter 7, the summary, covers the conclusion, the future work, and the potential improvements to the dynamometer system. 


\section{MODELING OF LOW SPEED ELECTRIC VEHICLES}

This chapter presents the mathematical model for an electric scooter. It can be applied to either a regular battery-powered electric scooter, or a fuel cell - battery hybrid electric scooter. The model will be used to determine the key parameters used in the vehicle simulation and testing. The study focuses on the use of an electric scooter due to its relative simplicity and representative architecture of most LSEVs. More complex LSEVs can be easily modeled using a similar approach. To this end, the first pair of test vehicles of LSEVs at our research laboratory consists of two identical electric scooters with different power plants, battery and fuel cell - battery hybrid.

\subsection{Objective of the Vehicle Model}

The objective for generating the mathematical model of a LSEV is to accurately predict the performance of the vehicle on the road, and to support the design optimization of the vehicle, including its powerplant and control system. The model can imitate the static and dynamic behaviors of the vehicle based on the physics principles and empirically determined parameters. Furthermore, the model can be incorporated into the dynamometer system to simulate the road behavior of the vehicle under different control systems and power plants.

\subsection{Power at Wheels of a Scooter}

The physical model of the electric scooter is usually based on the previous knowledge and practice of ICE-based scooters. Considerable work has been carried out in the area of electric scooter and LSEV design. A number of representative electric scooters were introduced in the Chapter 1 and more detailed information about several LSEVs is given in Appendix A.

To simulate the performance of a scooter, the "power at the wheels" of the vehicle in motion, $P_{\text {wheel }}$, as a sum of the total mechanical power demanded, is commonly used to 
measure the performance of the vehicle. The power at the wheels model, calculated as the dot product of the vehicle velocity and the various forces acting upon the vehicle (as shown in Figure 2-1), considers the following determining factors:

- Force for acceleration

- Force to overcome gravity that is introduced when the vehicle is traveling on an uneven surface

- Rolling resistance of the wheels

- Air resistance or drag

The power at the wheels model is given by;

$$
\begin{aligned}
P_{\text {wheels }} & =\sum \text { Forces } \times v=\left(F_{\text {acceleration }}+F_{\text {incline }}+F_{r r}+F_{\text {drag }}\right) \times v \\
& =\left(m a+m g \sin \theta+m g C_{r r} \cos \theta+1 / 2 \rho_{\text {air }} C_{D} A_{F} v_{\text {aero }}{ }^{2}\right) \times v
\end{aligned}
$$

where; $\mathrm{m}$ is the total mass of vehicle, passengers and cargo, $a$ is the acceleration of vehicle, $v$ is the velocity of vehicle, $\theta$ is the angle of slope, $C_{R R}$ is the coefficient of tire rolling resistance, $C_{D}$ is the drag coefficient, $\rho$ is the density of air, $A_{F}$ is the frontal crosssection area of the scooter, and $v_{\text {aero }}$ is the velocity of the vehicle plus the headwind $(\mathrm{m} / \mathrm{s})$. These force components of the model are illustrated in Figure 2-1.

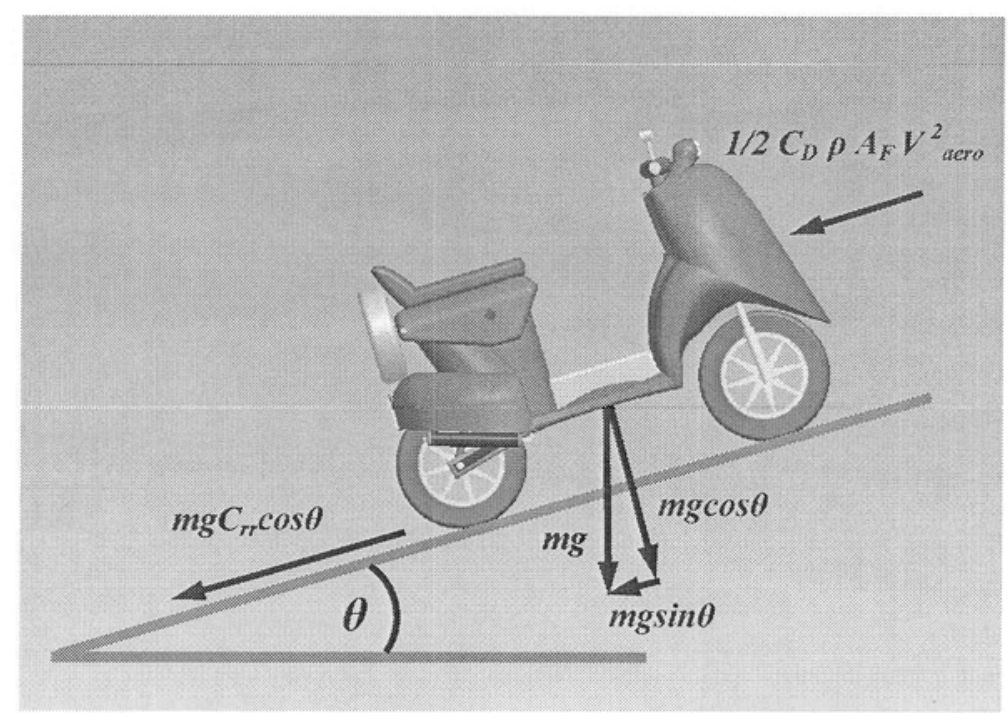

Figure 2-1 Free-body diagram of a scooter 
The power at the wheels scooter model maintains the static power balance of the scooter in motion. Variations of its contributing power terms lead to different conditions.

The first term ma equals to the force required to accelerate the mass can become negative if the vehicle is decelerating and the acceleration becomes negative. If the overall expression for the power at the wheels, $P_{\text {wheel }}$, is positive even though the acceleration term is negative, it means that energy is still needed from the power source to the wheels, because the drag and rolling resistances are larger than the deceleration term. If the $P_{\text {wheel }}$ is negative, this excessive energy is normally consumed by braking power unless active braking or a flywheel is used to absorb it. For an electric vehicle, the excess energy can be used to drive a generator to convert it into electric power and be stored in some type of energy storage devices through active braking. A battery or an ultra-capacitor that is capable of reabsorbing this energy can be used, although normally less than $70 \%$ of the kinetic energy is recoverable. This figure is reduced if rapid deceleration is required, because the battery can only charge up at a certain maximum rate. Ultra-capacitors potentially provide a method for absorbing more of the kinetic energy.

The second term, the opposing force due to the slope, incorporates the force of gravity, and is opposite to the direction of motion.

In the rolling resistance force term, the coefficient of rolling resistance $\left(C_{R R}\right)$ is experimentally obtained, and is a function of many factors including the deformation of the tire, weight of the vehicle, tire pressure, roughness of the surface, and radius of the wheel. It is the ratio of the rolling resistance force to the load on the tires. It is fairly constant for a given tire and road surface.

In the last term - that is, the force due to aerodynamic drag - the drag coefficient $C_{D}$ is a dimensionless constant that attempts to capture the resistance caused by the relative motion of the vehicle and the air. The $C_{D}$ can vary from as high as 1.2 for a bicycle with an erect rider, to 0.47 for a sphere, to 0.20 for a very aerodynamically styled modern automobile. Although the equation used to determine the drag power is a simplification, it avoids complex airflow simulation while preserving the general behavior of the drag 
force with respect to velocity. The frontal cross-section area used here is measured for the scooter by projecting a bright light directly onto the front of the scooter and then measuring the area of the shadow on a wall behind to obtain the cross-sectional area. The density of air $\rho$, is approximately $1.23 \mathrm{~kg} / \mathrm{m}^{3}$.

Vehicle modeling parameters for a typical electric scooter are listed in Table 3 with data for other vehicles for comparison.

Table 3 Typical modeling parameters

\begin{tabular}{|c|c|c|c|c|c|}
\hline Vehicle & $\mathbf{C}_{\mathbf{D}}$ & $\mathbf{C}_{\mathbf{R R}}$ & $\begin{array}{c}\mathbf{A}_{\mathbf{F}} \\
\left(\mathbf{m}^{2}\right)\end{array}$ & $\begin{array}{c}\text { Curb Weight } \\
(\mathbf{k g})\end{array}$ & $\begin{array}{c}\text { Auxiliary } \\
\text { Power W) }\end{array}$ \\
\hline Electric Scooter & 0.9 & 0.014 & 0.6 & 105 & 60 \\
\hline Roadster Bicycle & 1.2 & 0.008 & 0.5 & 10 & 0 \\
\hline Ford AIV Sable & 0.33 & 0.0092 & 2.13 & 1291 & 500 \\
\hline
\end{tabular}

In Table 3, the scooter coefficient of tire rolling resistance was estimated to be 0.014 , based on measurements done at the Desert Research Institute, while the drag coefficient and frontal area were obtained from researchers at the ITRI Mechanical Industry Research Laboratory (MIRL) [11]. A slight mass dependence (less than 6\%) in the drag coefficient reported by the MIRL researchers was ignored. The velocity dependence of the rolling resistance coefficient was likewise neglected. The values chosen were assumed to be for the average-sized rider in a typical position. The average driver weight is defined as $75 \mathrm{~kg}$ [1] (The product of drag coefficient and frontal area can vary dramatically in scooters and bicycles, depending on the size and posture of the driver). Although most two-stroke scooters weight about $80 \mathrm{~kg}$, the presence of lead-acid batteries and/or fuel cell plus hydrogen storage brings the mass of an electric scooter up to approximately $130 \mathrm{~kg}$ (from Table 2) as in the case of the Honda CUV-ES ${ }^{\mathrm{TM}}$ with Ni$\mathrm{Cd}$ batteries, therefore the curb weight was set at $105 \mathrm{~kg}$, as an average weight, which is also the weight of ZES-2000 ${ }^{\mathrm{TM}}$. Auxiliary power, in a typical scooter, the head lights, tail lights, and dashboard consume approximately $50 \mathrm{~W}$. The Ford AIV Sable ${ }^{\mathrm{TM}}$ is a light weight "aluminum-intensive vehicle" and is the size of a modem mid-sized sedan. The bicycle data is for a Roadster ${ }^{\mathrm{TM}}$ upright model [11]. 
To apply the introduced power at the wheels scooter model to the battery powered electric scooter and fuel cell - battery hybrid electric scooter at our research laboratory, the power at wheels, $P_{\text {wheel }}$, model is used with a set of vehicle specific parameters as given in Table 4.

Table 4 Modeling parameters of UVic's electric scooters

\begin{tabular}{|c|c|c|c|c|c|}
\hline & $C_{R R}$ & $C_{D}$ & $\begin{array}{l}A_{F} \\
\left(m^{2}\right)\end{array}$ & $\begin{array}{c}\text { curb } \\
\text { weight } \\
-(\mathrm{ka})\end{array}$ & $\begin{array}{c}\text { auxiliary } \\
\text { power } \\
\text { (W) }\end{array}$ \\
\hline $\begin{array}{r}\text { Battery powered electric } \\
\text { scooter }\end{array}$ & \multirow{2}{*}{0.014} & \multirow{2}{*}{0.9} & \multirow{2}{*}{0.6} & 60 & \multirow{2}{*}{60} \\
\hline $\begin{array}{r}\text { Fuel cell-battery hybrid } \\
\text { electrical scooter }\end{array}$ & & & & 80 & \\
\hline
\end{tabular}

Substituting the values in Table 4 (adding $75 \mathrm{~kg}$ driver weight) into equation (1) for both battery and fuel cell powered scooters, power requirements are obtained:

$$
\begin{aligned}
P_{\text {wheel }}^{\text {battry }} & =\left(\begin{array}{l}
135 a+(135 \times 9.81 \times \sin \theta)+(135 \times 9.81 \times 0.014 \times \cos \theta)+ \\
\left(1 / 2 \times 1.23 \times 0.9 \times 0.6 \times v_{\text {aero }}^{2}\right)
\end{array}\right) \times v \\
& =135 a v+(1324.35 \times \sin \theta \times v)+(18.54 \times \cos \theta \times v)+\left(0.33 \times v^{3}\right) \\
P_{\text {wheel }}^{f c-b t} & =\left(\begin{array}{l}
155 a+(155 \times 9.81 \times \sin \theta)+(155 \times 9.81 \times 0.014 \times \cos \theta)+ \\
\left(1 / 2 \times 1.23 \times 0.9 \times 0.6 \times v_{\text {aero }}^{2}\right)
\end{array}\right) \times v \\
& =155 a v+(1520.55 \times \sin \theta \times v)+(21.29 \times \cos \theta \times v)+\left(0.33 \times \mathrm{vv}^{3}\right)
\end{aligned}
$$

In normal urban use, these scooters are operated at low speed with minor wind as well as smooth and flat road. Due to the low speeds and insignificant tire rolling resistance for light scooter, the power needed for acceleration dominates the maximum power need. The effect of gravity on scooters traveling up a slope is also significant. In other words, for a scooter traveling on a level road and accelerating and decelerating in a typical stopand-start urban driving cycle, the dominant term is mav, and the total power requirement is thus dominated by the mass of the scooter/rider and the velocity/acceleration profile of the drive. Aerodynamic drag, which is related to the relative speed between the vehicle 
and air, tends to be a minor factor at the low speeds at which most scooters are driven, especially in urban areas with minor wind.

\subsection{Powerplant Power of a Scooter}

As mentioned previously, the instantaneous power required from the power plant of the scooter must be higher than the power at the wheels of the vehicle, depending upon the efficiencies of the powertrain, and the power consumption of auxiliary devices and the control system. The amount of power, put out by the power source, is determined as the power at the wheels divided by the motor and control efficiency, plus the auxiliary power.

$$
P_{\text {output }}=\left(P_{\text {wheel }} / \eta_{\text {drivetrain }}\right)+P_{\text {auxiliary }}
$$

where $P_{\text {auxiliary }}$ is the power required by the auxiliary devices (headlights, signal lights, dashboard, etc.), and $\eta_{\text {drivetrain }}$ is the efficiency of the electric motor and controller subsystem (approximated as 0.77) [11].

For a fuel cell power plant, additional power will be needed to satisfy the parasiticpower required by the blowers, fans and coolant pumps. From equation 4 , the power needed at the fuel cell power plant is given by,

$$
P_{\text {output }}=\left(P_{\text {wheel }} / \eta_{\text {drivetrain }}\right)+P_{\text {auxiliary }}+P_{\text {parasitics }}
$$

where, $P_{\text {parasitics }}$ is the parasitic power needed by the fuel cell system. The parasitic and auxiliary powers are the extra electric power requirements in addition to the 0.77 efficiency loss of the controller and the motor. A more sophisticated model would replace the simple single value of $\eta_{\text {drivetrain }}$ by an efficiency map to determine the electric motor efficiency as a function of wheel speed and torque. The factors not considered for this mathematical model include:

- Turning, where the velocity is not parallel to the acceleration direction 
- Wind blowing at an angle to the direction of motion Resistances in other parts of the scooter

Friction in the transmission is assumed to be captured by the drivetrain efficiency 


\section{LOW SPEED ELECTRIC VEHICLE (LSEV) PERFORMANCE TESTING}

The performance of a LSEV is a loosely defined term. In general, many characteristics of the vehicle, including torque and power, braking distance, suspension dynamics and fuel efficiency, are possible performance measurements. In this work, the power demand and system response characteristics of a LSEV are studied to assist the design and development of the FCHLSEVs.

\subsection{Objective and Scope of Vehicle Performance Testing}

During performance testing, empirical data from the tests are analyzed to diagnose and identify specific problems of a given vehicle. Once the weakness of the vehicle is identified, modifications to the original design and its control parameters can be made, and the modified vehicle can be tested again until satisfactory performance is accomplished. Performance tests also serve a critical role in validating various mathematical models and computer simulation programs. Without these tests, the valuable performance models of the LSEV and its power plant cannot be directly used to guide design and development.

Performance testing often examines the power demand and system response characteristics of a vehicle under particular driving patterns or cycles. To best duplicate and represent the typical usage of a vehicle, driving or load cycles are obtained through statistical data of vehicle power demands for a specific application, or its mathematical abstraction. The developed driving cycles can be applied to the performance model of a vehicle, and subsequently to the vehicle itself to simulate and bench test the performance of the power plant. In the case of a fuel cell vehicle, the power plant is the hydrogen fuel cell system.

The needed power of a FCHLSEV to follow a given driving cycle has to be satisfied by the power in the on-board energy storage device and fuel cell power system. For 
instance, the peak power demand during sudden acceleration of vehicle is normally satisfied by the full power of the fuel cell power system and the excessive energy stored in the energy storage device, a battery or an ultra-capacitor. This will allow a smaller fuel cell system with lower cost to be used without sacrifice the acceleration performance of the vehicle. To meet the transient driving cycle, the power demand on the power sources changes according to the driving conditions and the control strategy. An energy storage device, particularly an ultra-capacitor, can release energy much faster than whatever a fuel cell can produce, improving the dynamics of the vehicle as well. Load cycles, based on driving cycles, can then be developed for the fuel cell system by isolating its power demand characteristics from the energy storage device.

Knowledge of the power demand and the system response characteristics assists in the sizing of the key powertrain components of a FCHLSEV (mainly the fuel cell system and the storage device) and the design of control strategy. The control strategy determines the power output from each power source and the components are sized such that most of the power demand can be met. If the power demand and response characteristics are based on a particular driving cycle, the most effective powertrain system of a vehicle used for the given driving patterns in certain geographic areas can be designed.

In the past, the main purpose of driving cycles was to provide tests on various vehicles to collect tailpipe emission data. During these emission tests, the vehicle is normally placed on a dynamometer to go through the simulated drive cycle. This eliminates the inconvenience of road tests and ensures consistent test results. Most drive cycles have high power peaks that require the vehicle to accelerate rapidly to a certain velocity. This type of cycle is more representative of actual driving behaviors than a simple constant driving speed test. Typical small automobile driving cycles include the American mFUDS (Modified Federal Urban Driving Schedule - used for motorcycles) and TMDC (Taipei Motorcycle Driving Cycle). There exist many other standard test cycles; however, most of these driving cycles are based on the same concept and their differences are mainly due to different driving patterns of different geographic locations. 
TMDC originates from the Institute of Traffic and Transportation at the National Chiao Tong University in Taiwan. The velocity profile of the cycle is generated fi-om an instrumented "chase vehicle" that followed a scooter along a specific road route [16]. The Taipei Motorcycle Driving Cycle has an average speed of $19.32 \mathrm{~km} / \mathrm{h}$ and duration of 951 seconds (Figure 3-1/left).
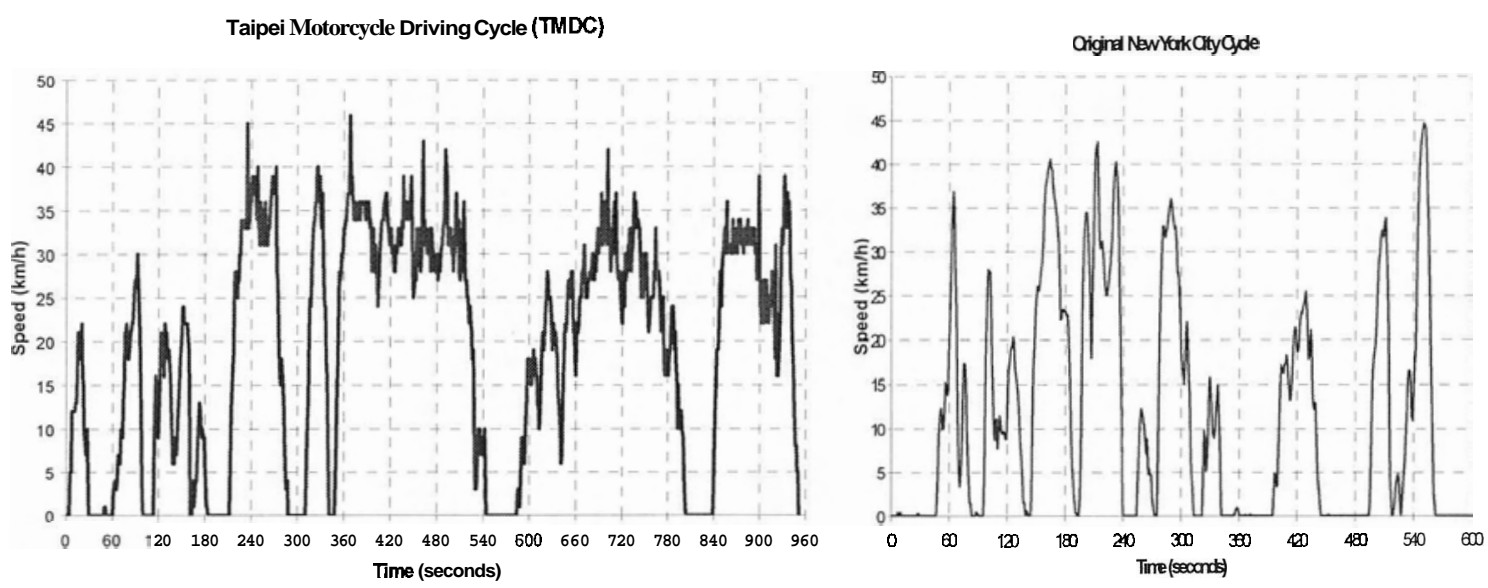

Figure 3-1 Taipei Motorcycle Driving Cycle - New York City Cycle [16]

The New York City Cycle (NYCC) is designed to simulate automobile driving conditions in a large city (Figure 3-1/right). The NYCC simulates traffic conditions that require quick acceleration, short constant speed driving and frequent stops. The velocity of the vehicle can hardly remain constant for a period of time. This test cycle is created by the United States Environmental Protection Agency (USEPA). The NYCC has an average speed of $11.41 \mathrm{~km} / \mathrm{h}(7.09 \mathrm{mph})$, and a maximum speed of $44.58 \mathrm{~km} / \mathrm{h}(27.7 \mathrm{mph})$. The duration of the NYCC test is 598 seconds.

The difference in driving patterns between New York City and Taipei is very noticeable. The average speed of the Taipei driving cycle is approximately 35 percent lower than the New York City's, while the maximum acceleration is approximately 64 percent higher.

In the development of vehicles for diverse markets such as North America and Asia, it is important to consider the different driving patterns that the vehicle is subjected to. 


\subsection{Methods of Vehicle Performance Testing}

There are several methods for testing and optimizing vehicles for specific driving conditions. Computer modeling of automobiles has become an invaluable part of the development strategy for many designers. As described in Chapter 2, the model of a vehicle usually consists of many interrelated mathematical equations that describe its dynamics and system characteristics. These equations are typically implemented into a software package that when given an input will carry out the necessary operations to predict the performance of the vehicle as the output. For a computer model of the fuel cell powered vehicle, the output may include the power produced at the wheels and actual speed of the vehicle, while the input to the model might be the pressures and flow rates of the hydrogen fuel and oxidant air to the fuel cell stack. With the help of such a model, a designer could identify the optimal pressure, flow rate and fuel to oxidant ratio to obtain the maximum power at the wheels, or to find how well the vehicle under design can follow the traffic, defined by the driving cycle, without physically testing any hardware. Furthermore, the designer could hold the input constant and alter the model parameters (such as fuel cell size) to see their effects on the output. It is important to note that the results provided by a model are only as accurate as the model itself. There is no substitute for physical tests and it is essential to validate results obtained through modeling with testing of a real vehicle.

Many useful vehicle performance tests can be carried out on the road, some of which include maximum velocity, braking distance, and maneuverability. However, inherent limitations exist in road testing [17]:

- Difficulty in accumulating tangible data pertaining to: torque, power output, drive train efficiencies and other specific characteristics.

- Repeatability in attempting to obtain experimental data. It is difficult to accurately simulate a driving cycle test by controlling the throttle manually and even more difficult to consistently repeat the test under manual control.

- Other factors inherent to difficulty in road testing include: temperature, humidity, pressure vary constantly, compromising the testing integrity. 
It is therefore advantageous to accompany the road test with other performance tests, such as dynamometer tests that keep many of the variables constant. Dynamometers, commonly referred to as "dynos", are widely used in the automobile industry to measure the torque and the power characteristics of a vehicle at various speeds.

\subsection{Dynamometer for Vehicle Performance Testing}

Dynamometers are used to isolate a particular parameter, generally the torque and the power output of the motor, from the overall vehicle performance and to accurately quantify the parameter effect on said performance. When combined with drive cycle simulations, dynamometer testing can also serve as an evaluation tool in vehicle design and optimization. The results from dynamometer testing can serve as a gauge for theoretical models and can be used to develop realistic load cycles for testing fuel cell systems.

\subsubsection{Types of Dynamometer}

There are two different types or configurations of dynamometer, engine dynamometer and chassis dynamometer (Figure 3-2).
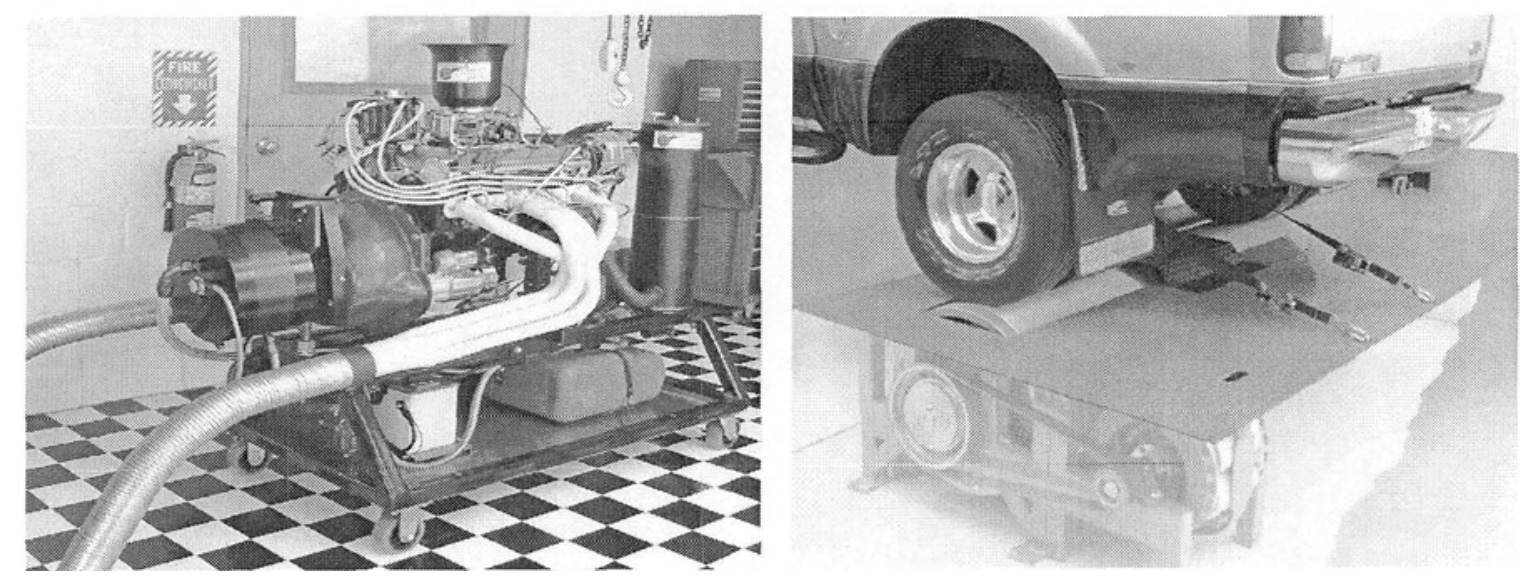

Figure 3-2 An Engine Dynamometer (left) - A Chassis Dynamometer (right) [18]

Engine dynamometers measure the actual output of the engine without the drive train losses, as the dynamometers are coupled directly to the output shaft of the motor. The 
major advantage of engine dynamometers is that they require little additional hardware; therefore, this reduces the cost and the space of the equipment. The engine dynamometer is ideal for the cases where the output shaft of the motor is accessible or the motor is not installed in a vehicle, eliminating the time-consuming task of dismantling the drivetrain in order to hook up the dynamometer to the motor

Chassis dynamometers measure the motor output at the wheels, taking the drive train losses into account and do not require drive train disassembly. The process requires positioning of the vehicle drive wheels on a roller or rollers through frictional contact. The acceleration of the vehicle is directly related to the torque output at the wheels. It is crucial that the rollers are sized properly due to possible deformation of the tire if the roller is considerably smaller than the wheels. The major disadvantages of the chassis dynamometers are that the higher costs of the roller assembly and needed floor space for the chassis dynamometer.

\subsubsection{Components of a Dynamometer}

The chassis dynamometer normally consists of an inertial component and steady-state load component. The inertial component simulate the mass of the vehicle using a constant mass, very likely in the form of a roller, and this mass is further compensated by a dynamic load to obtain the equivalent mass momentum of the vehicle. The steadystate load component of the dynamometer simulates the drag, the force needed to overcome gravity force when the vehicle is on uneven road, and the rolling resistance of the vehicle.

The major advantages of inertial dynamometers are simplicity, good repeatability and maintainability. There is no braking mechanism; therefore, no waste heat that must be dissipated is generated. The main disadvantage is the inability of testing steady-state load on the vehicle during constant-velocity operation and no-flat road operation. The vehicle must accelerate from one speed to another in order to obtain data. Many manufacturers have combined an inertial roller with a steady-state power absorber or brake to remedy these limitations. 
Steady-state dynamometers apply a controlled load on the vehicle by absorbing the power on the wheel or the roller using a braking device or power absorber. There are several types of absorbers available for steady state dynamometer testing: hydraulic oil pump absorbers, water pump absorbers, DC and AC absorbers and Eddy current absorbers. A strain gauge (inside a load cell) is attached to the roller to measure the actual value of the load to both allow the fine control of the load to mimic the operation condition of the vehicle and to record the performance of the vehicle.
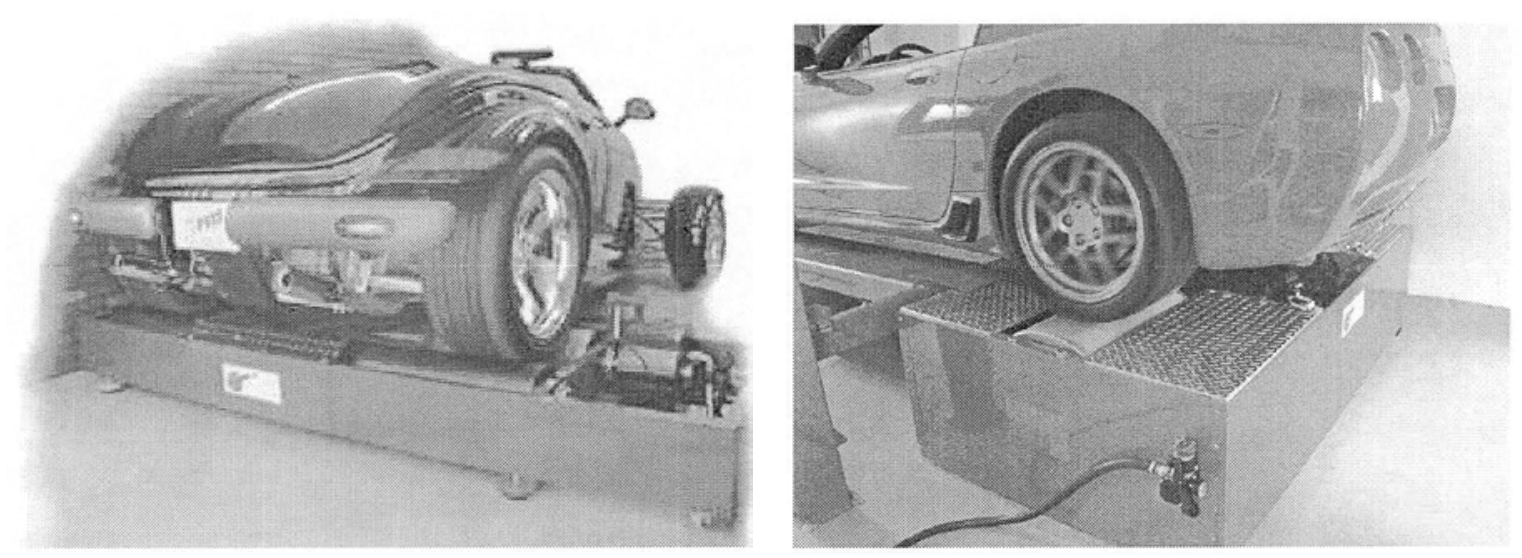

Figure 3-3 Chassis / Steady state dynamometers [18]

The adjustability of the absorber accounts for the main advantage of steady-state dynamometers, which is for a simulation of different driving conditions. The theoretical velocity and acceleration of the vehicle can be calculated with the feedback from the tachometer. This information can be used to simulate different dynamic properties of the vehicle; it is possible to simulate the effects of vehicle inertia by increasing or decreasing the breaking torque applied by the absorber according to the acceleration of the vehicle, aerodynamic drag can be factored into the controlling software so that the braking torque increases with the velocity of the vehicle, and the braking torque can be varied to simulate changes in road grade.

\subsubsection{Data Acquisition from Dynamometers}

All types of dynamometers use some form of data acquisition to collect information related to the vehicle during testing. Basic systems collect data relating only to the torque 
and speed of the vehicle, while more complex systems collect data related to the conditions of the ambient, motor and absorber temperatures, and other vehicle characteristics.

In dynamometer testing, the appropriate parameters of the vehicle need to be entered into the system to best duplicate the vehicle for real world simulations. The load cycle can be applied to simulate operation of the vehicle. During the test, simultaneous measurements of the engine speed and torque are taken to obtain the instant power at the wheel,

$$
P=T \cdot \omega
$$

where, $\mathrm{P}$ is the power $(\mathrm{W}), \mathrm{T}$ is the torque $(\mathrm{Nm})$, and $\omega$ is the angular velocity $(\mathrm{rad} / \mathrm{s})$. The power, torque and angular velocity can be measured using different units. The standard unit is often used in US and Canada instead of the ISO and MKS units. In the standard unit, torque is measured in pound-feet $(l b-f t)$, and $1 \mathrm{lb}$-ft equals to $1.356 \mathrm{Nm}$. Similarly power is measured in horsepower ( $\mathrm{Hp}$ ) and rotation speed is measured in rotation per minute (RPM). In the standard unit, the power can be calculated by

$$
P(H p)=T(l b \cdot f t) \times \frac{n(\mathrm{RPM})}{5,252}
$$

where, $P$ is the power (Hp), T is the torque (lb-ft), and $n$ is the rotation speed (RPM). Somctimcs, the shaft rotation speed $n$ is simply called RPM. A sample power calculation and details of this formulation is given in Appendix B.

An ICE or a DC motor has its own power-torque characteristics. The motor will only be able to produce certain amount of power and torque at a given shaft rotation speed. The torque generated from a typical ICE and DC motor, measured at different RPMs, is plotted in Figure 3-4. The plot represents the relations between the power and torque of an engine at different shaft rotation speeds.

From the graph on the left, it can be determined that the peak horsepower and torque ratings - the actual highest value of horsepower and torque, and at what RPMs are 
obtained. These values are the most common way of describing the power generated by an engine and is expressed as " $320 \mathrm{Hp}$ at $6500 \mathrm{RPM}, 290 \mathrm{lb}$-ft torque at $5000 \mathrm{R} \mathrm{PM}$. From the formulation, horsepower has to equal torque at 5,252 RPM and therefore, the lines will cross at this point. Torque will always be higher than the horsepower below 5,252 RPM, equal to horsepower at 5,252 RPM and less than the horsepower above 5,252 RPM. That is why the torque peak occurs at a lower RPM than the horsepower peak
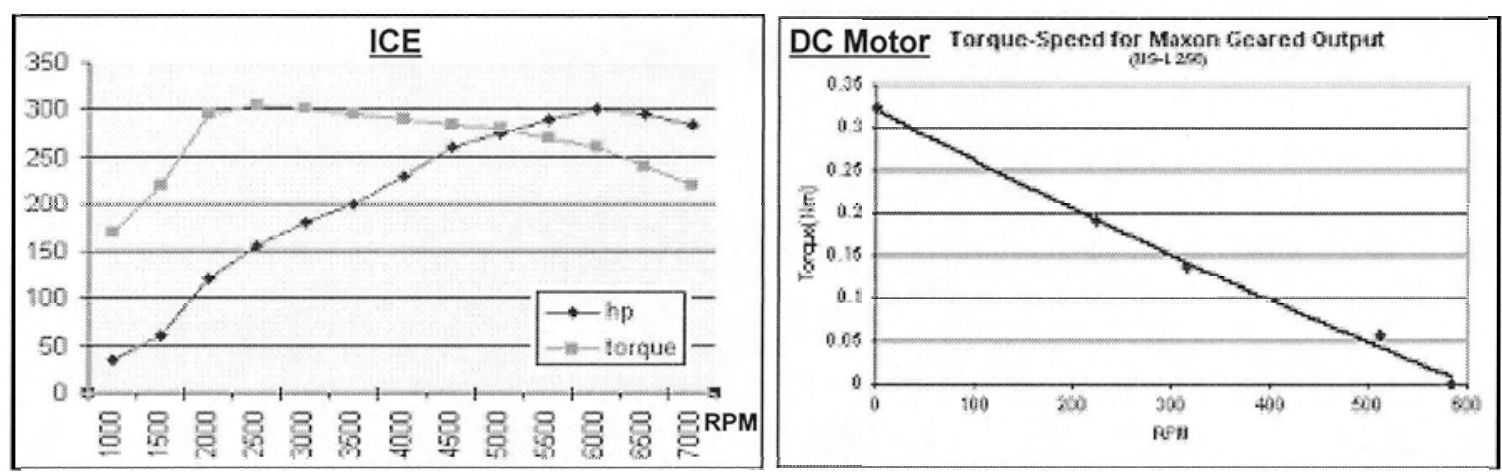

Figure 3-4 Typical Torque-Speed Curves for an ICE [19] and DC motor [20]

The graph on the right shows a torque/speed curve of a typical D.C. motor. Torque is inversely proportional to the speed of the output shaft; it reduces as the speed increases. Details are discussed in Appendix C. Maximum torque point is when shaft is not rotating (stall torque) and maximum output rotational speed of the motor point is when no torque is applied to the output shaft. From equation (6), due to the linear inverse relationship between torque and speed, the maximum power occurs at the point where $\omega=1 / 2 \omega_{\mathrm{n}}$, and $\mathrm{T}=1 / 2 \mathrm{~T}_{\mathrm{s}}$ (Figure 3-5).
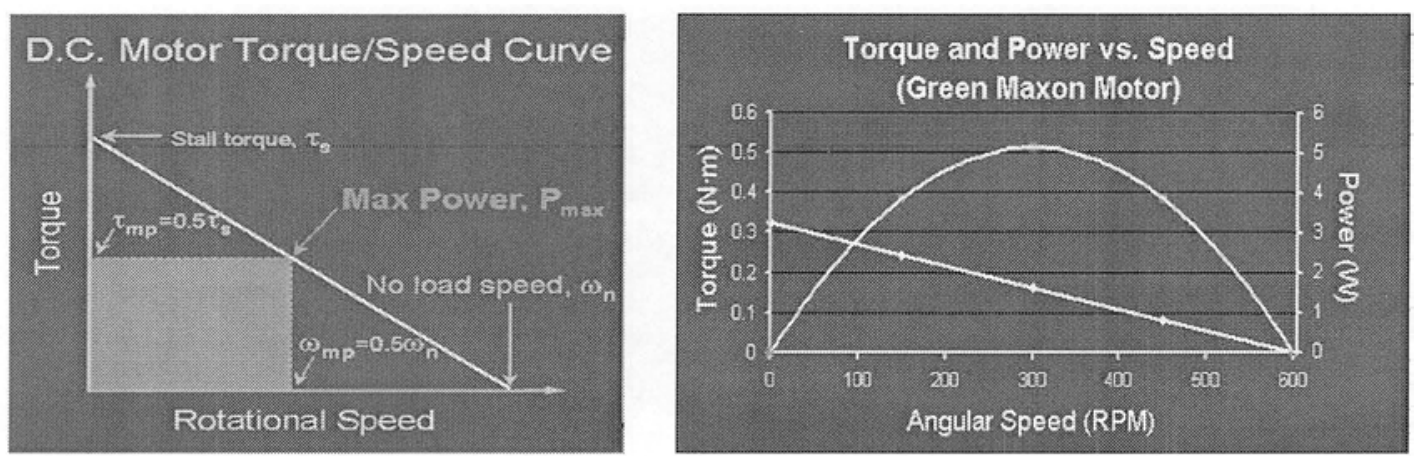

Figure 3-5 Power-torque curve for DC motors (right) [20] 


\section{DESIGN OF THE LOW SPEED ELECTRIC VEHICLE TEST BED}

A dynamometer system for testing FCHLSEVs is designed and developed at the University of Victoria. Due to the lack of adequate complete commercial system, the dynamometer system is built using functional components of commercial products.

The design requirements of the dynamometer system for testing FCHLSEVs covers small two-wheel vehicle, such as electric scooter, to medium sized golf cart, to larger four wheel utility vehicles, such as the "E-Gator".

The dynamometer system consists of roller unit, eddy-current absorber and controller, a custom platform, custom connection and adjustment parts, data acquisition electronics and software, and research software developed at UVic (drive cycle application). A larger roller unit is considered as a future addition to test larger fuel cell vehicles. To accommodate LSEV of different sizes and configurations, the system needs to have the following key components:

a) A platform that can carry the test vehicle and allow the vehicle to be secured during the operation tests,

b) A roller system that can simulate the inertia of the vehicle and its payloads or the majority of it,

c) A brake system that can simulate the driving loads of the vehicle, including rolling resistance, aerodynamic drag, hill climbing, and compensate the mismatch between the vehicle inertia and the roller inertia,

d) Sensors for measuring the vehicle speed, torque and power at the wheel,

e) A computer data acquisition and processing unit and associated control programs that acquire the system data and adjust appropriate loads during the testing,

f) A computer system that can load, process, and apply various driving cycles to the test vehicle, as well as automatically change the loads during the test to reflect the road conditions. 
Due to the dramatic variation of vehicle size, weight and configuration, it is found that these tasks cannot be accomplished using one unique set of hardware [21]. The concept design is then based on one core system design with two sets of replaceable rollers and brake systems. The first configuration of the system uses a 5" roller assembly and a 20 Hp Eddy current brake; the second configuration of the system uses a larger 12" roller system and a 50-200 Hp water brake; and both configurations fit into one unique platform design, sensors, data acquisition and processing systems, computer control systems, and load applying software. The rollers, brakes, sensors, and computer control software are acquired from Land \& Sea Inc [18]. Land \& Sea Inc. has produced high performance automotive and marine dynamometer equipment for over twenty years. This product line is extensive and adaptable, covering many different types and configurations of dynamometers. The Dynomite ${ }^{\mathrm{TM}}$ roller series from Land and Sea is relatively compact and versatile; addition inertial masses can be added to the system if required. The Dynomite $^{\mathrm{TM}}$ Kart brake (Eddy-Current Absorber) from Land and Sea is compact, versatile, and well integrated into the control system. Dynomax $2000^{\mathrm{TM}}$ data acquisition and control system satisfies the need of the control system for the dynamometer. These are chosen as component modules for the designed system. The commercial dynamometer systems, available from Land \& Sea Inc. and Dynojet Inc. [22], are not directly used due to its significantly larger size and capability than the requirements of LSEV test. The custom designed system will provide better cost-benefit and high resolution of data for the experiments.

\subsection{Purposes of the LSHEV Testing Facility at UVic}

The system is designed to assist in the analysis and development of FCHLSEVs as well as the validation of current vehicle performance modeling methods. It will be used as a design and evaluation tool for fuel cell powered vehicles.

\subsection{Key Components and System Configuration - an Overview}

The dynamometer system includes Dynomite ${ }^{\mathrm{TM}}$ kart chassis roller assembly, Dynomite ${ }^{\mathrm{TM}}$ data acquisition electronics, Dynomite ${ }^{\mathrm{TM}}$ Eddy-current absorber and controller, and 
Dynomite $^{\mathrm{TM}}$ software and complementary research software developed at UVic from the Dynomite $^{\mathrm{TM}}$ product line of Land \& Sea Inc. Dynomite ${ }^{\mathrm{TM}}$ vehicle chassis roller assembly is considered as a possible future addition to test larger fuel cell vehicles [18], [21]. The platform and adjustments are discussed in Chapter 5.

The following sections describe the various components of the dynamometer system. The configuration of the system is illustrated in Figure 4-1.

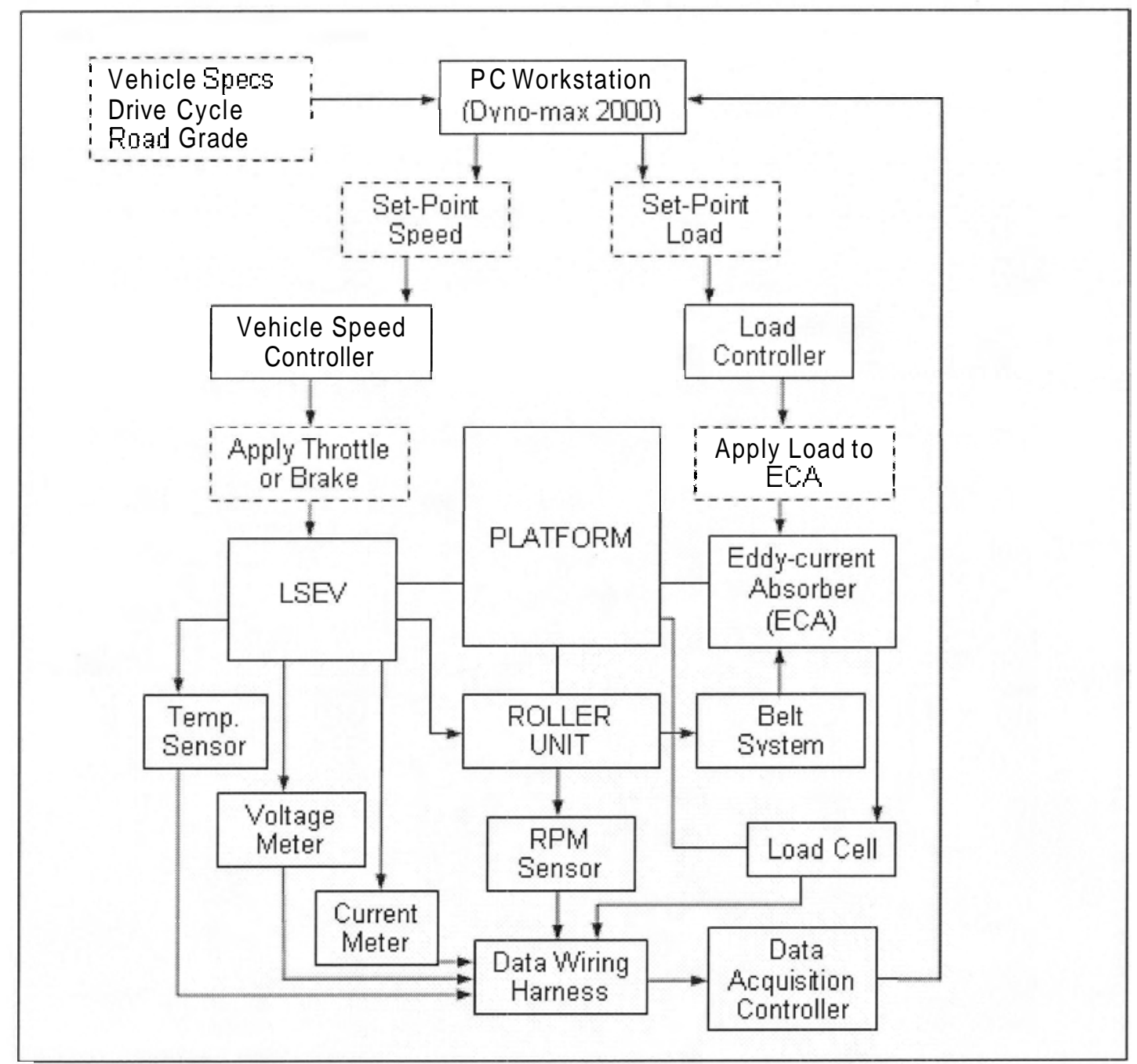

Figure 4-1 Control Flow Chart of UVic's dynamometer system 
The driving wheel (in the scooter case - rear) of the test vehicle is placed on the rollers. Engaging the throttle starts the wheel and the rollers spin simultaneously with no-slip condition. The rotation speed and torque on the wheel of the vehicle are measured by sensors attached to the rollers. The Eddy current absorber (ECA) is connected to the roller through a belt-pulley system that reduces vibration and shock from the tests. When current is supplied from the controller to ECA to create resistance between the rotor and the stator, the outer housing of the stator tends to spin up to the current amount applied. The outer housing is also connected to the load cell with the torque arm for the acquisition of the torque data. The strain gauge inside the load cell provides a signal proportional to the torque being applied. Finally, this signal is sent to the computer which is interpreted as a torque reading.

\subsubsection{Roller Units}

Dynomite ${ }^{\mathrm{TM}}$ " Kart Chassis Roller Assembly is the roller unit of dynamometer system. Although this particular product is commonly used for testing go-karts, it is also suitable for testing electric scooters since both vehicle types have similar size and weight characteristics. The rollers, as shown below in Figure 4-2, can provide an inertial force similar to what the scooter would be subjected to typical road situations.

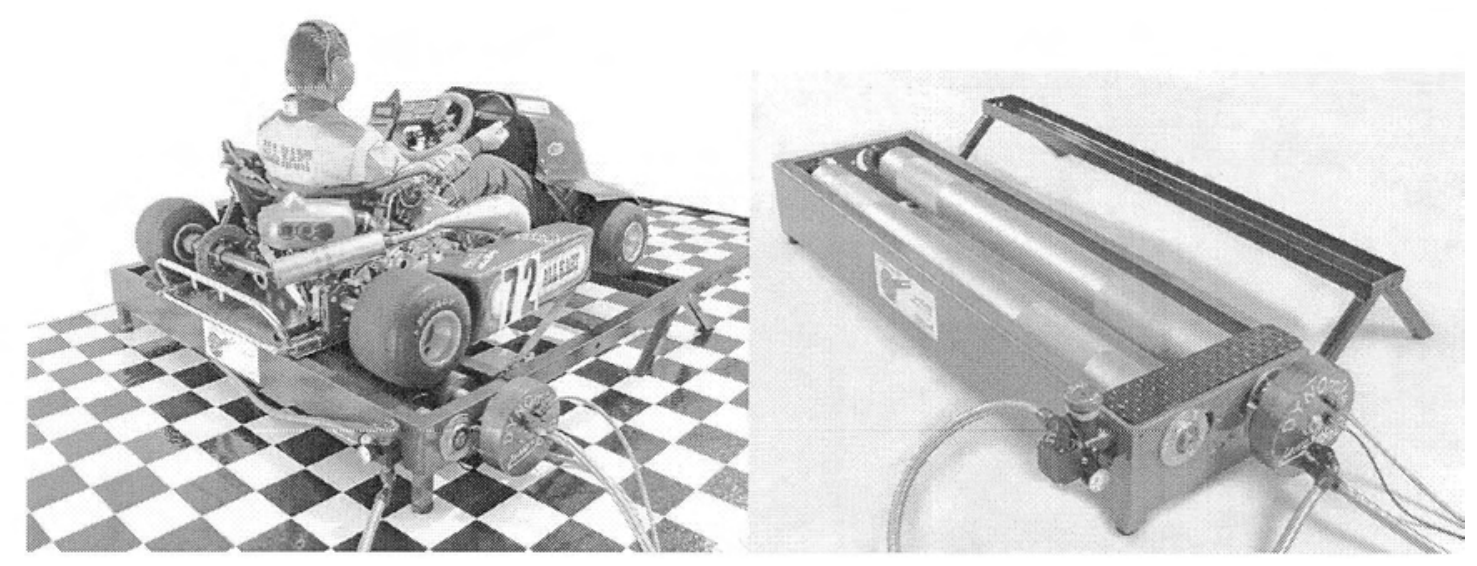

Figure 4-2 Go-Kart testing on DYNOmite ${ }^{\mathrm{TM}} 5$ " Roller Unit [18]

The technical specifications of the 5" roller unit are given in Table 5 . 
Table 5 5' Roller unit specifications [18]

\begin{tabular}{|c|c|}
\hline Rollers & $\begin{array}{l}\text { - } 400 \mathrm{lb} \text { capacity. } \\
\text { - } 5 " \text { x 55" (diameter x length) dual rollers, adjustable and } \\
\text { greasable bearings, medium inertia. } \\
\text { - Balanced up to } 100 \mathrm{mph} \text {. } \\
\text { - Traction grooved for maximum frictional contact between } \\
\text { roller and tire. }\end{array}$ \\
\hline Frame & Structural steel, vibration pads. \\
\hline Approx. size & $67^{\prime \prime}, 14 ", 10 "$ (length, width, height) \\
\hline Weight & $400 \mathrm{lb}$ \\
\hline
\end{tabular}

Taking Newton's Third Law into account, if the vehicle is accelerating on the ground, then the force provided to the ground $(\mathrm{F}$, ,) by the drive wheel(s) must be equal and opposite to the force used to accelerate the vehicle $\left(F_{v}\right)$. However, in the case of the vehicle being on the dynamometer, the vehicle does not move when the wheel turns and therefore does not have an inertial component. The purpose of the inertial roller is to simulate a force, proportional to what it would "feel" during acceleration. It provides an inertial force similar to what the scooter would be subjected on the road. Therefore, the inertial force of the roller $F_{r}$ is desired to be equal to $\mathrm{F}$,, at the tire-roller interface (Figure 4-3)

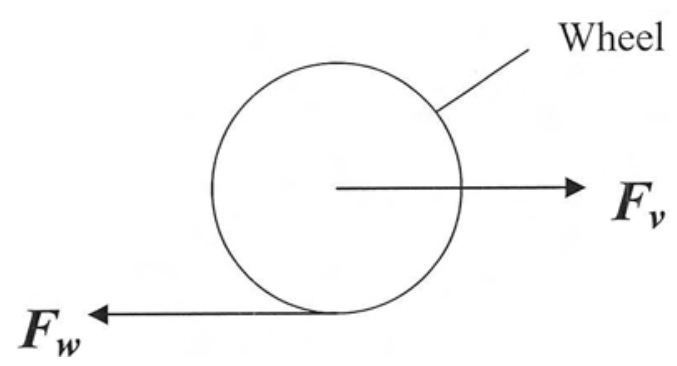

Figure 4-3 Forces acting on the wheel

$$
F_{v}=m_{v} a_{v}
$$

The main intent of a roller with inertial characteristics proportional to the vehicle is to simulate the vehicle's inertia can be tested. An inertial roller is only required to simulate inertial effects during acceleration and deceleration. The main disadvantage is the inability of testing steady-state load on the vehicle during constant-velocity operation and 
no-flat road operation. The vehicle must accelerate from one speed to another in order to obtain data.

Dynomite $^{\mathrm{TM}}$ 12" Vehicle Chassis Roller Assembly is considered as a possible future addition, the configuration II, to test larger fuel cell vehicles (Figure 4-4). The approximate dimensions and weight of the 12 " roller unit are 33"W x 114" $\mathrm{L}$ x 14" $\mathrm{H}$ and $2850 \mathrm{lbs}$, respectively.
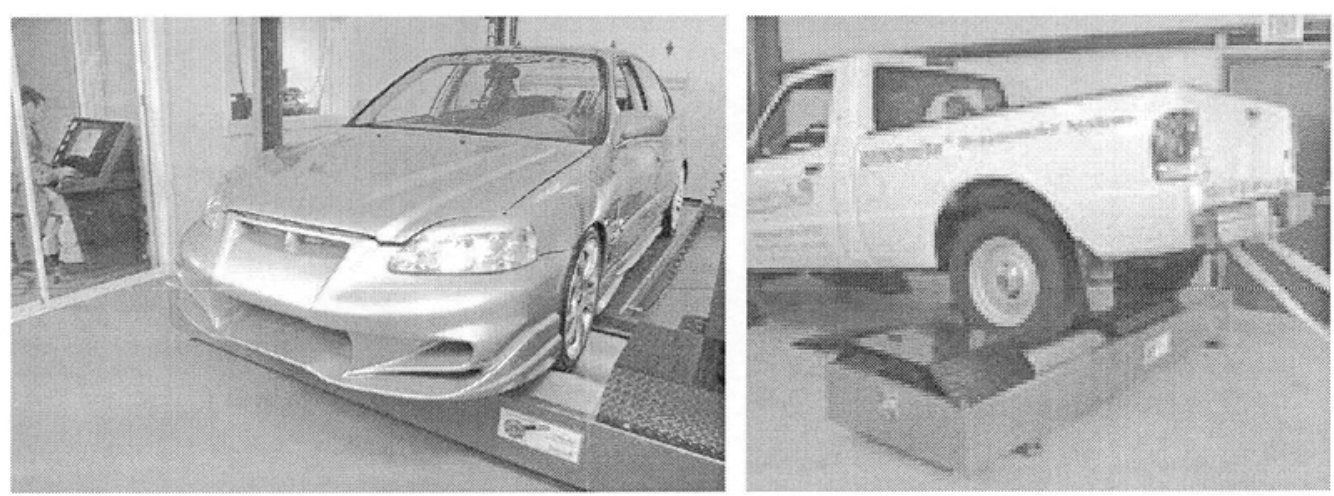

Figure 4-4 12" Dynomite Chassis Roller [18]

\subsubsection{Dynamic Load Absorber and its Controller}

The Dynomite ${ }^{\mathrm{TM}}$ 20Hp Eddy-Current Absorber (ECA) is a medium inertia, air cooled device that provides braking torque (Figure 4-5).
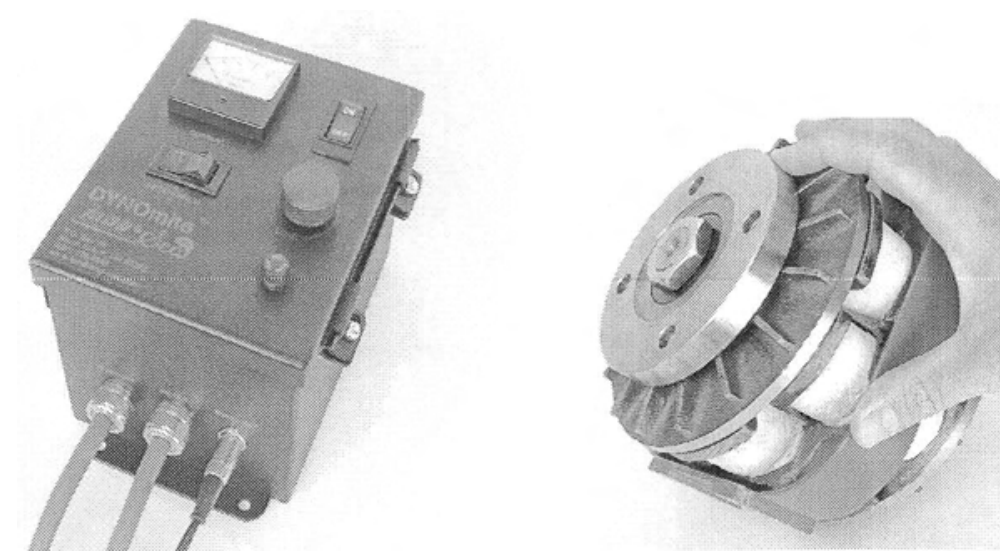

Figure 4-5 Eddy-currentabsorber (right) and the control unit (left) [18] 
The Eddy current is a phenomenon caused by a moving magnetic field intersecting a conductor or vice-versa. The relative motion causes a circulating flow of electrons or current within the conductor. These circulating eddies of current create electromagnets with magnetic fields that oppose the external magnetic field. The stronger the magnetic field, or greater the electrical conductivity of the conductor, the greater the currents developed, and the greater the opposing force.

The electro-magnetic field (EMF) induced in an electric circuit always acts in such a direction that the current it drives around a closed circuit produces a magnetic field which opposes the change in magnetic flux which produces the EMF [23].

Eddy currents are induced electrical currents that flow in a circular path. ECA subject a rotating conductor to a magnetic field resulting in the presence of swirling currents, or Eddy currents, inside the conductor. When alternating current is applied to a conductor, a magnetic field develops in and around the conductor. If another electrical conductor is brought into close proximity to this changing magnetic field, current will be induced in this second conductor. By Lenz's law, the current swirls in such a way as to create a magnetic field that opposes the change. The detailed drawing of the ECA is illustrated in Figure 4-6.

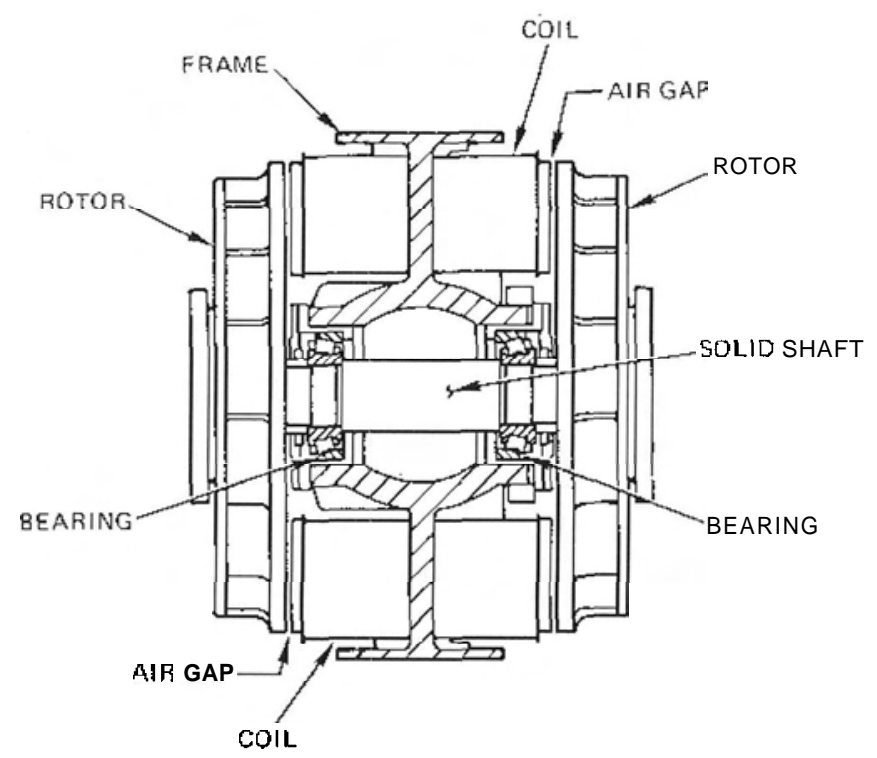

Figure 4-6 Eddy Current Absorber details [18] 
In the ECA, a metal stator containing an electromagnet exposes the rotor conductor to a magnetic field, generating Eddy currents in the rotor. The Eddy currents oppose the rotation of the rotor, in accordance with Lenz's Law and serve to apply a torque to the rollers that opposes the torque applied by the rollers by the engine via wheel.

The Eddy current brake applies an equal and opposite torque to the roller and the wheel of the vehicle. The attached load cell measures the amount of tangential force applied by the stator of the Eddy current brake. This force can be calibrated to provide an indirect measure of the torque applied to the wheel of the vehicle.

In an Eddy current absorber, the magnetic field of the electromagnet expands as the alternating current rises to maximum and collapses as the current is reduced to zero. The magnetic interaction between the applied field and the opposing field generates heat while slowing the rotor down. Therefore, air or water cooling is necessary to keep the temperature in the safe range. It is possible to simulate the effects of vehicle inertia by increasing or decreasing the breaking torque applied by the absorber according to the acceleration of the vehicle.

To simulate the operation of a larger vehicle, more resistance force needs to be applied. The power absorbed by the brake will increase considerably. The effectively get rid of the waste heat generated, a water or oil brake provides better solution. In the present design a water brake and a 12" roller are used for larger vehicles. Water pump absorbers are another type of hydraulic absorber; they convert kinetic energy into a rise of water temperature. They typically use a veined rotor spinning in between pocketed stator housings. The load is controlled by the varying the level of water supplied to the pump increases the rotational drag of the rotor and therefore increases the torque required to turn it. It is important to note that this type of absorber is rpm dependent, so at low speeds it will not provide much braking torque. The main benefits of water pump absorbers are that they can absorb a large amount of energy relative to their physical size and they are completely inexpensive. One disadvantage is that precise load control of the water supply to the pump is required, and the response time of the system is usually inadequate for high precision tests. 
Hydraulic oil pump absorbers, as other alternatives, are usually seen on low rpm, moderately powered dynamometers. They utilize a positive displacement pump as the absorber and incorporate a throttle valve to restrict the flow and provide the load. The power applied by the vehicle is converted into a rise of oil temperature. The oil is usually sent to a cooling system before recirculation.

In addition, $\mathrm{DC}$ and $\mathrm{AC}$ absorbers act as generators that convert kinetic energy into electric energy which is then dissipated as heat or stored in a battery or capacitor. The main advantage of these types of absorbers is that the load can be readjusted anywhere from zero to full in micro seconds. Also, the absorber can be used as a motor to drive the vehicle and obtain data that could be used to calculate the drive train efficiency. The main disadvantage is the overwhelming cost of the absorbers itself and the controlling hardware.

\subsubsection{Data Acquisition Electronics, Analysis and Load Control}

The Dynomite ${ }^{\mathrm{TM}}$ data acquisition electronics facilitatc the experimental testing procedures by eliminating paper and pencil data logging. The computer automatically records true power, torque, rotation speed, elapsed time, etc. at up to 1,000 readings per second, per channel. It can be set to automatically apply standard SAE correction factors for air temperature, barometric pressure, and relative humidity. Test results display on the attached computer and print outs can be taken.

The data acquisition electronics consist of several key components as shown in Figure 47:
a) The data acquisition controller (A)
b) The data wiring harness (B)
c) The load cell (C)
d) The rotation speed or rpm reader and its sensor (D)
e) Temperature Sensor (E) 


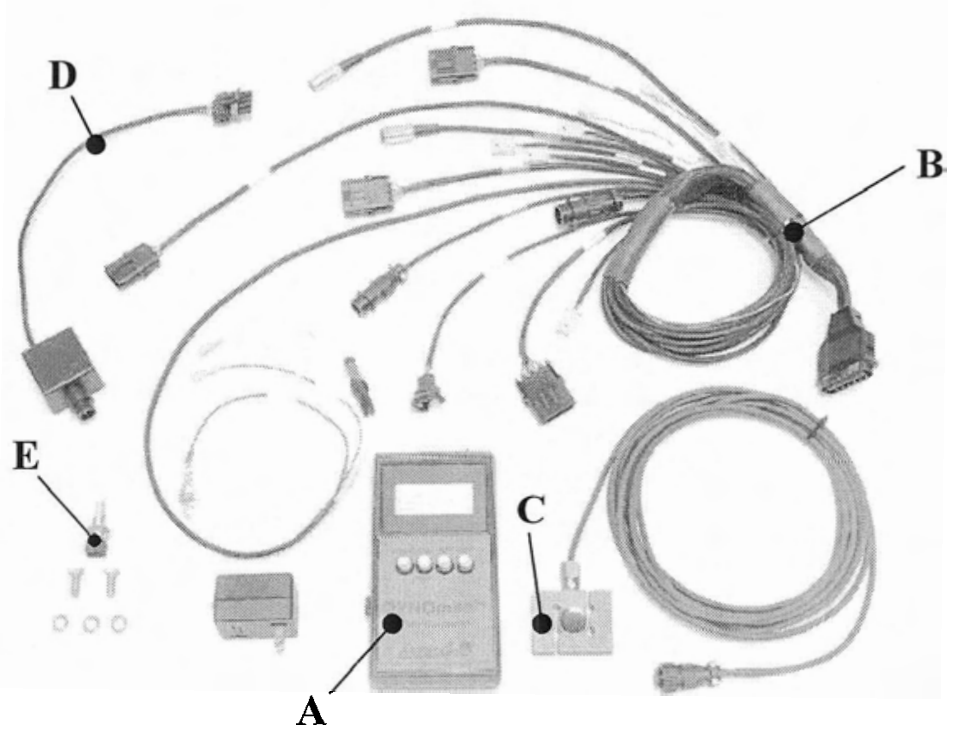

Figure 4-7 Data acquisition equipment [18]

Dyno-max $2000^{\mathrm{TM}}$ software package allows a personal computer to monitor and control the dynamometer. It communicates, via the PC's port(s), with Dynomite ${ }^{\mathrm{TM}}$ data acquisition controller (B). Because it handles most of the high-speed data acquisition and control, it reduces the load on the PC. It primarily handles just the data display, storage, post processing, and printing.

The software creates a full engine dynamometer lab console on any Windows PC. Features of the software include: real time trace graph display, adjustable limit-warnings, push button controls, and user configurable analog and digital gauge ranges. Publicationquality color graphs and detailed reports are available for printing or importing into other programs.

Dyno-max2000 ${ }^{\mathrm{TM}}$ 's console set up, graph set up, channel calibration, etc, are all stored in individual configuration files. A new specific configuration library can be created that makes facilitates the initiation of a new test session by pulling together an appropriate set of configuration files with its environment (.env) by files. Each environment file can point to a different group of the custom configuration files.

Extended Full Function Data Cable (C) has the capability of allowing the Dynomite ${ }^{\mathrm{TM}}$ data acquisition controller to record fuel-flow, pressures, etc. and control other advanced 
functions when used in conjunction with the appropriate sensors, controls, and or software upgrades.

A load cell (D) is a transducer that converts force/weight acting on it into an analog electrical signal. This conversion is achieved by the physical deformation of strain gages which are bonded into the load cell beam and wired into an electric circuit (Figure 4-8).

The strain gage is the heart of a load cell. A strain gage is a device, basically very small grids of wires that change electrical resistance when stressed and are used to measure the infinitesimal deformations in objects under load. The gages are developed from an ultrathin heat-treated metallic foil and are chemically bonded to a thin dielectric layer. "Gage patches" are then mounted to the strain element with specially formulated adhesives. The precise positioning of the gage, the mounting procedure, and the materials used all have a measurable effect on overall performance of the load cell.

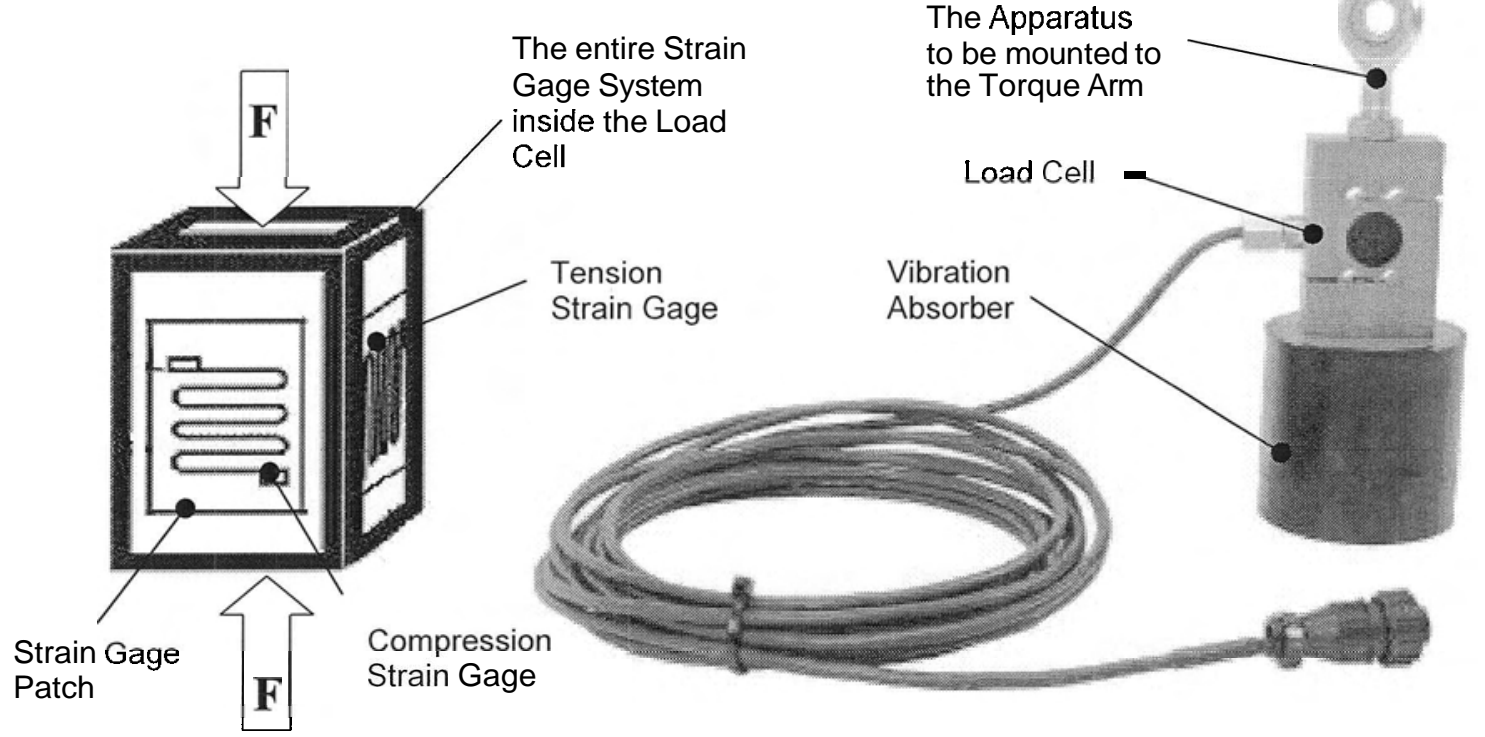

Figure 4-8 The Strain gage and the Load Cell

Each gage patch consists of one or more fine wires cemented to the surface of a beam, ring, or column (the strain element) within a load cell. As the surface to which the gage is attached becomes strained, the wires stretch or compress changing their resistance proportional to the applied load. One or more strain gages are used in the making of a load cell. 
Multiple strain gages are connected to create an electric circuit. When an input voltage is applied to the circuit, the output becomes a voltage proportional to the force on the cell. This output can be amplified and processed by conventional electrical instrumentation.

When using a strain gauge to measure torque, it is important to periodically calibrate the system. This is typically done by hanging a known mass at the end of the torque arm while holding the absorber housing stationary. The distance from the point of support to the mass, multiplied by its weight gives the torque applied to the arm. This exact value should appear on the computer.

\subsection{Dynamometer Load Calculation}

\subsubsection{Inertial Load Calculation of the Roller}

The roller is used to simulate the inertia of the vehicle and its payloads with the assistance from the ECA. The inertial torque that simulates the acceleration of the roller can be calculated as follows:

$$
T=I \cdot \alpha
$$

where $\mathbf{I}$ is the mass moment of inertia of the roller and $\mathbf{a}$ is the angular acceleration of the roller. The inertia of the roller can be found using the following equation for a solid cylinder, $I=1 / 2 m r^{2}$, where $m$ is the total roller mass and $r$ is the radius. The roller mass can be found by considering the total volume of the cylinder and the density of the material, $m=\rho V$

The angular acceleration of the roller would be obtained from sensors on the roller assembly and are usually approximated for a small time interval depending on the sample rate of the acquisition system.

On the other hand, the inertia of the test vehicle and its payloads can be calculated by

$$
F=\sum m_{i} a
$$


where $m_{i}$ is the mass of the test vehicle and its payloads, including passenger and cargos, and $\mathrm{a}$ is the acceleration of the vehicle. To support the simulation, the following relation has to be satisfied:

$$
r_{\text {wheel }} \sum m_{i} a=I \alpha+T_{E C A}^{a c c}
$$

where $r_{w h e e l}$ is the radius of the wheel of the test vehicle, $T_{E C A}^{a c c}$ is the component torque from the ECA to match the inertia difference between the roller and the vehicle with payloads (Figure 4-9). The value of $T_{E C A}^{a c c}$ is to be calculated for different vehicle and its payloads, given the roller.

\subsubsection{Static Load Calculation from the Eddy Current Absorber}

As discussed previously, the main purpose of the ECA is to simulate various static load of the vehicle, such as:

$$
T_{E C A}^{\text {static }}=\left(f_{\text {drag }}+f_{\text {inc }}+f_{\text {rr }}\right) \times r_{\text {wheel }}
$$

where, $f_{\text {drag }}$ is the force due to the aerodynamic drag, $f_{\text {inc }}$ is the force due to the slope, $f_{r r}$ is the force due to the rolling resistance of the vehicle, and $r$ wheel is the radius of the vehicle wheel.

$$
\begin{aligned}
f_{\text {drag }} & =\frac{1}{2} \rho_{\text {air }} C_{D} A_{F} V_{\text {aero }}^{2} \\
f_{\text {inc }} & =m \boldsymbol{g} \sin \theta \\
f_{r r} & =m g C_{r r} \cos 13
\end{aligned}
$$

Now the total torque that is to be generated in the ECA at an instance will be:

$$
T_{E C A}=T_{E C A}^{\text {static }}+T_{E C A}^{a c c}
$$


The torque is generated, measured, and controlled by the control system of the test software.

\subsubsection{Combined Load from the Roller and the Eddy Current Absorber}

At a given instance, the total or combined load to the test vehicle will be the sum from both the ECA and the roller,

$$
T_{\text {vheel }}^{\text {vehicle }}=I \alpha+T_{E C A}^{a c c}+T_{E C A}^{\text {static }}
$$

During down hill operation, the gravity force on the vehicle and its payload will actually produce a driving force, instead of a resistant force. The value of $f_{\text {inc }}$ component in Equation (12) is negative. The value of $T_{E C A}^{\text {slatic }}$ may be positive, zero or negative, in principle, depending on the slope of the hill. However, the Eddy current brake can only serve as a brake; unlike a DC motor, it cannot apply an active force to drive the vehicle. This property of the ECA presents a limitation of the testing system. The seldom case of stiff down-hill operation of the vehicle cannot be simulated.

Another issue is the friction in the system that causes additional torque. The friction in the system caused by the bearings and the belt-pulley connections should also be taken into account. The torque created by the friction of the system can be calculated by measuring the time period required for the rollers to come to rest alter the ECA and scooter torques have been removed from the rollers. Taking the formulation below as a reference,

$$
\omega_{f}=\omega_{o}+\alpha \cdot t
$$

where $\omega_{f}$ is final, and $\omega_{o}$ is the initial velocities. Measuring $\omega_{o}$ and $t$, and taking $\omega_{f}$ zero, a value can be found. Going back to equation (9), due to $\mathbf{I}$ is constant, friction torque of the system is obtained. 


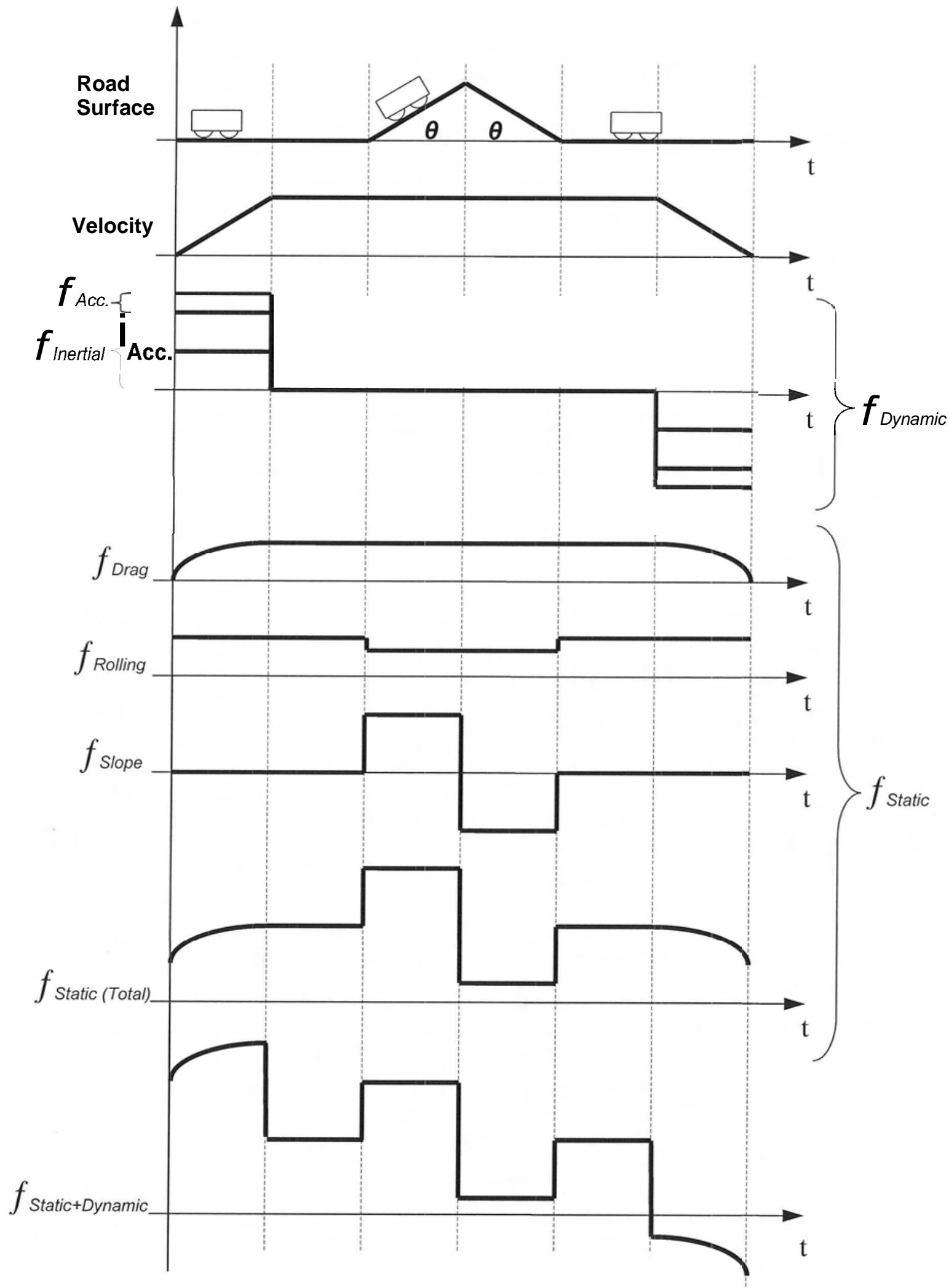

Figure 4-9 Static and Dynamic Load Simulations 


\section{DETAILED DESIGN OF LOW SPEED ELECTRIC VEHICLE TEST BED}

In this section, the design and construction of the dynamometer platform and the interior mechanism of the dynamometer system are discussed. The potential variations of the dynamometer system for testing various low-speed fuel cell - battery hybrid electric vehicles (LSFCHEVs), including the fuel cell powered electric scooter and utility vehicle are carried out, using the Pro/ENGINEER (Version Wildfire2) CAD system.

In developing a dynamometer platform design for LSFCHEVs, it is important to consider a range of vehicle characteristics in conjunction with the modules of the dynamometer system (i.e. 5" - 12" roller assemblies and Eddy-current absorber) to determine the most versatile design.

From the data presented in Table 2, the approximate maximum wheel track, wheelbase and curb weight of four wheeled low-speed vehicles can be developed. These values, shown in Table 6 , become crucial in specifying the dimensions of the dynamometer platform frame.

Table 6 Max Low-Speed Vehicle Specifications

\begin{tabular}{|r|l|}
\hline Characteristics & Requirement \\
\hline Max Power & $5000 \mathrm{~W}$ \\
\hline Curb Weight & $800 \mathrm{~kg}$ \\
\hline Top Speed & $65 \mathrm{~km} / \mathrm{h}$ \\
\hline Max Wheel Track & $1500 \mathrm{~mm}\left(60^{\prime \prime}\right)$ \\
\hline Max Wheelbase & $1940 \mathrm{~mm}\left(77^{\prime \prime}\right)$ \\
\hline
\end{tabular}

\subsection{LSEV Test Bed Platform Design for Housing Dynamometer Components}

The need for the portability of the entire dynamometer system for the cases of moving demand possibility and carrying the entire system all at once, and to minimize the 
potential hazards from the roller connections failing and unleashing the rotating rollers during testing, together with the difficulty of stability of the standing vehicle's front and rear wheels on separate pieces, brings the idea of having a platform for housing the dynamometer components to be mounted inside.

\subsubsection{Design to Accommodate Two Different Roller Units}

The first step in the design process of the dynamometer platform, is drafting of the dynamometer roller units. The roller units have 5" diameter rollers for the scooter and 12 " diameter rollers for the fuel cell gator, electric utility vehicle, which is a possible future addition (Figure 5-1, the technical drawings are given in Appendix D).

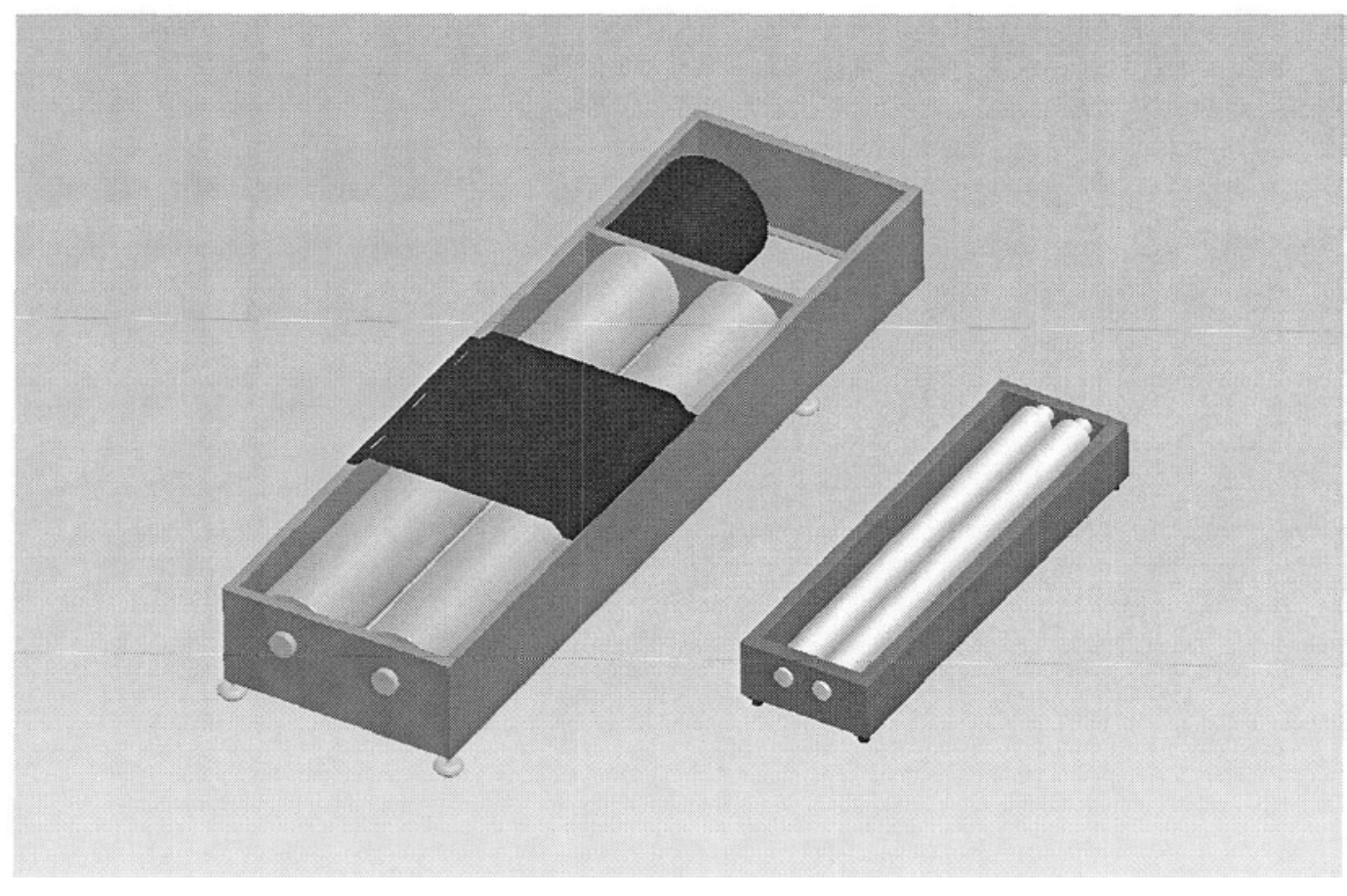

Figure 5-1 12" (left) and 5"' (right) Roller Units

The frame of the platform is considered to be based on the wise of square steel tubing of dimensions 2" x 2", with 0.25" wall thickness (Figure 5-2). In some particular vertices as illustrated with circles in the same figure, the tip(s) of the tubes were decided to make $45^{\circ}$ angle for the feasibility of construction. 
The dimensions of the platform frame were basically determined, according to the criteria of the largest vehicle for which the platform must accommodate. From Table 6, the maximum wheelbase dimension of the Gator is approximately 77". Thus, the distance between the centerline of the two rollers' axes (aligned with the rear wheel's axle) and the edge of the platform, at which the vehicle front is located, is required to be greater than 77 ". This distance was designed to be $90 "$ and the overall length of the platform was made to be 110 " (without the side sheet covers).

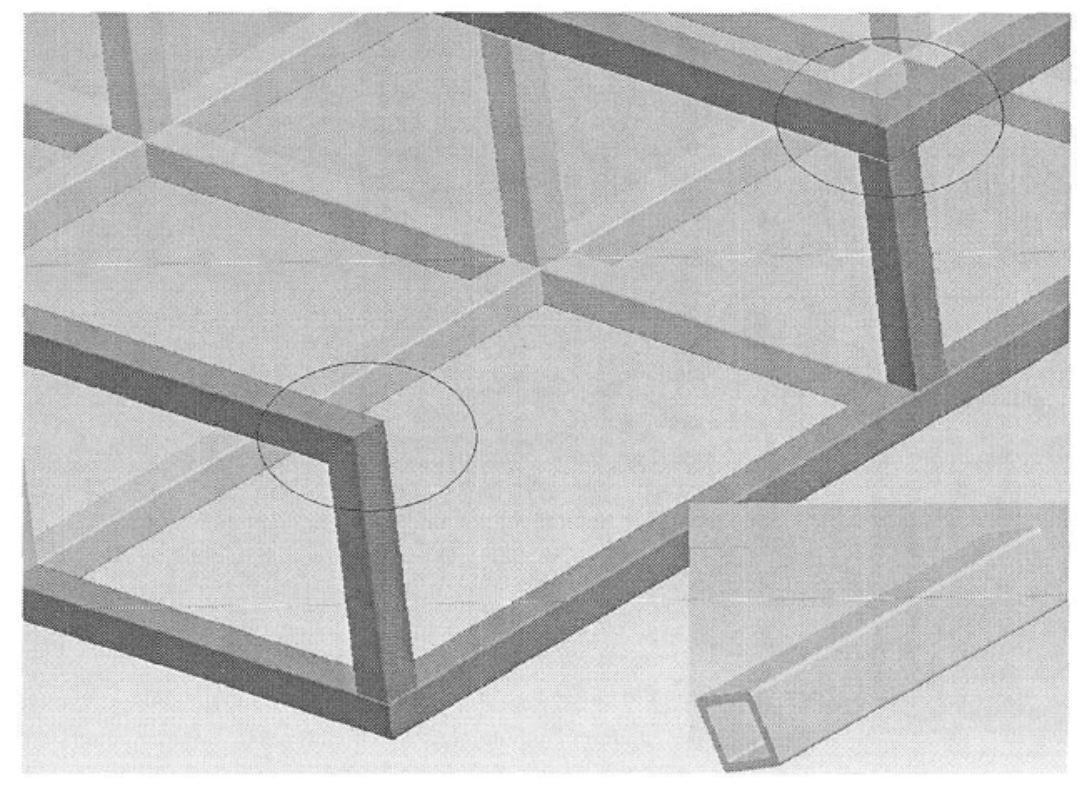

Figure 5-2 Steel square tubing of the platform frame

The top surface of the roller units' frames and the platform frame requires being at the same level in order to keep the LSEVs horizontal. Thus, the height of the platform is designed to be 16 ": 12 " diameter roller unit frame has 14 " height, plus the square steel tubing's 2" thickness that passes underneath the roller unit. Also, the entire frame is supported with bars for the safe carriage of the vehicle on the platform, as shown in Figure 5-3 and Appendix D.

In order to reduce the vehicle's sliding factor on the platform, diamond tread plate is considered as the material of the top surface cover. When the $5^{\prime \prime}$ roller unit is placed, due to its smaller dimensions in comparison to the 12 " roller unit, additional surface cover with the same material is taken into account to cover the blank area. 


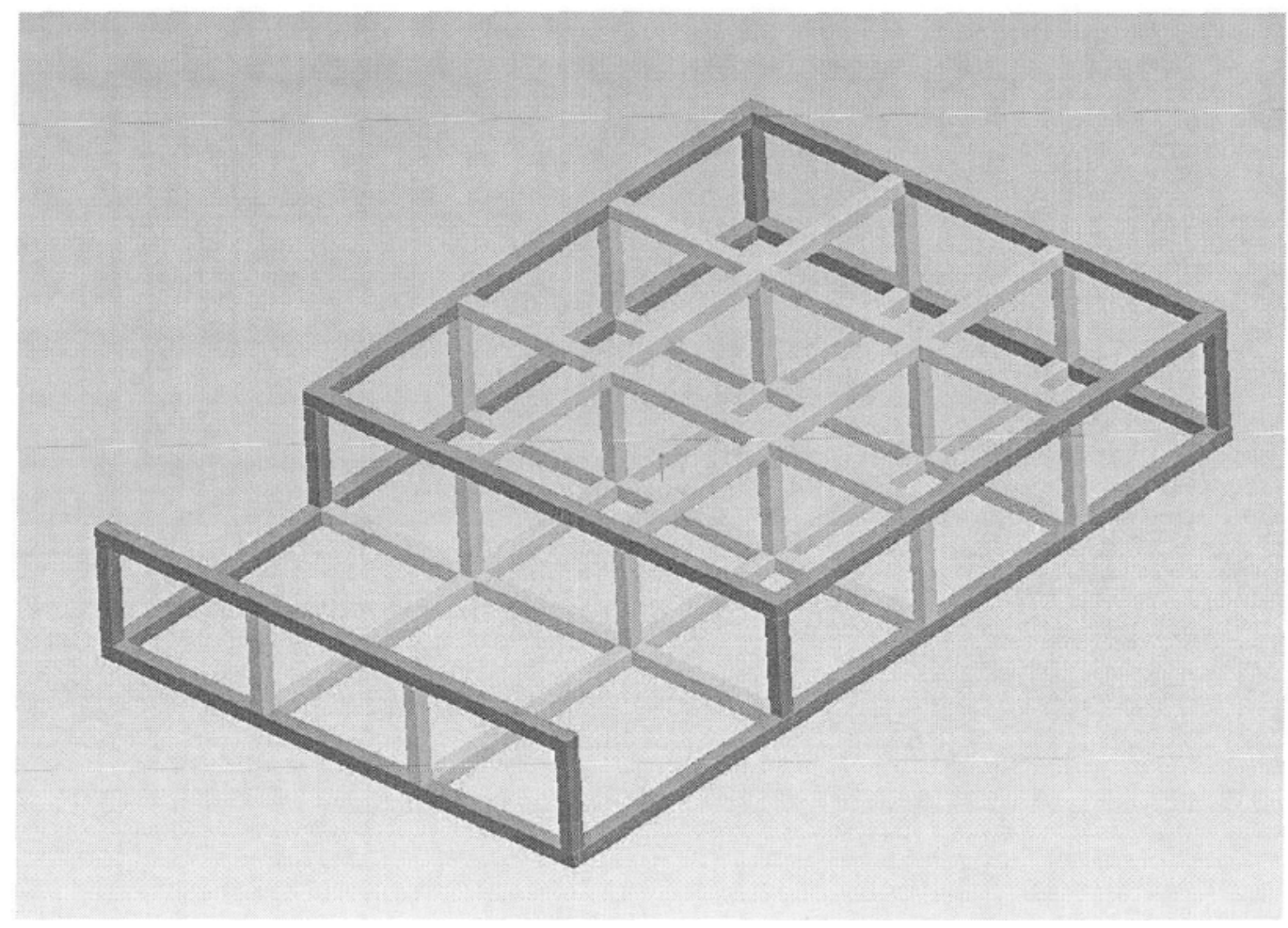

Figure 5-3 The Dynamometer Platform Frame

Another concern is the heat that occurs in the Eddy-current absorber (ECA) component of the system. Due to the fact heat dissipation is supposed to be performed with air; ECA is located outside the platform for more efficient air flow. In order to keep the top surface level of the 5" roller unit same level as the top surface of the platform, exchangeable steel tubings are modeled underneath the 5" roller unit (There exists 4" difference between 5" and 12" roller units). Inside the platform space, where the rollers sit, every single part requires being exchangeable (mounting with bolts instead of welding) due to volume of the 12 " roller unit occupies all of this space.

These bars are modeled wider than the platform width to create a base and a frame for the ECA's protective cover outside the platform. In order to avoid human contact with dangerously high voltage and current generated by the ECA, and to enable air flow at the same time, the cover plate can be a grilled sheet. 


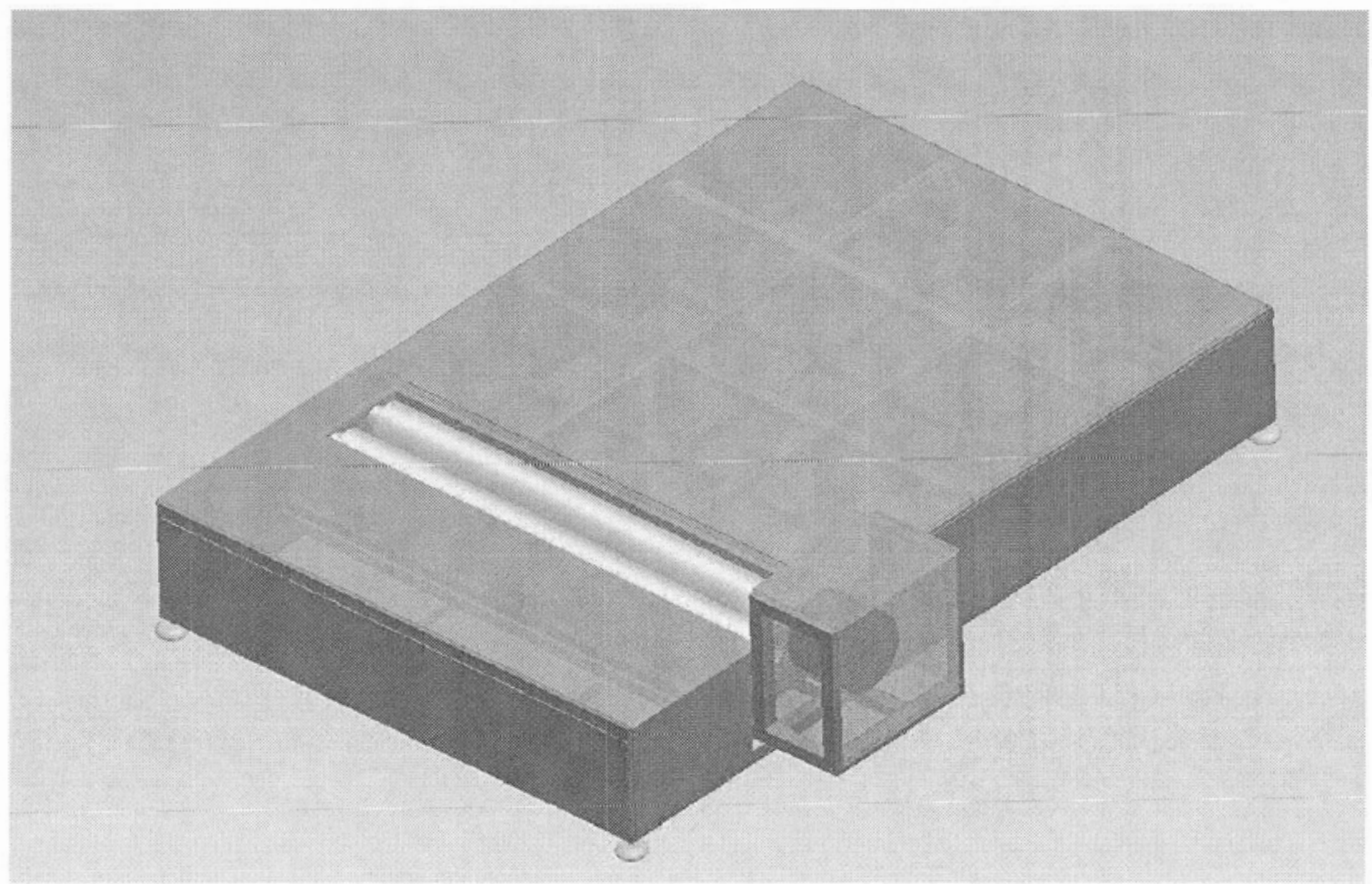

Figure 5-4 The assembly of 5" roller unit inside the dynamometer platform

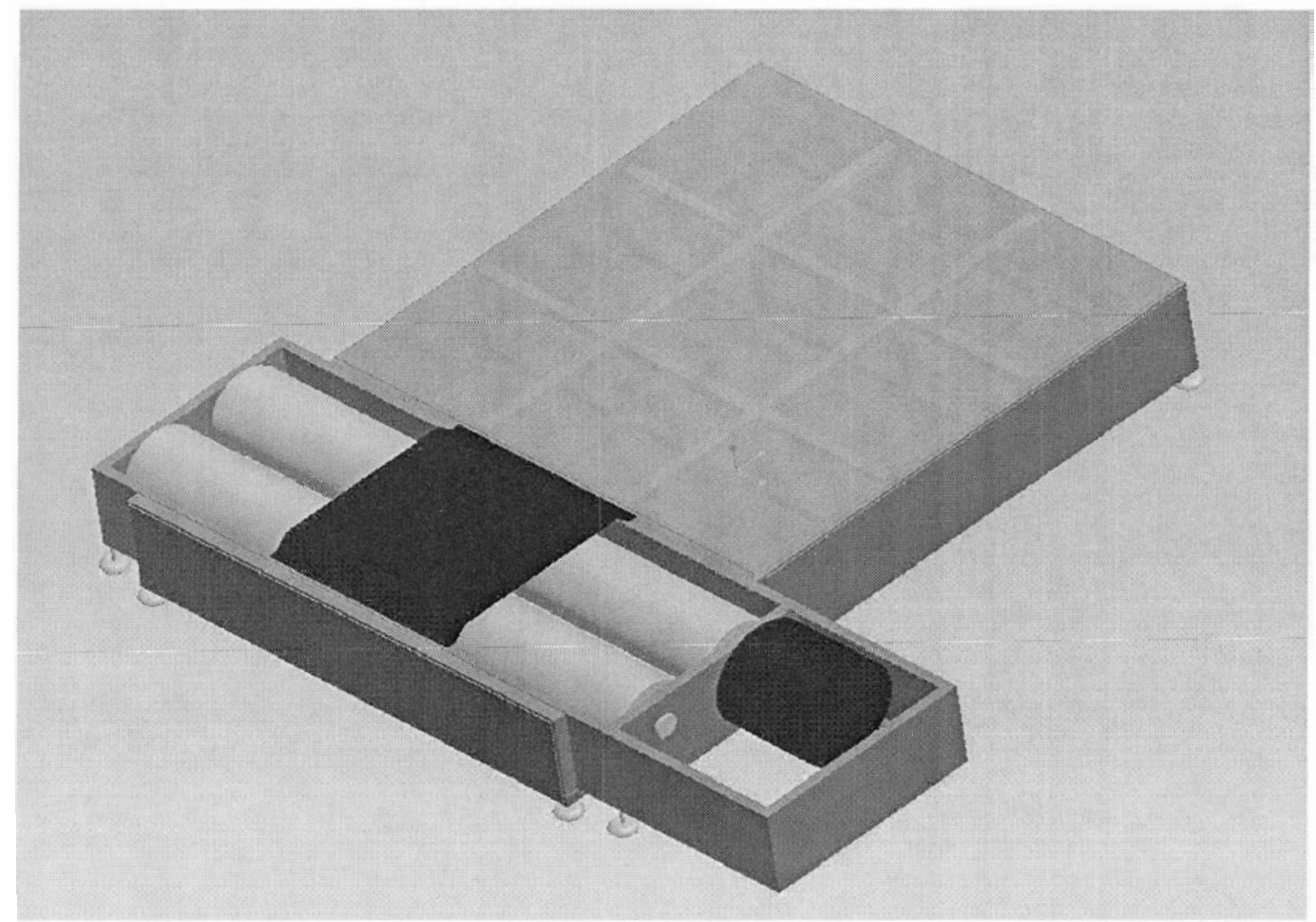

Figure 5-5 The assembly of 12' ' roller unit and the dynamometer platform 
Figure 5-4 and Figure 5-5 illustrates the assembly of the 5" and 12"' roller units inside the dynamometer platform, respectively. The top surface cover plate (diamond tread plate) of the dynamometer platform appears as transparent in those figures to show the structural design of the platform frame.

\subsubsection{Conceptual Design of fuel cell powered E-Gator}

To have a versatile dynamometer system, the design has to be able to accommodate different test vehicles. To make it feasible for testing the medium sized utility vehicle, the dynamometer platform is designed to be able to handle the 12 " roller assembly for testing the fuel cell E-gator. The dimensions of the E-gator are taken from John Deere's present utility vehicle. A new appearance of the E-gator is given for the UVic's vehicle. The new gator has an improved aesthetic body style. At present, the university is considering the feasibility of introducing a fleet of fuel cell powered E-gator. The dynamometer is designed to accommodate this development if lunched eventually.

Figure 5-6 illustrates the concept fuel cell gator which is created using Pro/E Wildfire2 Version. The wheelbase and wheel track dimensions, which are critical for the dynamometer platform, are same with the referred model. Four head and tail lights are designed to improve the illumination capabilities of the gator. It can be seen that the rear design of the gator is improved with extra cargo box capacity for more efficient usage of fuel cell gator's facilities. The passenger room is kept same with John Deere Gator utility vehicle. The clearance of hydrogen tanks and the side of the gator is designed with enough room to prevent any damage in case of any non-desired impact. Detailed design drawings are given in Appendix D. 


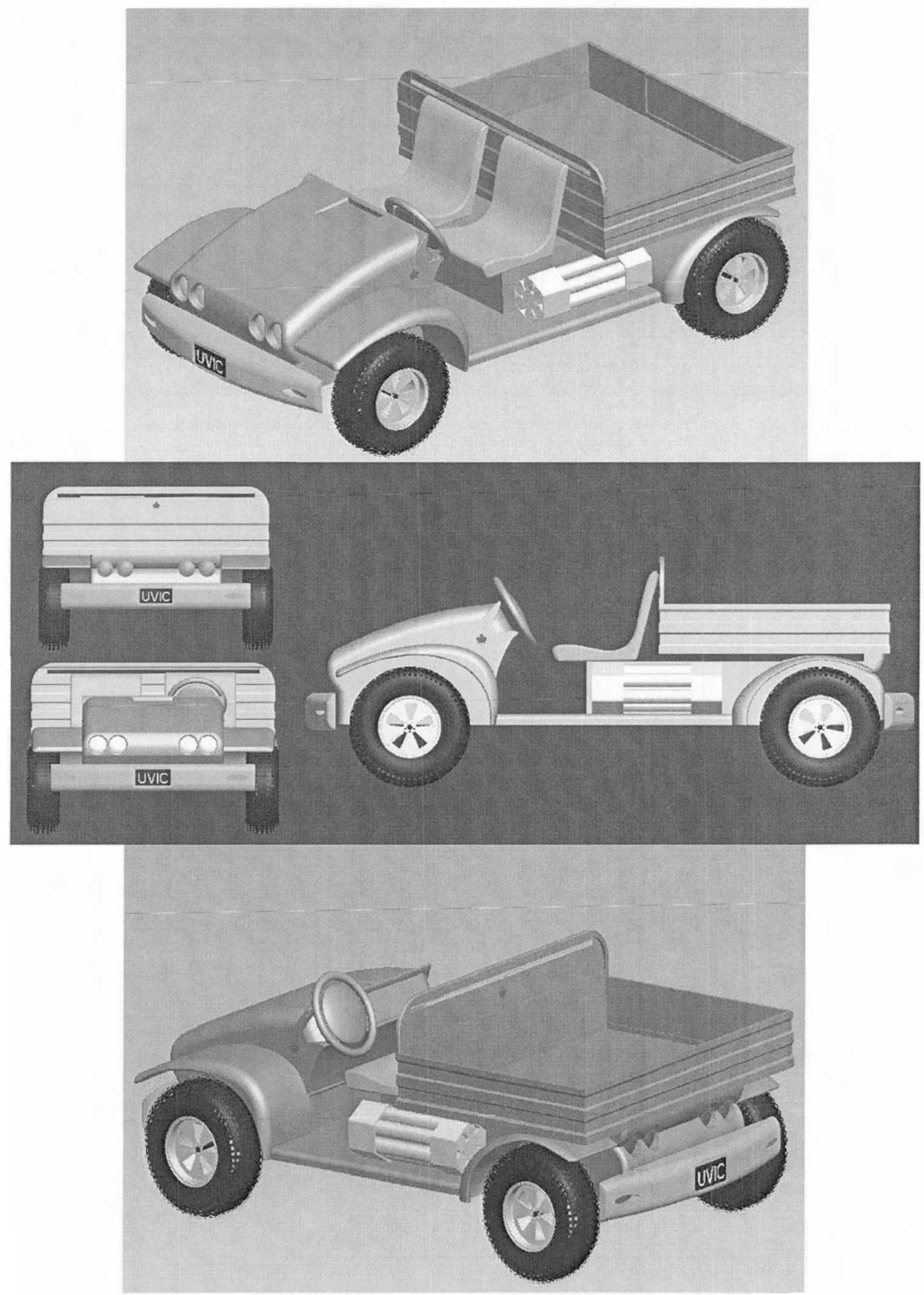

Figure 5-6 Concept fuel cell powered utility vehicle E-Gator 


\subsubsection{FCHLSEVs settings on the Dynamometer Platform}

At present, the test FCHLSEV in our research laboratory is a fuel cell battery hybrid electric scooter. This vehicle is selected due to its simplicity and representative features. Two electric scooters with identical design and motor, one powered entirely by lead acid battery and the other powered by the fuel cell and battery hybrid power system, are used as test vehicles, to better understand the performance characteristics of FCHLSEV and to test the FCHLSEV modeling, analysis, and design optimization techniques. The Configuration I of the dynamometer system is designed and produced to carry out this task. With some modifications, the design can be used for larger vehicles, such as the Egator.

The fuel cell vehicles are placed on the dynamometer to examine the performance characteristics during typical driving activities, including idling, cruising, acceleration, and deceleration. The fuel cell scooter [24] and the concept fuel cell gator on the dynamometer are illustrated in Figure 5-7 and Figure 5-8.

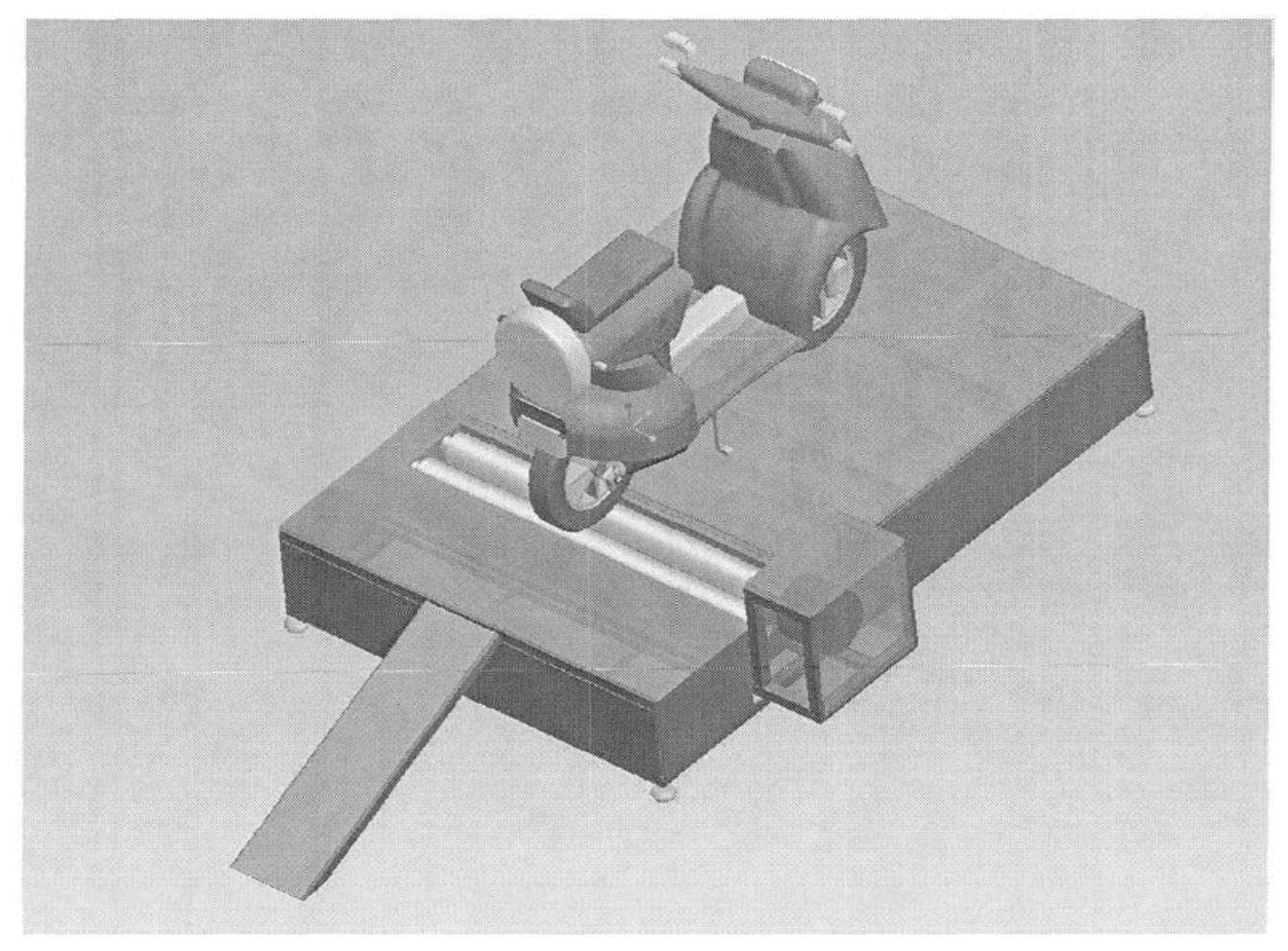

Figure 5-7 Fuel cell scooter setting on the dynamometer platform with 5' roller unit 


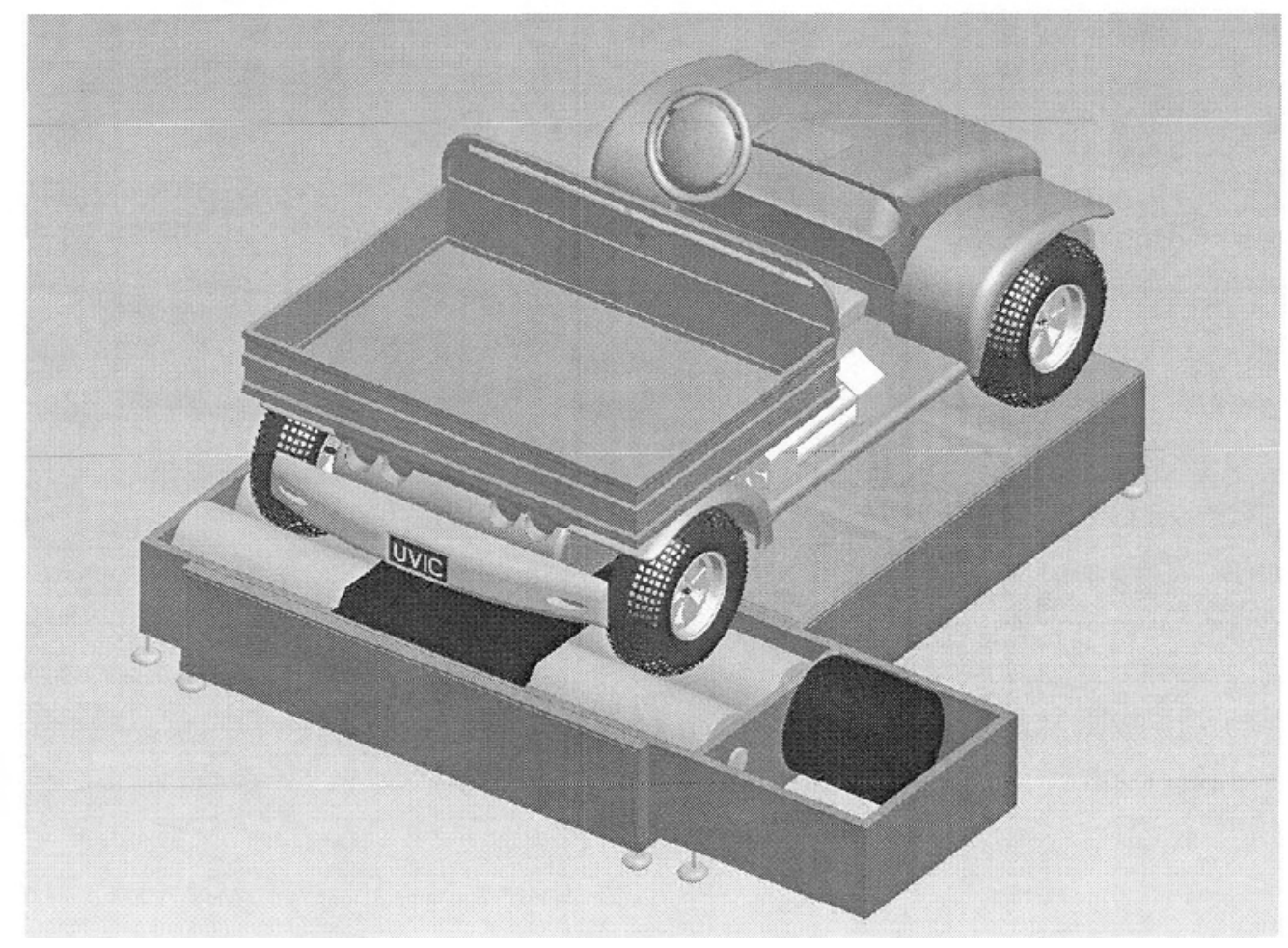

Figure 5-8 Fuel cell gator setting on the dynamometer platform with 12" roller unit

\subsection{Vehicle Test Bed Design for Motion Transmission and Load Applications}

During the test, the wheel motion of the fuel cell scooter is transmitted to the roller-unit and then to ECA. The loads from the ECA and the roller are transformed back to the vehicle.

A belt system is designed to perform the motion and force transmission inside the platform space and to damp possible vibration and shock from the wheel. This belt system consists of one belt, two pulleys to hold the belt, and two bushing flanges to mount those pulleys to the extension of the cylinder ending with taper axle, and the shaft of ECA. Alignment of the bearings is a major concern in the design of the supporting structure and adjustment components. A special design is introduced, as shown in Figure $5-9$. 


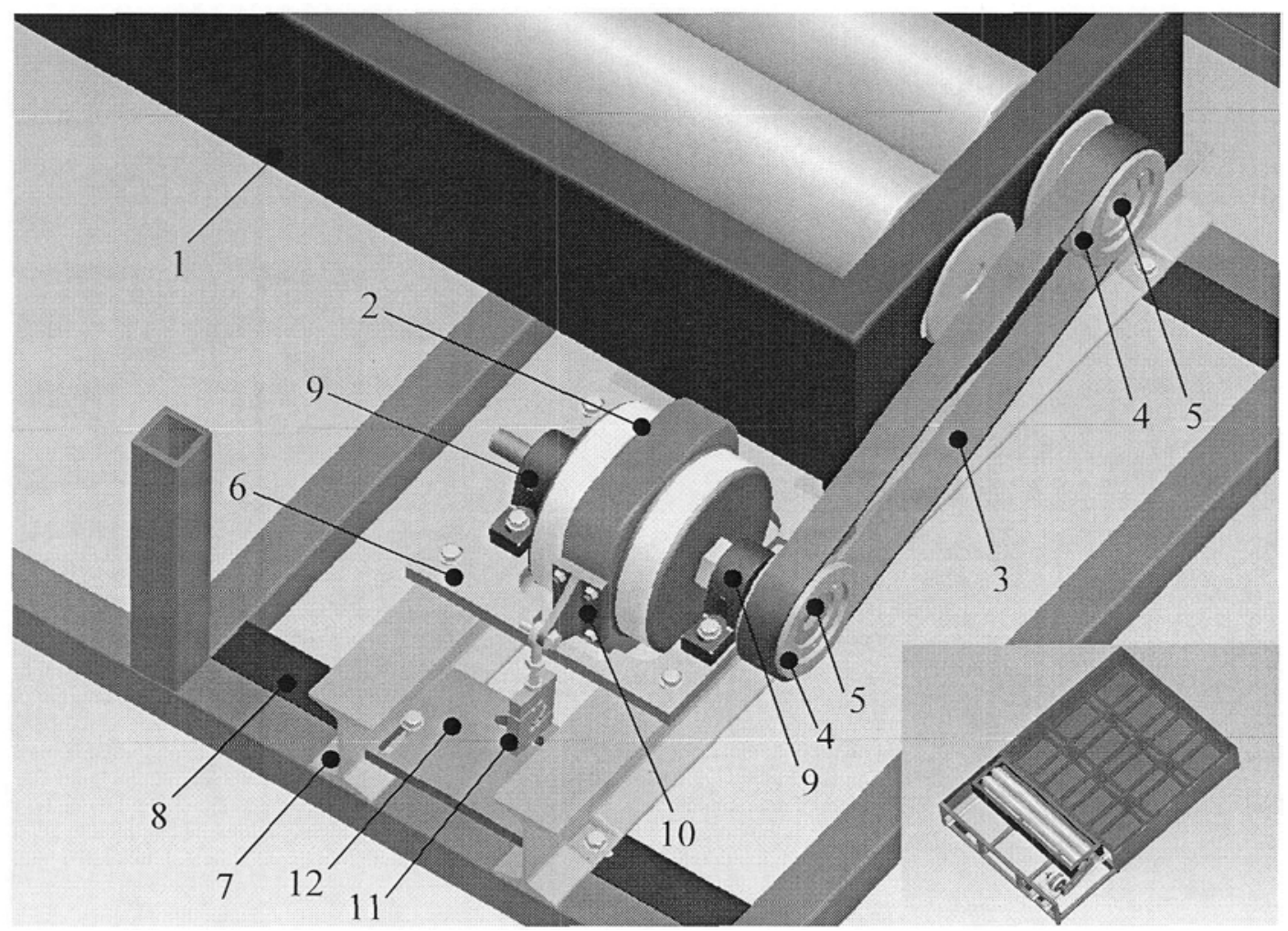

Figure 5-9 The assembly of the dynamometer interior mechanism

The illustrated portion of the dynamometer was designed to carry out three distinct tasks: rotation transmission, dynamic load generation, and load sensing. These tasks and the designs are discussed in details in the following sections. The numbered items in Figure 5-9 are: 1.Roller Unit, 2.Eddy-Current Absorber, 3.Belt, 4.Pulleys, 5.Bushing Flanges, 6.Alignment Plate, 7.1-Beams, 8.Angles, 9.Bearings, 10.Torque Bar, 11.Load Cell, 12.Load Cell Support Plate.

The need for placing all the components of the dynamometer inside the platform frame space also brings the need for some supporting features. At the beginning of the entire design, ECA was considered to be outside the platform which requires an additional protection box resulting with occupying some additional space outside the platform (Figure 54). This system used to have square tubing bars to raise and support the roller unit by 4" due to height difference between 5 " and 12" diameter roller units, where the frame of the dynamometer platform is designed for both. Considering the heavy mass of the roller unit and in addition to that, the need for a cut on those tubing bars which 
occurred in advance, they were replaced with 4" height I-beams which have much more strength values [25] and suitability to have a cut (discussed in 5.4.1), when compared to tubing bars (Figure 5-10).

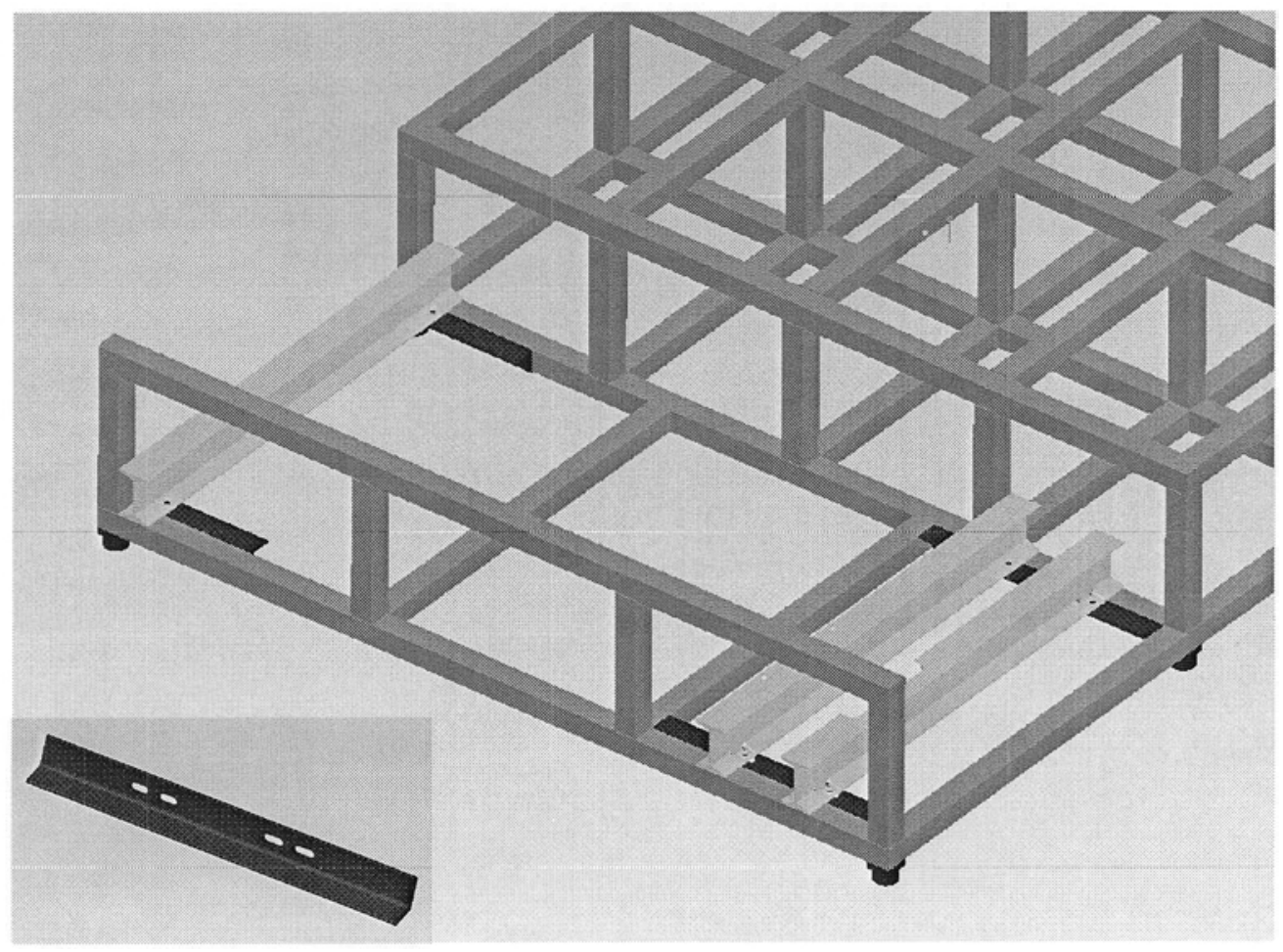

Figure 5-10 I-beams and the angles

Due to aim using less number of components to generate less cost, one of the I-beams was designed to accommodate both for the eddy current absorber's bearing and the roller unit's two feet at the same time. Drawings of the I-beams are illustrated in Appendix E.

In order to mount I-beams to the main platform frame with bolts (UNC 3/8"-16), aiming to have an exchangeable form, additional L cross-sectional angles were welded to the frame - not to make any interference when $12 "$ roller unit sits - due to the insufficient space on the opposite sides of the frame bars to tighten the bolts with the nuts (Figure 510 left/bottom). Also, I-beams' inclined inner sides of the bottom surfaces are a drawback for the bolt's heads and/or washer's surface fit to the I-beam surface. Those areas around the bolt holes were grinded to maintain the horizontality for an efficient tightening of the bolts. 


\subsubsection{Eddy-Current Absorber (ECA) Configuration}

This part of the interior mechanism of the dynamometer system was designed to be consisted of ECA, the bearings to hold this absorber from its shaft and the metal plate considering the alignment of those bearings (Figure 5-11).

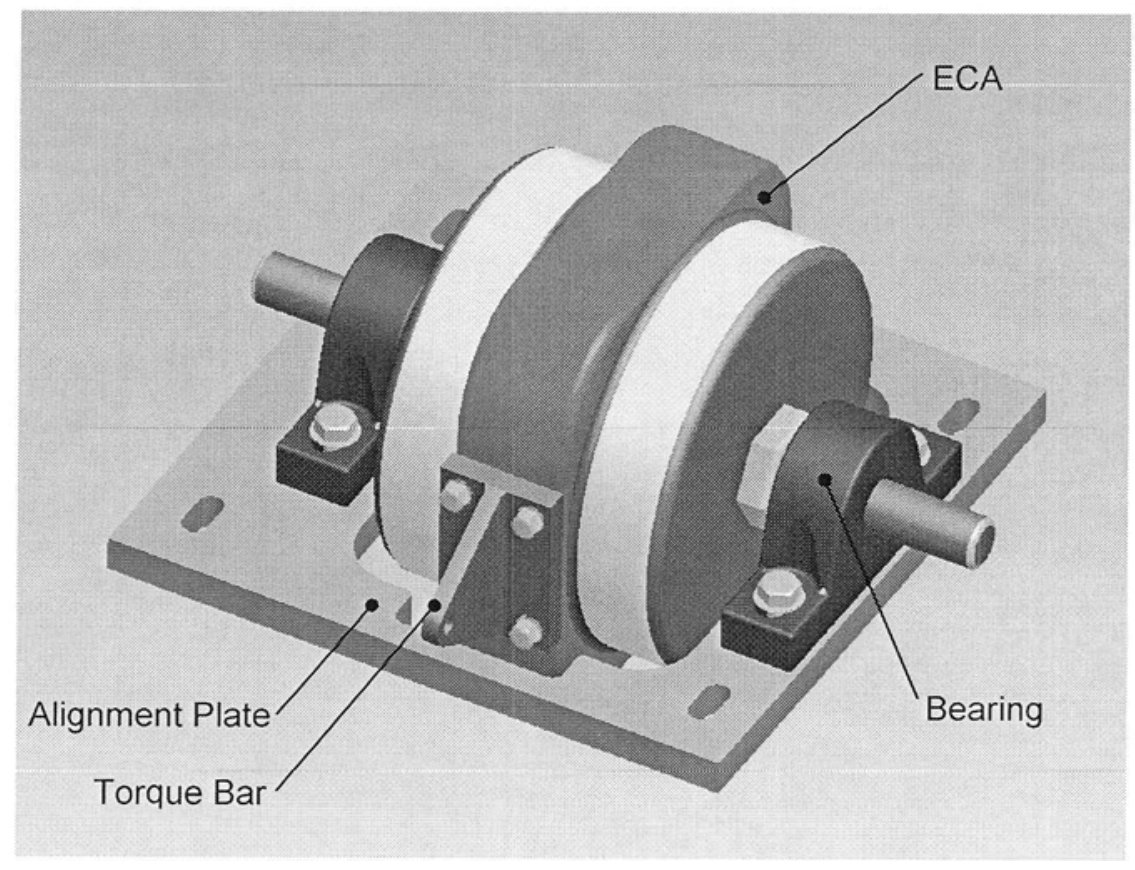

Figure 5-11 The assembly of the ECA system

Generally, alignment of two parts is much harder if they are not mounted on one single part due to the fact that the alignment of the other part(s) has to be taken into account, which requires more attention on design and/or more sensitive machining, meaning higher cost. In this system, instead of mounting the bearings separately on two I-beams, one metal plate (Figure 5-12) was considered to be mounted between the bearings and Ibeams in order to avoid those negative aspects.

The objective of this plate is not only to accomplish the alignment of the bearings, but also to give some adjustability to the system for the tightness of the belt. Slotted holes give the system that capability. Slotted holes can be described as larger holes or two holes together jointed with a path way hole where the bolt can travel. After the entire 
assembly, one can move the plate already fixed with the bearings, which means fixed with ECA as well, along the slotted holes as far as the slotted holes let the bolt move.

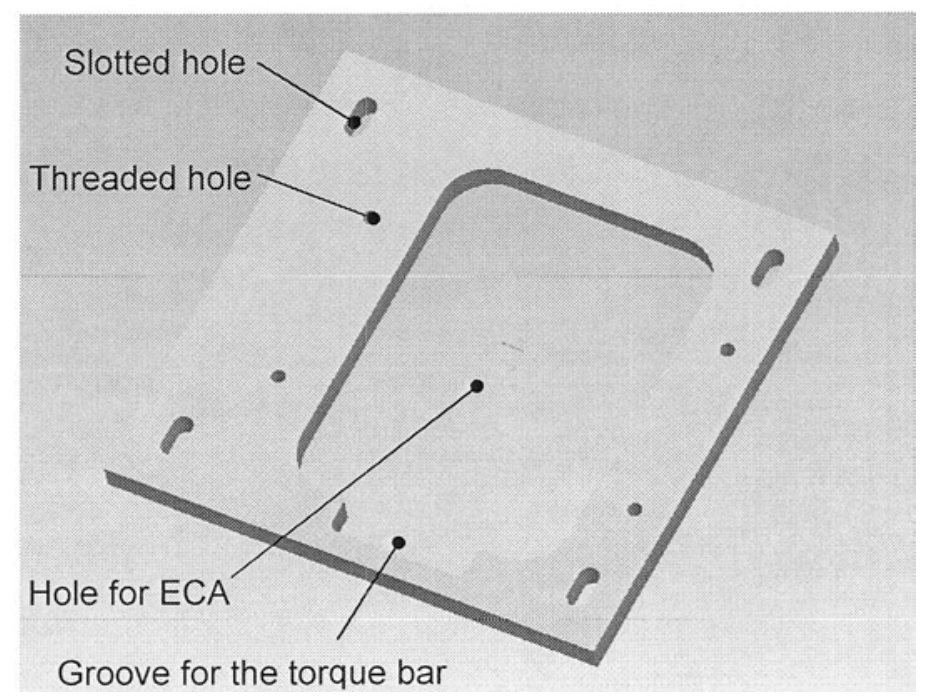

Figure 5-12 The alignment plate

Moving the plate on the I-beams causes the moving of bearings, ECA's shaft, bushing flange and finally the pulley which holds the belt. The desired tightness of the belt can be adjusted through this process and can be fixed by tightening the bolt in a certain position. Therefore, the metal plate has four slotted holes to be mounted on two I-beams, four threaded holes for two bearings to be mounted on it, and a much larger hole for ECA and its torque bar to be located through the plate. The material of the metal plate is decided to be aluminum due to the fact it is not subjected to a load except the weights of the absorber and two bearings. The detailed drawings can be examined in Appendix D.

\subsubsection{Belt Connection}

Once ECA is decided to be inside the platform, a belt mechanism is the only solution due to lack of room to transfer rotation of the cylinders to ECA. This belt mechanism consists of one belt, two pulleys and two bushing flanges. Bushing flanges were decided to enable the coupling of the belt's one pulley to the roller and the other pulley to ECA's shaft (Figure 5-13). 


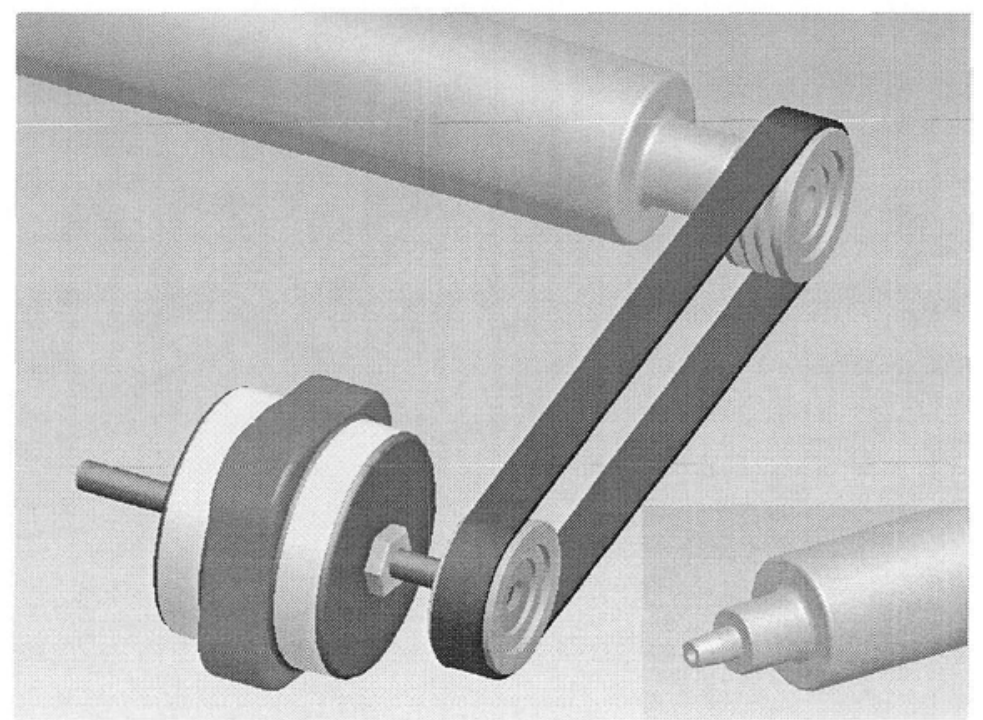

Figure 5-13 The assembly of the belt mechanism with ECA and the roller

Because the tip of the roller (Figure 5-13 right/bottom) is a taper ( $4^{\circ}$ conic), the inner hole of its bushing flange required to be redesigned different from standard bushing flange (which was used for ECA's shaft) with the same conic angle to fit the outer surface of the taper. This conic shape, with a bolt that is put to the threaded hole along the axis of the roller, passing through the axis of the flange, prevents those two components from sliding. With the same logic, the outer surfaces of the flanges that fit into the pulleys and pulley's center hole surfaces are also a taper. The mounting of the bushing flanges to the pulleys was carried out with three bolts through three threaded holes both on the side surfaces of the flanges and pulleys (Figure 5-14). The technical drawing of the bushing flange with conic inner hole is illustrated in Appendix D.

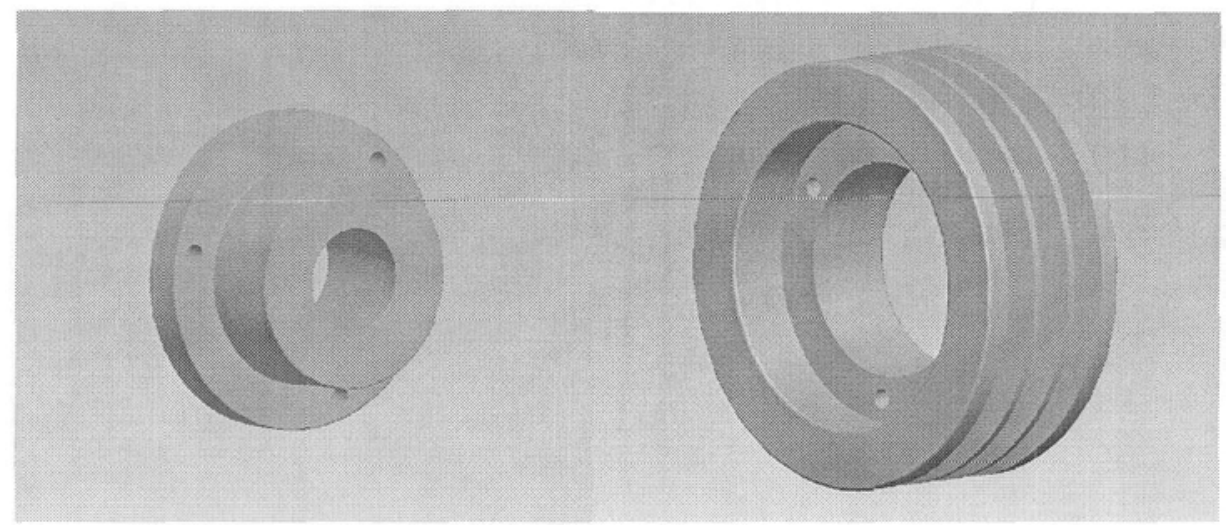

Figure 5-14 The bushing flange and the pulley 


\subsection{Vehicle Test Bed Design for Data Acquisition}

To ensure appropriate loads are applied during the vehicle test. The torque and rotation speed at the wheel of the vehicle, or equivalently at the roller and ECA, are measured using torque and RPM sensors. A data acquisition system retrieves the sensor data and passes them to the load control system and to the analysis unit for later processing. To send the torque and force measurement to the computer, signal conditioners are utilized to permit direct communication from the load cell via conversion of the load cell's analog signal signals to digital information.

\subsubsection{Torque Measurement}

The torque measure is carried out by measuring the force applied at certain location to produce or stop a rotation about an axis. The distance from the axis of rotation, or fulcrum, to the point where the force is applied is called the torque arm, $d$. In Figure 515 , it is shown as a vector pointing to the left. The torque $\mathrm{T}$ is the product of the force $\mathrm{F}$ and the torque arm, $d$.

$$
T=F \cdot d
$$

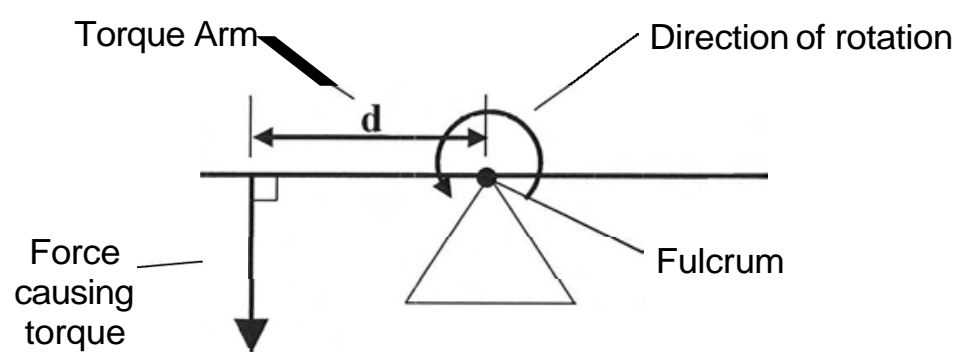

Figure 5-15 Torque generation

In the present design, the housing of ECA, free-spinning with respect to the shaft and the rotor of the ECA when no current is applied, is mounted to the load cell. The distance from the shaft of ECA to the load cell is considered to be the torque arm (Figure 5-16). 


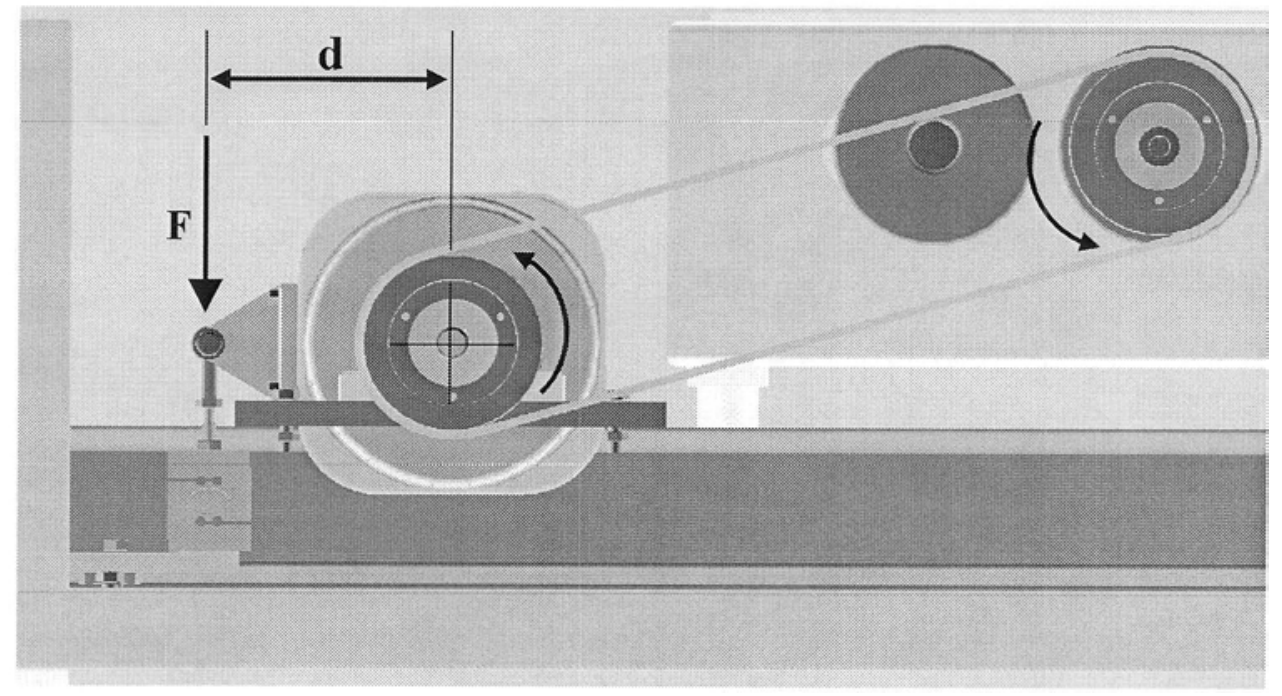

Figure 5-16 F force acting on the load cell, d distance from the ECA's shaft axis

The rotation of the ECA housing is prevented by the use of a torque bar, mounted on the housing and connected to the frame of the dynamometer. The torque bar is mounted onto the load cell to make 90 degree angle using a bolted connection. Force applied by the vehicle tire attempts to spin the rollers, and the rollers - via belt connection - spins the rotor of the ECA. When current is applied from the controller to the electromagnets of the ECA, a counter-acting torque, proportional to the amount of current, is generated. In other words, the ECA creates some resistance between the rotor and the housing, and the resistance prevents continued free-spinning of the rotor. The resistance torque is measured by the load cell according to Equation (19).

In this work, it is assumed that the slipping between the tire of the test vehicle and the roller, and between the belt and the pulleys; and the frictions in the bearings of the rollers and Eddy current rotor can be both neglected. This will considerably simplify the modeling without sacrificing the accuracy of the measurement. Alternatively, a loss coefficient of less than 1 can be introduced to account for the loss.

\subsubsection{Load Cell Mount and Adjustment Design}

The load cell needs to be mounted to somewhere rigid in the system due to its sensitivity for the force measurements. Thus, a threaded mill to mount the load cell to the torque bar 
and to enable the force transmission from torque bar to the load cell, and a support plate for load cell's support when force is applied was considered (Figure 5-17, Appendix D).

There exist two threaded holes on the top and the bottom edges of the load cell. From the top hole, it is mounted to the torque bar with a mounting apparatus, with a threaded mill. This threaded mill also gives height adjustment along the $Z$ direction to the load cell. From the bottom hole, it is bolted to the support plate.

The load cell support plate is mounted onto the bottom plates of the two I-beams using the same bolts that hold the I-beams and the frame of structure together. With the slotted holes for those bolts, the plate can move along the $\mathrm{X}$ direction to bolt the load cell to the plate through the plate to the threaded hole at the bottom edge of the load cell. This hole was made slotted as well to give some adjustability to the load cell to move along the $\mathrm{Y}$ direction to be mounted vertically to the support plate. The connections of the load cell are illustrated using the computer model, shown in Figure 5-17, and the picture of the manufactured hardware, shown in Figure 5-18.

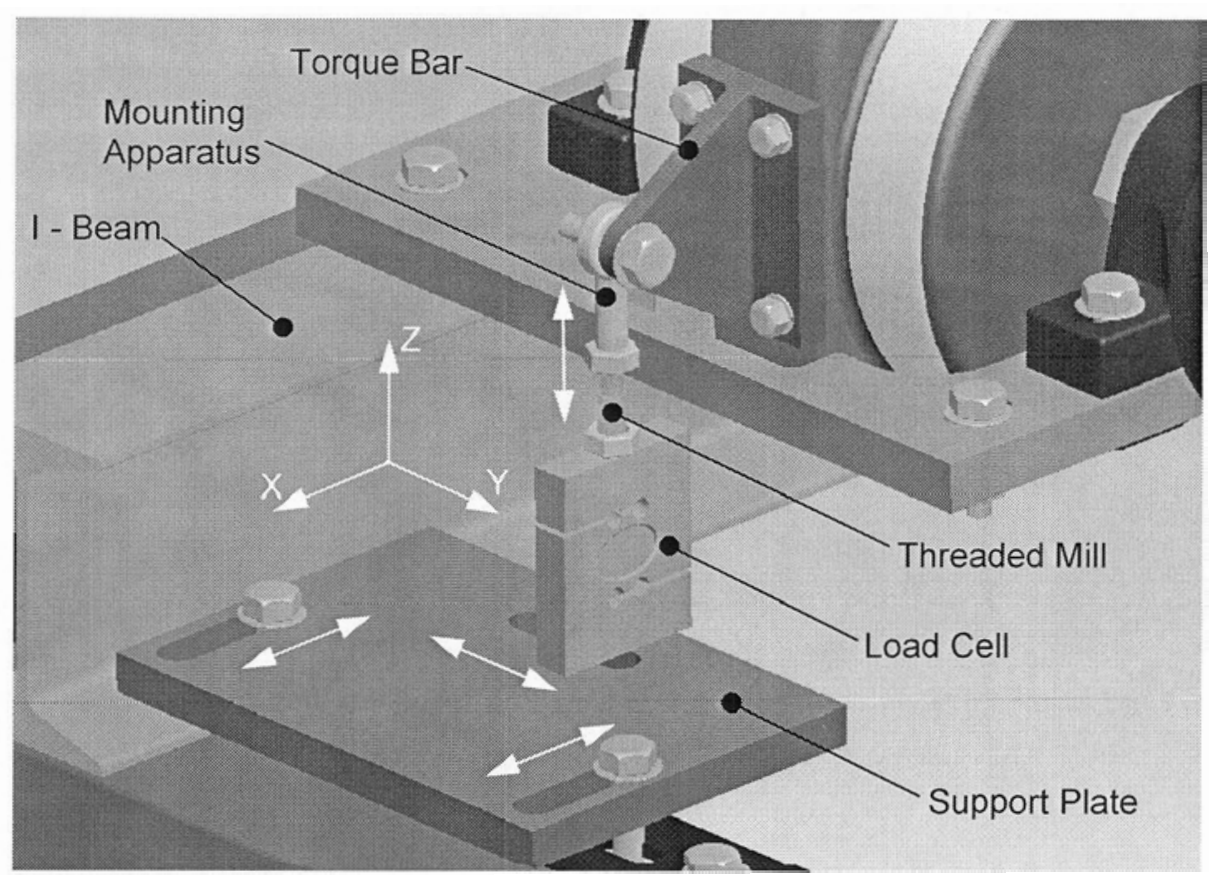

Figure 5-17 Load cell and its support plate configurations 


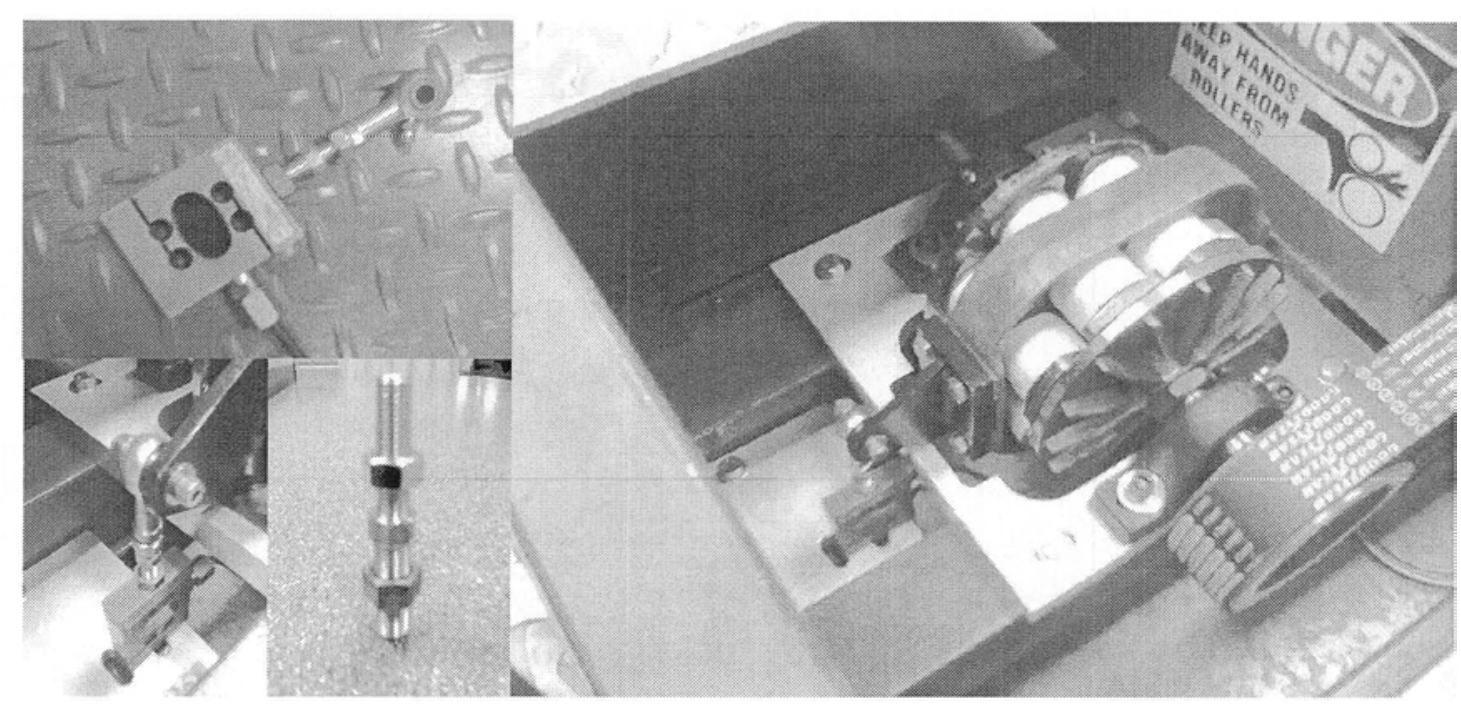

Figure 5-18 Load Cell and the related hardware

\subsubsection{Mount of RPM Pick-Up Sensor}

A rotation speed sensor is used to sense the rotation speed of the wheel of the vehicle, as well as the distance of the travel and the acceleration indirectly. The rotation speed sensor used in this work is a magnetic RPM pick-up mounted onto the frame of the dynamometer and the shaft of Eddy current rotor due to convenience. The RPM signal is read into the data acquisition controller through a jack-shaft RPM data channel. The RPM reader (mounted onto the shaft of the roller) and the pick-up sensor (mounted the main frame with a bracket) can be seen in Figure 5-19 from different angles.
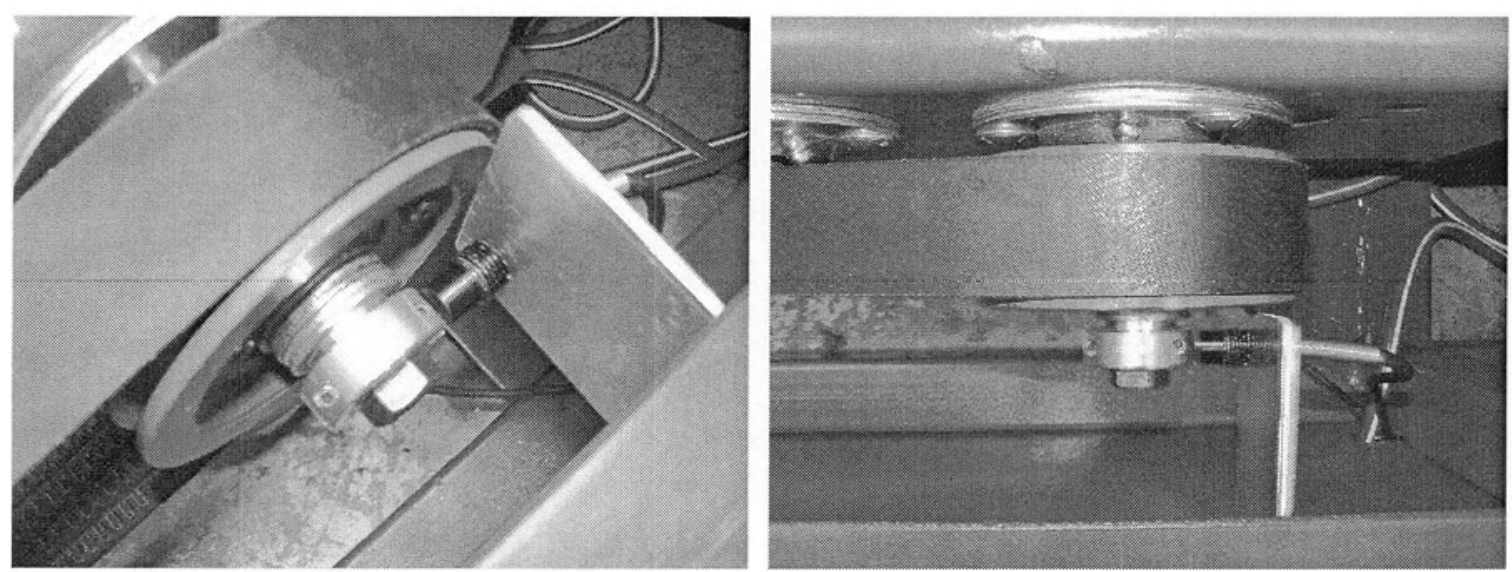

Figure 5-19 RPM reader and its sensor 


\subsection{The Interferences in the Interior Mechanism Design}

In the interior design, the proper layout of the belt-pulley system, the placement of the torque and RPM sensors are the major concerns.

\subsubsection{Location of the absorber}

The position of the ECA along the I-beams' length, which means the places of I-beam holes for the metal plate, are determined according to the $\mathrm{R}$ distance between two axes of the pulleys assembled with the belt (Figure 5-20). As a requirement of the design, the particular position of the roller unit, which is adhered to the platform frame, obviously brings a certain fixed position of one of the pulleys which is mounted on the cylinder. The axis of this pulley can be assumed as the center of the circle path that the other pulley is only allowed to follow on. The intersection of this path and the axis of the ECA's pulley when the metal plate is placed on the I-beam, gives us the exact location of ECA and its components.

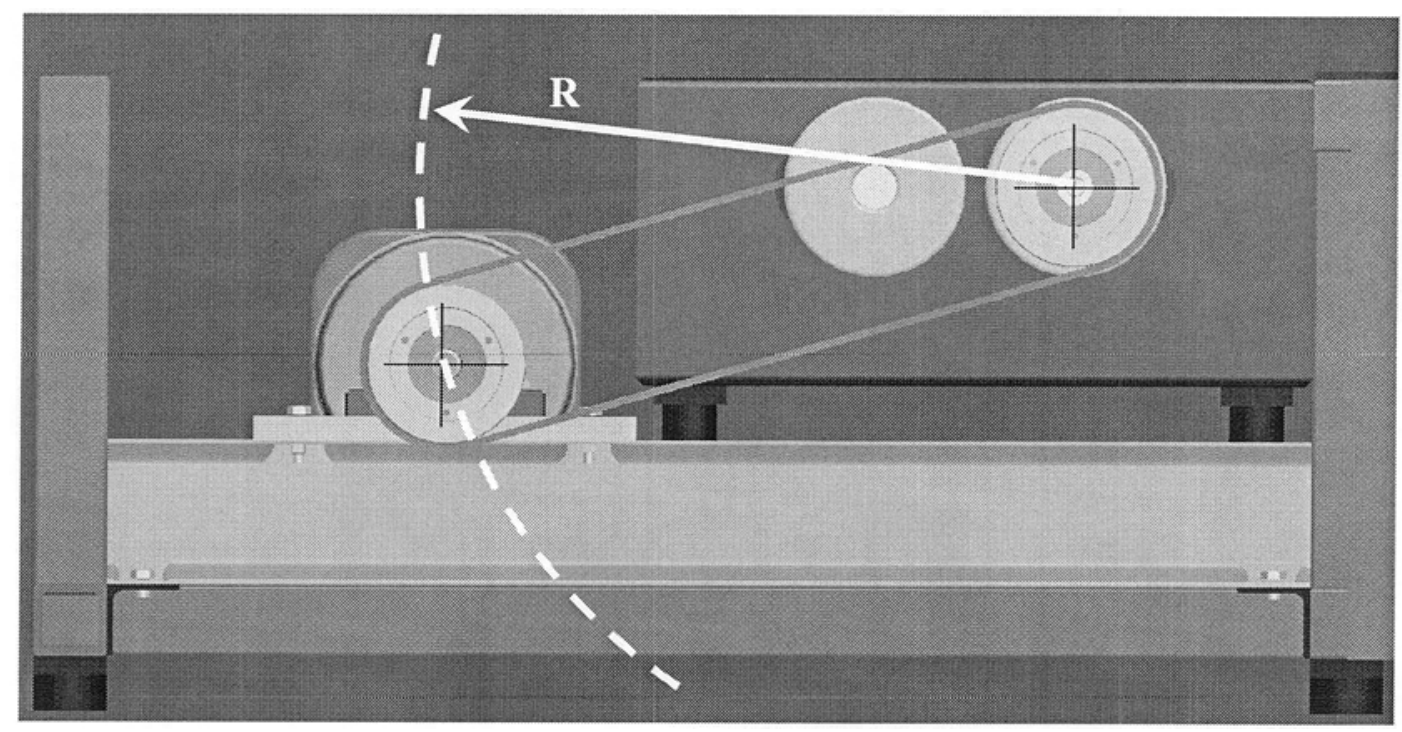

Figure 5-20 The relevance with the belt length

In positioning ECA along I-beams' width (Figure 5-21), the following requirements are to be satisfied: 
1. Alignment of both pulleys for an efficient belt run,

2. Maintenance of a particular distance "I" between the roller unit and the pulley 1 (due to the bushing flange inside the pulley 1 ),

3. The inadequate shaft length "SL" of the absorber (the cylindrical hole of the bushing flange 2 should be filled with the shaft not to lose friction surface between two),

4. Particular surface width of the I-beam "IW" (considering to maintain sufficient strength and distance for the feet of the roller unit).

Consequently, one side of the top surface of this I-beam has to be cut to provide appropriate room for the fit. The detailed drawings of this I-beam are given in Appendix D.

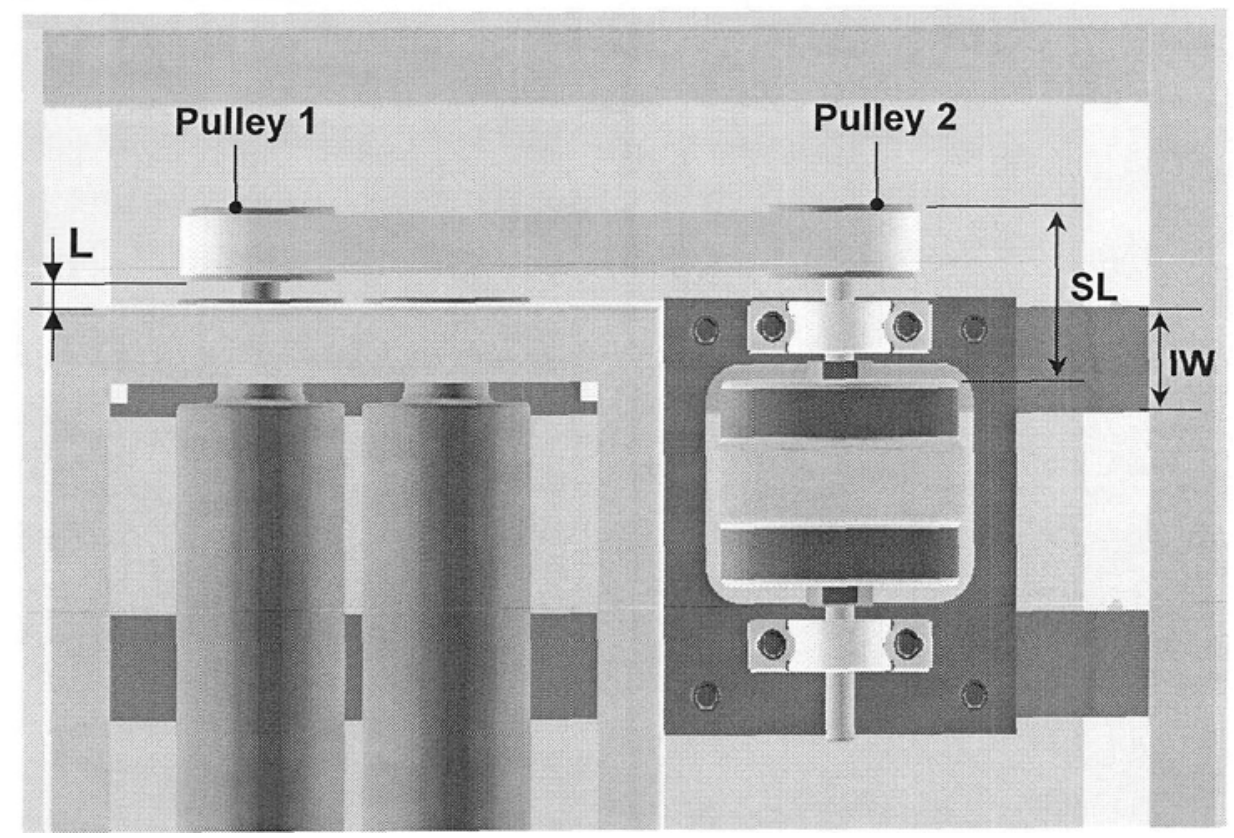

Figure 5-21 The distance limitations causing the I-beam cut

\subsubsection{Adjustability of the rollers}

During the course of the interior mechanism design of the dynamometer, the adjustment of the distance between the two rollers for different test vehicles is also taken into 
consideration. The distance of the rollers can be adjusted up to 1.5" horizontally within the case of the roller unit along the direction of the I-beams (Figure 5-22).

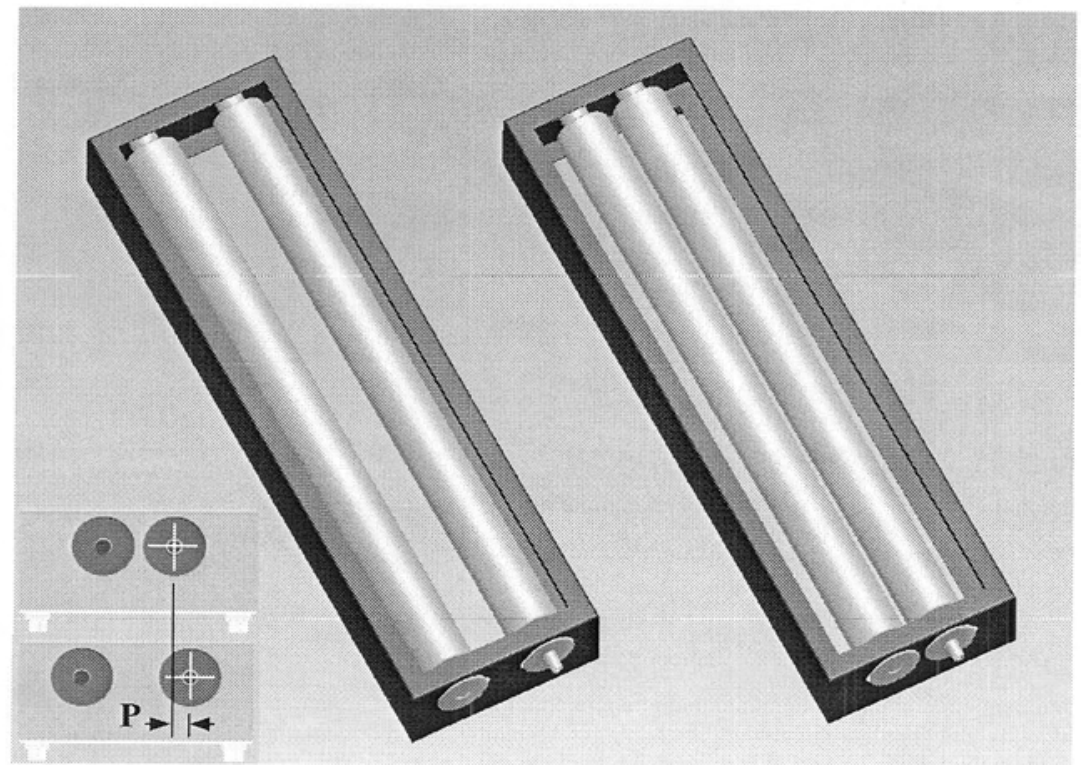

Figure 5-22 The wide and narrow positions of the rollers

The adjustment of the roller position and their gap, the horizontal distance, $\mathrm{P}$, consequently leads to the horizontal movement of one of the pulley. Design to accommodate the offset is needed to ensure the proper function of the belt-pulley system. However, due to the insufficient distance between roller unit and ECA, which is less than $\mathrm{P}$, the roller unit will interfere with the ECA. To solve this problem, ECA is raised along the belt's radius circle path, as shown in Figure 5-23. 


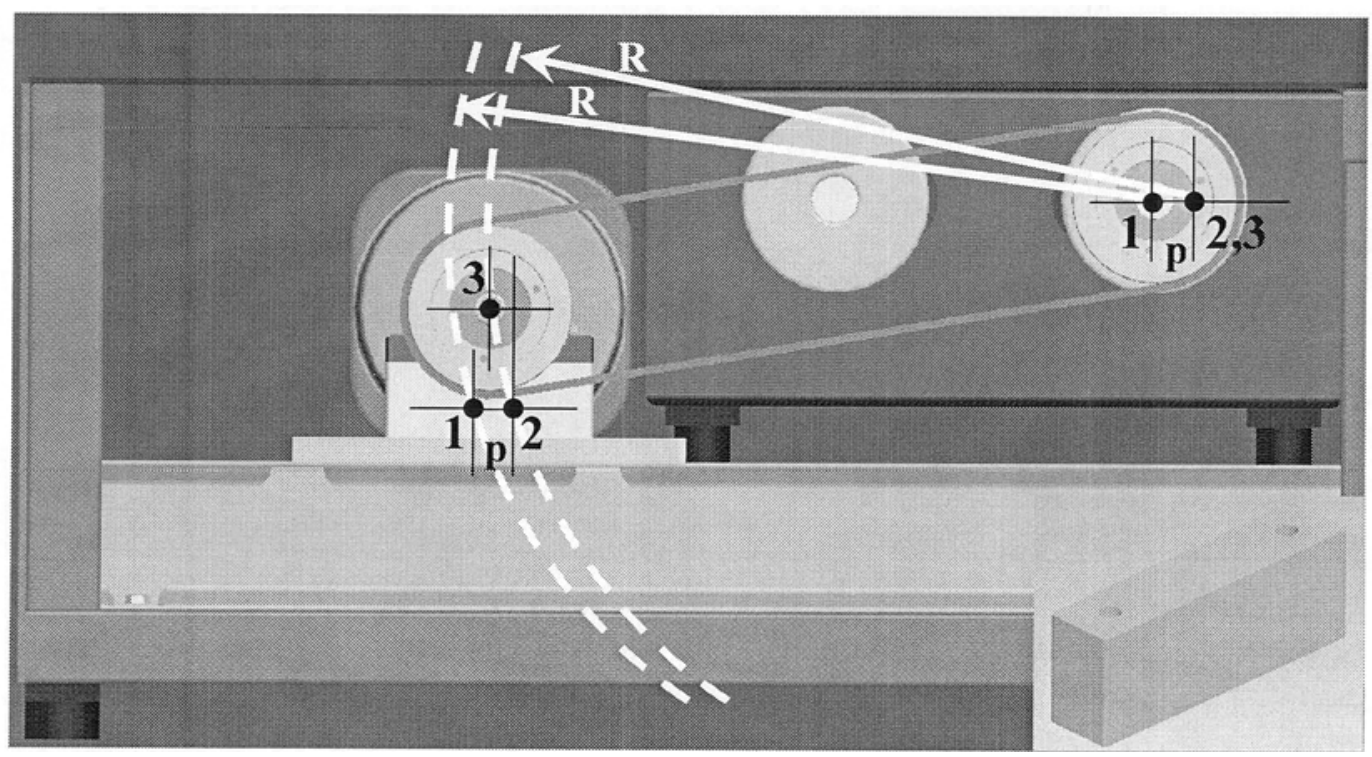

Figure 5-23 Rollers in wide position and the additional raising part

In Figure 5-23, point 1 indicates the pulleys' axes at narrow position, point 2 indicates the axes at wide position (sliding the pulleys with the dimension of $\mathrm{P}$ ) which can not be positioned due to roller unit interference and finally, point 3 illustrates the raised position of the absorber and its components, which are rotated about the cylinder's pulley axis. The 2" vertical raise of the absorber along the path gives an additional 0.69 ", which is sufficient with the existing 1.47 " gap between the roller unit frame and the eddy current absorber. Therefore, additional two pieces (one for each bearing) of 2" height solid metal block (appropriate to the bearings ${ }^{7}$ bottom surfaces) can be considered between the alignment plate and the bearings. In order to keep the rigidity for the alignment of the bearings, bolting of the raising metals is considered to be through two threaded holes, from bearings to the alignment plate (Technical drawing of the metal block and the study of the measurements for this part are given in Appendix D). 


\section{OPERATION OF LOW-SPEED ELECTRIC VEHICLE TEST BED (LSEVTB)}

Construction of the low-speed vehicle test bed was completed and the finished system is located at the Advanced Manufacturing Laboratory at UVic. This chapter presents the general procedures for carrying out vehicle testing, for the testing system calibration and initialization, as well as for the operations of the test fuel cell - battery hybrid scooter at our research laboratory.

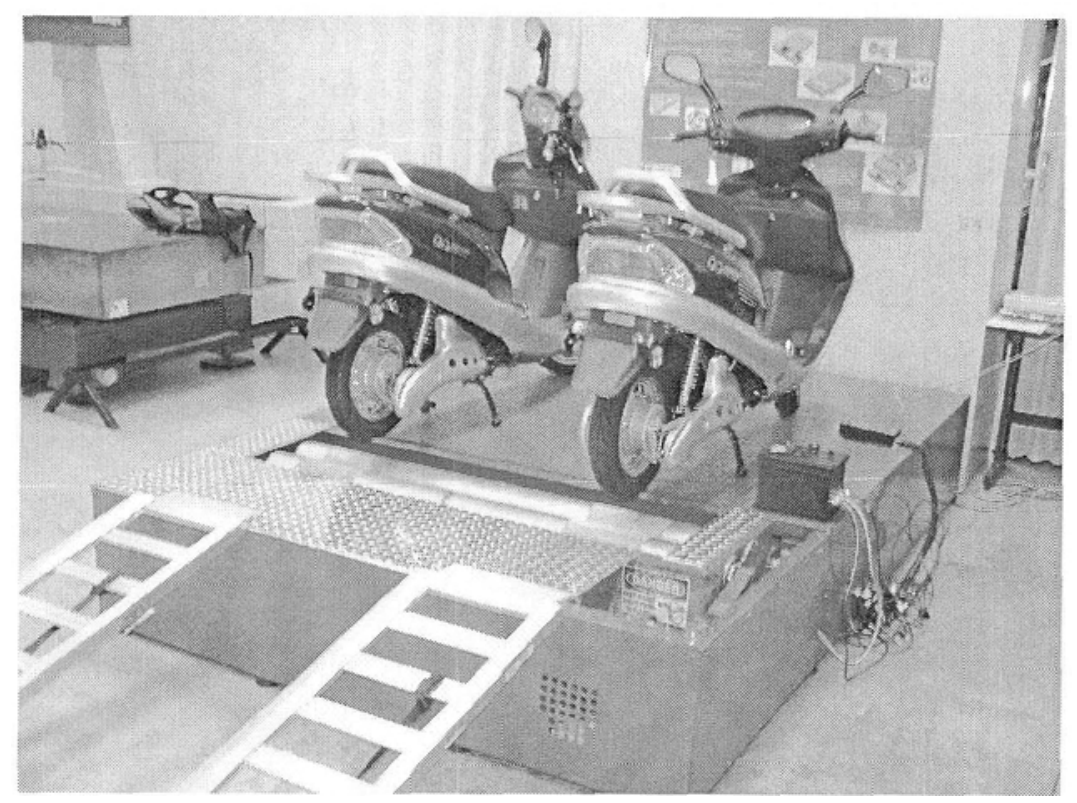

Figure 6-1 Constructed test bed at UVic

\subsection{General Procedures for Vehicle Testing}

Before getting started to test the vehicle, the following checks are to be made:

- Ensuring the proper connections of the power and communication systems. Wiring harness connections are all hooked up properly.

- Ensuring the proper setup of the scooter. The spinning wheel of the scooter should sit on the rollers properly and enough tire pressure should be applied to avoid sliding. 
- The data acquisition controller, ECA, ECA controller and PC workstation are powered up and ready.

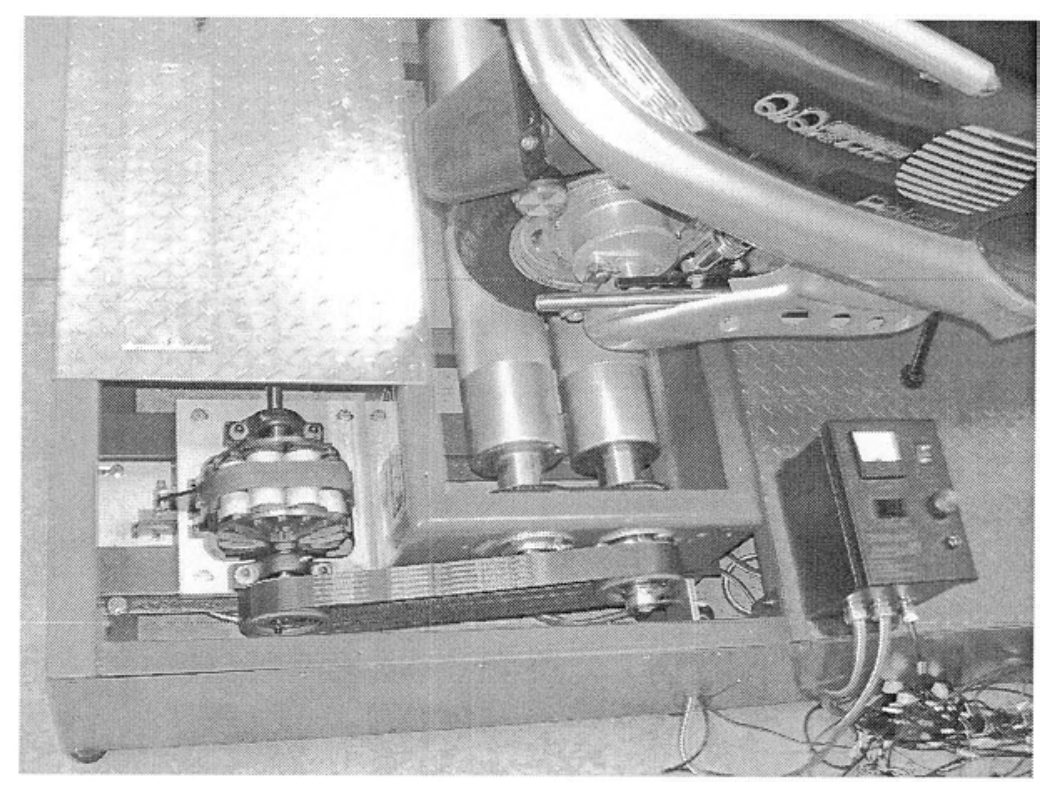

Figure 62 The proper wheel setting on the rollers

\subsection{System Calibration and Initialization}

System calibration consists of load cell calibration, rough dynamometer driveline loss calculation, and the set-up of the software console.

Calibration of the load cell is needed before the system can be used to ensure the accuracy of the measured torque. The calibration is carried out by calculating the torque value from the product of a known force and a known torque arm distance, to be entered to the software. After disconnecting the load cell form the system, a standard weight of $25 \mathrm{lbs}$ was placed on the top of the load cell to apply a known compression. The product of this weight with the 6" torque arm distance of our dynamometer system (the distance from the axis of the absorber to the load cell axis) gives us the standard torque of 12.5 in foot-lbs to be entered to the software.

The parasitic losses of the roller and absorber system due to bearings, belt-pulley connections etc, also needs to be defined for accurate vehicle simulations. In principle, 
this value can be calculated using Equation 18 through a coast down test. After the scooter reaches its maximum speed, the wheel of the scooter is lifted off the rollers and the time needed for the roller system to come to a full stop is measured. Once this result is recorded into the software, driveline losses can be obtained more accurately to avoid the inaccuracy of time measurement using a stop-watch.

A coast down test on the constructed dynamometer system was performed and the driveline power loss factor was found to be $0.305 \mathrm{~kW}$ at $1556 \mathrm{RPM}$. The test result is illustrated in Figure 6-3.

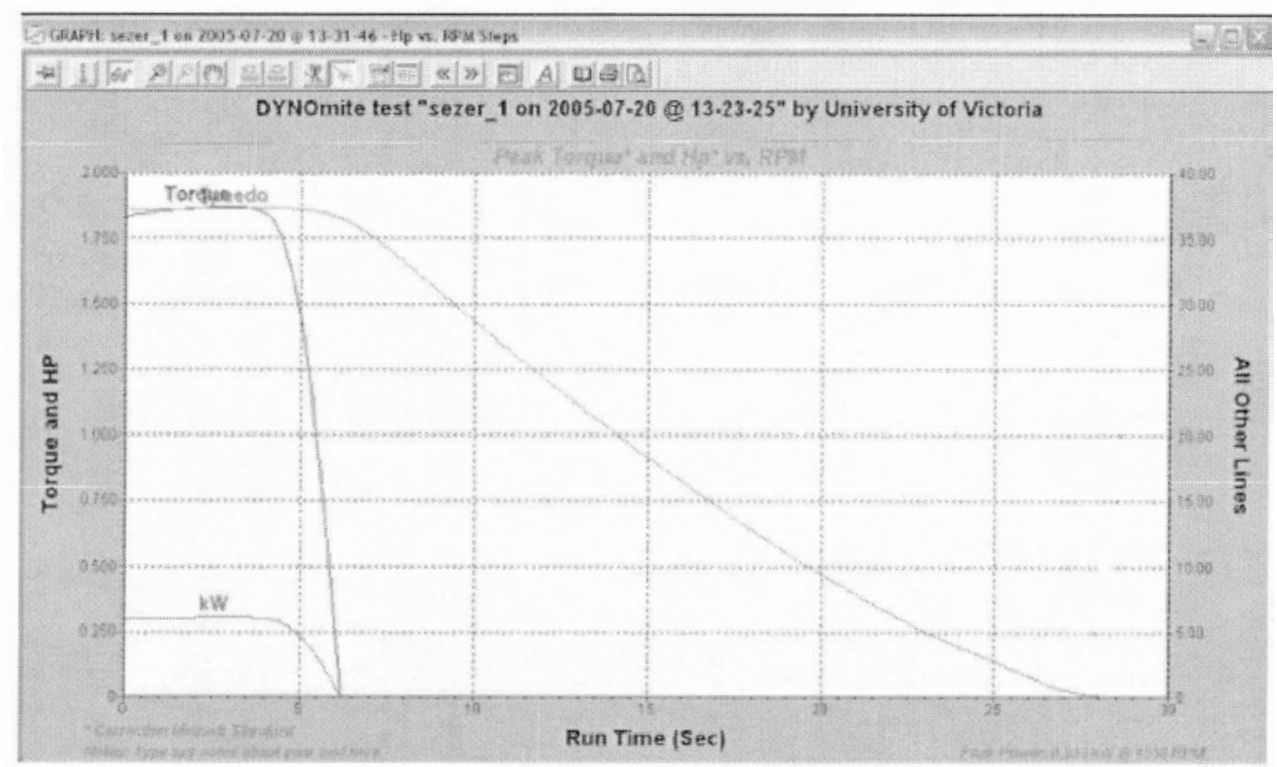

Figure 6-3 Coast-down test

To test the dynamometer system, several experiments, including the maximum speed test and the random cruising test, were carried out to find whether the acquired data are meaningful. A sweep test was also carried out to verify the proper function of the absorber.

The maximum speed and random cruising tests showed that the system is fully functional and reacting properly to the speed-up and speed-down actions. Changes of the expected maximum speed and the torque values were obtained and shown in Figure 64 and Figure 6-5. At present, due to the lack of an additional optical RPM pick-up sensor to measure 
the wheel rotational speed of the vehicle, the power of the vehicle cannot be calculated; the power value was thus not given on these graphs. The graphs settings of the system were calibrated to the speed versus the running time, and the $\mathrm{kW}$ readings could not be obtained in the tests.

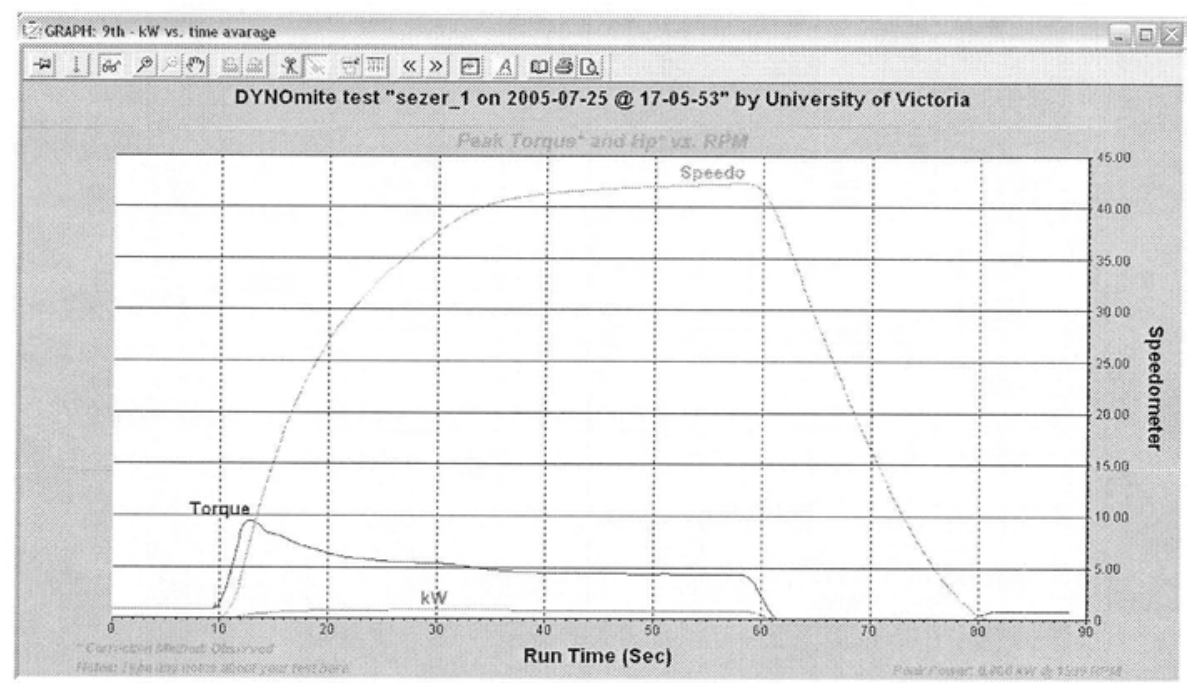

Figure 6-4 Maximum speed test

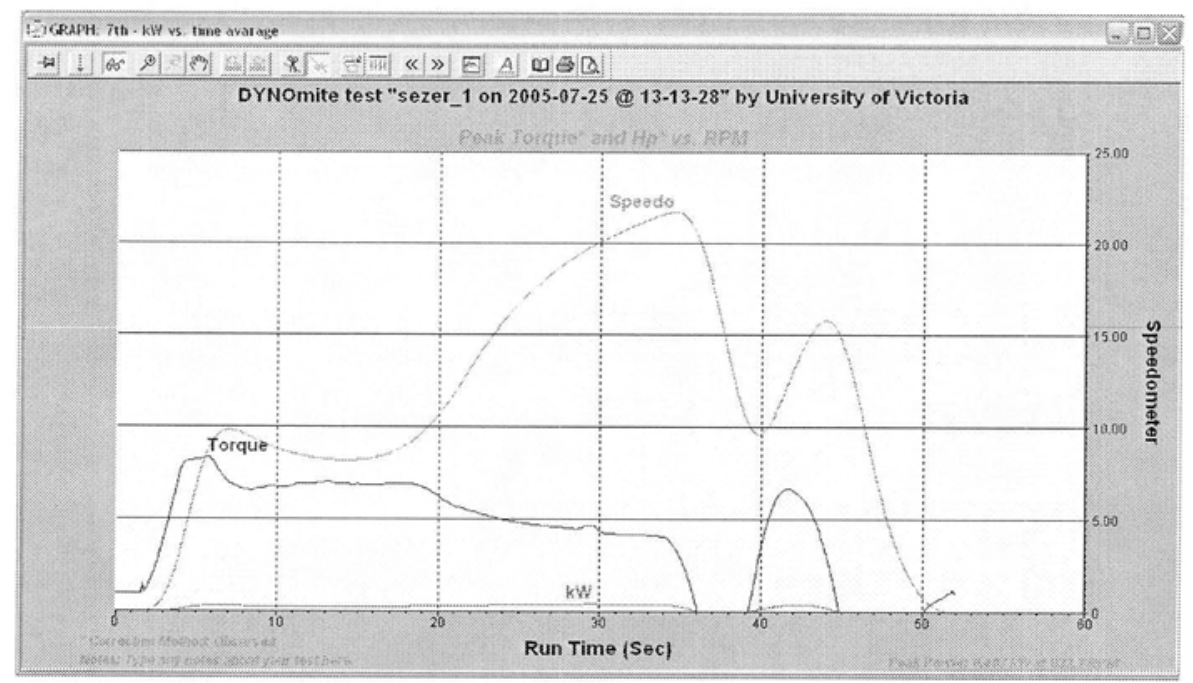

Figure 6-5 Random cruising test

The rotational speed of the wheel can be either measured from the RPM sensor mounted onto the shaft of the scooter wheel or obtained from the ratio of the roller diameter to the 
vehicle wheel diameter. However, use of the additional rotational speed sensor is a more appropriate choice due to

- possibility of wheel diameter chance due to tire pressure variation;

- difficulty in measuring the installed wheel diameter accurately; and

- slippery between the driving wheel of the vehicle and the rollers.

To run a sweep test, for example to speed up the scooter from $10 \mathrm{~km} / \mathrm{h}$ to $16 \mathrm{~km} / \mathrm{h}$ with a certain acceleration rate, these values are entered to the computer and the absorber automatically applies required force to the rollers, and to the wheel of the vehicle, even though the scooter throttle is fully engaged. The test results showed that the reactions of the system with satisfactory results (Figure 6-6).

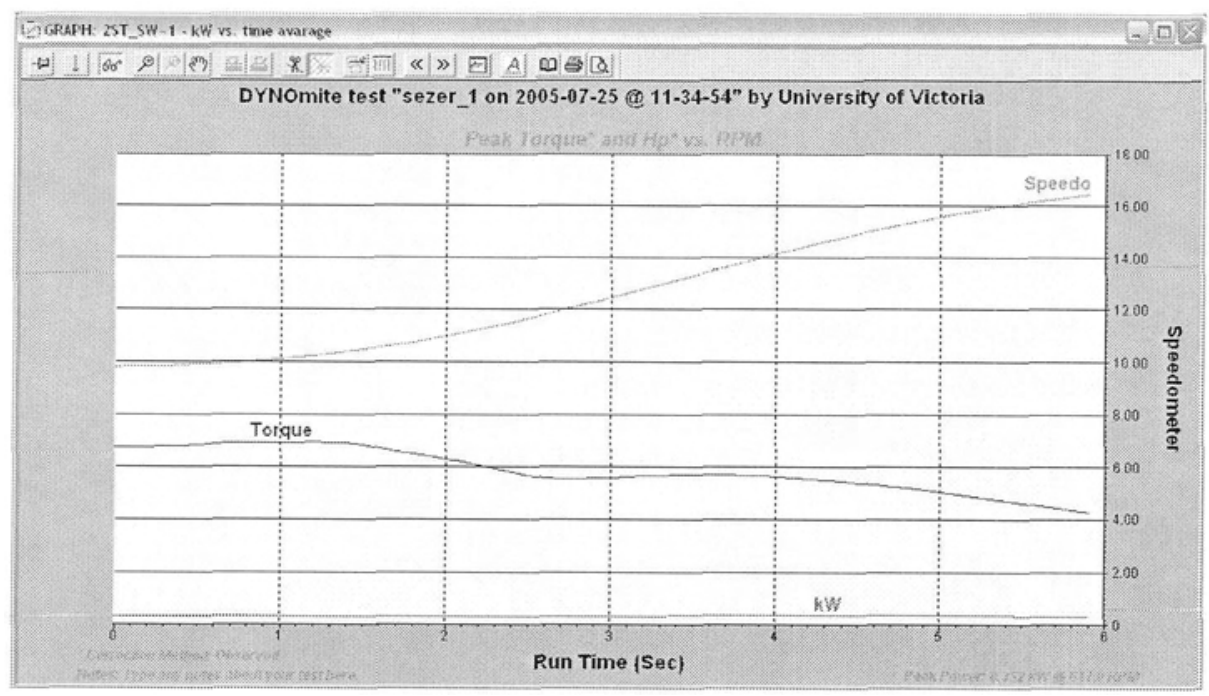

Figure 6-6 Sweep test

The software uses several configuration files for storing its default settings and custornization. These include things $s$ the console's gauge layout and ranges, engine run information, report format, graph choices, etc. During the use of the test bed, every time a global change is made to the software (calibrating channels or configuring controls); the system will keep those settings as long as it is saved under a specific name. For a new run, all of the last saved settings will be used unless they are changed or a different setting is chosen. The system does have a default setting. 
Because the pulleys of the belt system (roller-absorber) used in our system are identical, the drive ratio 1 was entered to the system. The air flow settings in the software, which are for the turbine calibrations at the top of the carburetor in IC-powered vehicles, not related to aerodynamic air drag, have nothing to do with our system. The console is also modified according to an electric vehicle data and the units of the console and other formulations in the software adjusted to metric system (Figure 6-7).
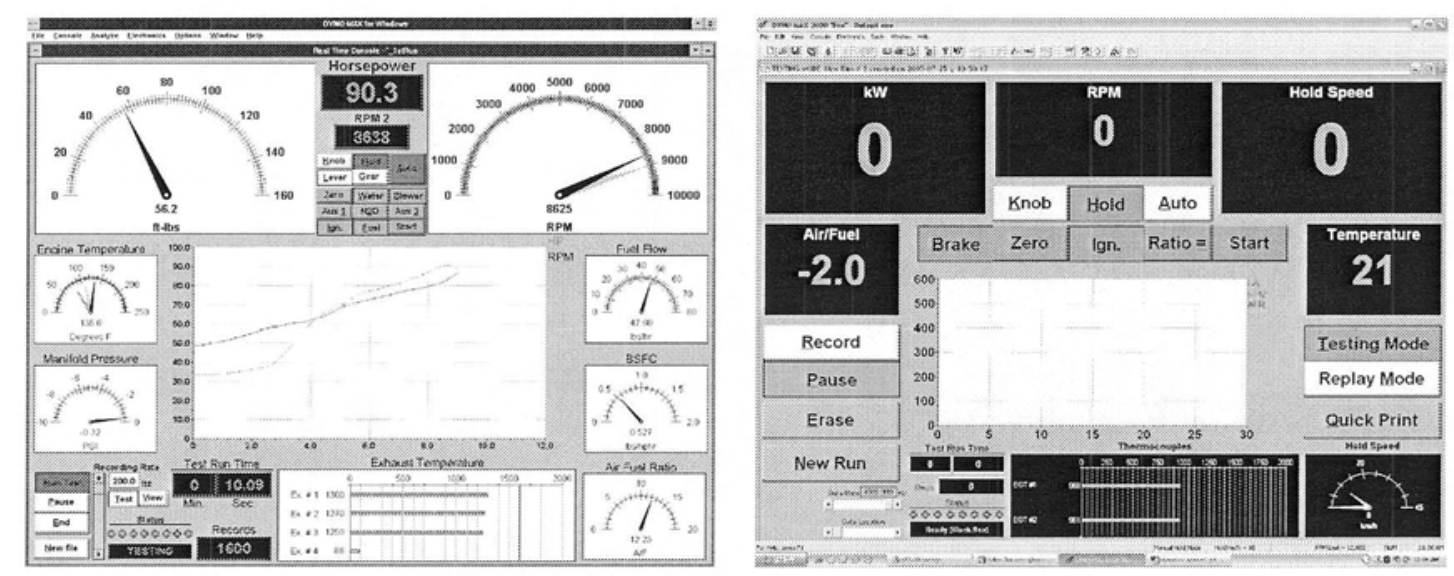

Figure 6-7 Software Console (left - original, right - modified)

\subsection{Operation of Test Fuel Cell - Battery Hybrid Electric Scooter}

The operation of the fuel cell scooter consists of several tasks: checking the hydrogen fuel supply; turning on power; and making routine maintenance [10].

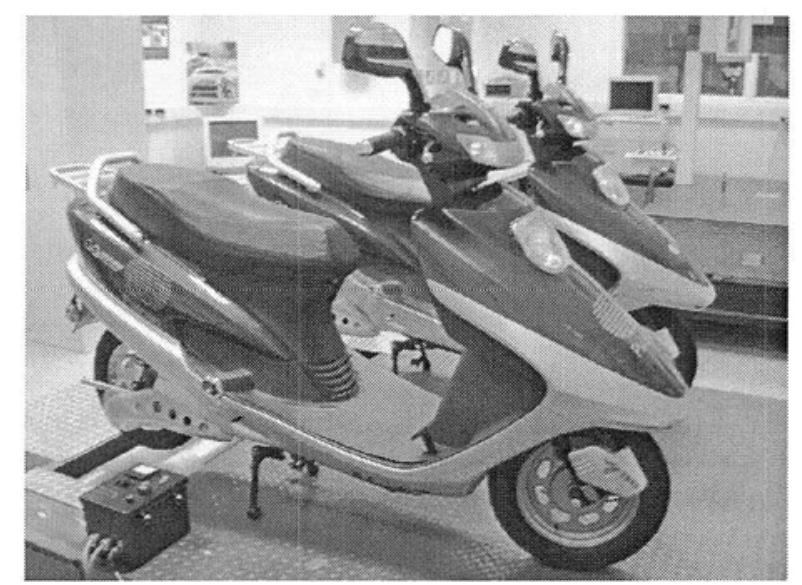

Figure 6-8 UVic fuel cell scooter 


\subsubsection{Hydrogen Fuel Supply}

For the hydrogen fuel refill, the external hydrogen source quick connect is situated in the glove box. The coupling piece is taped to the wall inside the glove box. It is attached to a high pressure flex hose from a 0-200 psig source of hydrogen. In the glove box, there also exists a manual valve with a red handle. It should be turned and pointing to the left, "FC CLOSED". The flex hose is purged by applying a small pressure of hydrogen ( -50 psig) and depressing the white plastic stopper at the end of the coupling. This assures that no air enters the metal hydride canisters. On the top left side of the glove box there is the quick connect body (Figure 6-9).
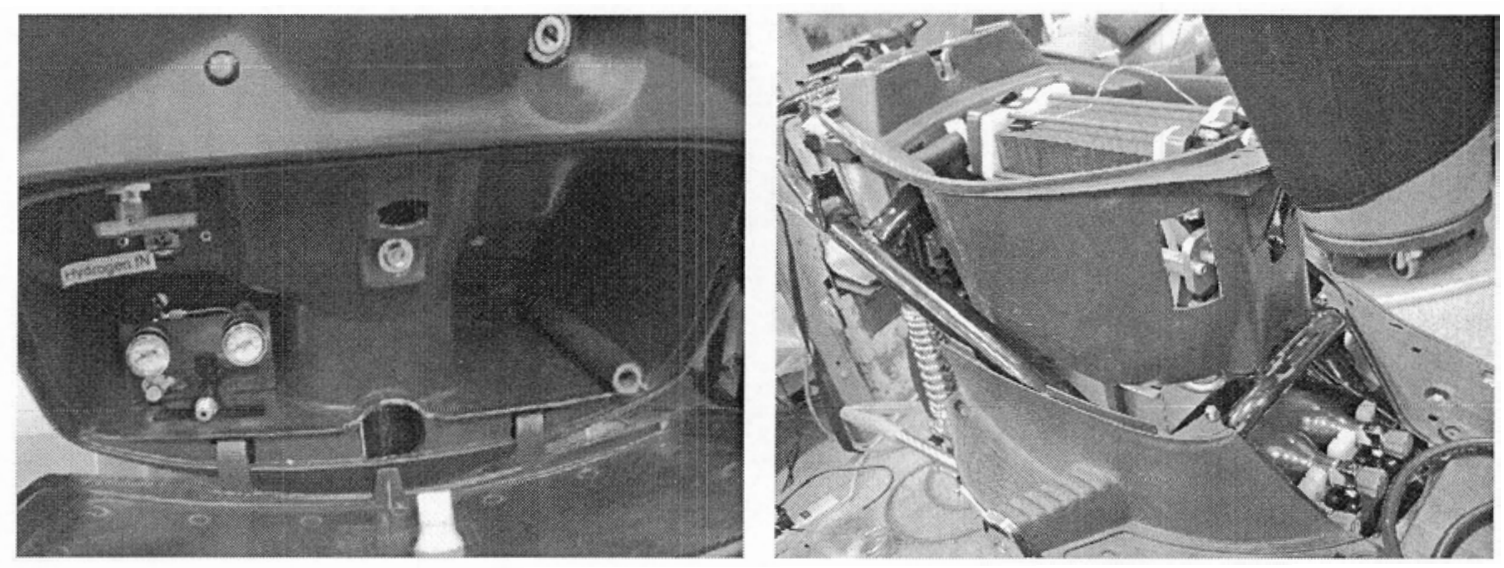

Figure 6-9 Glove box (left), fuel cell stack and metal hydride canisters (right)

The quick connect coupling is inserted in the quick connect body until a "click" is heard. To refill the metal hydride canisters, the canisters need to be manually opened. Between the driver's legs, under the seat, an air intake grid can be seen holding in place by four black finger-tight screws to be unscrewed and the grid to be taken off. The three metal hydride canisters are opened by turning the blue valve clockwise (three of the canisters to be opened). With that, the hydrogen from the external source flows in the canisters. The external regulator is increased to $150 \mathrm{psig}$. It can be noticed, the filling by feeling the heat on the metal hydride canisters produced by the exothermal absorption reaction. To activate the absorption process a fan should be placed in front of the air intake vent and cool air should be blown in the canister direction. The end of the absorption process is reflected by the return to room temperature of the canisters. The metal hydride canisters 
can be closed (if they are not to be used immediately) or left opened for a ride. The quick connectors are uncoupled by pushing in the small plate on the quick connect body. If an off-board hydrogen source (external source of hydrogen) is to be used to run the scooter, a pressure of more than 30 psig should not be used.

\subsubsection{Operation}

To start the scooter, the metal hydride canisters should be fully opened or that there is an external source of hydrogen attached to the scooter. The red handle manual valve must be set at "FC CLOSED". The water level of the cooling loop should be toped at the full line, and then the ignition key is to be turned on. On the left side of the handle bars, opposite to the ignition key there is a red button to be depressed and to be hold for at least one second. If no sound is heard (i.e. water pump or air pump starting), the ignition key is turned off and on again. Once the pumps is heard going, the red handle manual valve is turned pointing slowly to the right, " $\mathrm{H}_{2}$ to $\mathrm{FC}$ ". The scooter is left running for a few minutes before applying any load.

The scooter power system can either be turned off by pressing momentarily the red button or turning the ignition key to the off position (red handle manual valve to "FC CLOSED"). It is suggested to turn off all 3 metal hydride canisters or remove the external hydrogen source when the scooter is not being used.

\subsubsection{Basic Maintenance}

About the basic maintenance, it is important that the water loop is filled with pure water before operating the scooter. Because of evaporation through the sides of the MEA, cooling loop water needs to be toped up regularly. To change the water in the water loop, the loop needs to be drained first. A black plastic quick connect coupling has been provided in the glove box. To drain the cooling loop, insert the coupling in the quick connect body situated at the front left of the rear wheel is inserted. This opens the valve and the water will flow out immediately. The refilling cap is to be blew in, to expulse most of the water from the system. The quick connector coupling is removed by pushing 
on the button on the quick connect body, this closes the valve. To refill the cooling water loop, pure water is to be used as soon as the scooter has started. After reaching the top line, it needs to wait a few minutes and add water to the top. 


\section{SUMMARY}

\subsection{Conclusions}

Performance testing is an important part of Fuel Cell - Battery Hybrid Low-Speed Electric Vehicle development. Vehicle testing using a dynamometer system can isolate and quantify specific vehicle operation parameter from overall performance and aid the design and optimization of LSEVs and FCHLSEVs. The results from the dynamometer tests can develop realistic load cycles that can be used in the design and the evaluation of fuel cell systems.

In this research, a dynamometer system was custom-designed and built using key commercial components to satisfy the need of FCHLSEV research and testing. A system with 5" roller unit and Eddy current absorber, with the possibility to convert to 12 " roller unit and water brake absorber, and with structures to support all sensing, data acquisition and auxiliary devices was designed and built. Extensive computer modeling using Pro/ENGINEER CAD system was carried out for all components of the designed dynamometer system and the representative FCHLSEVs, including UVic fuel cell scooter and E-Gator utility vehicle.

This work provides the foundation and experimental tools for future experimental and theoretical research on FCHLSEVs.

\subsection{Future Work and Potential Improvements}

The design and construction of the dynamometer system have been completed in this work as presented in previous chapters. Future work along this line of research includes the further testing and calibration of the dynamometer system, and the development of the drive cycle loading mechanism. 
The present dynamometer system can simulate the operation of LSEV and FCBHLEV in principle. However, the accuracy of the simulation can only be approved by analyzing and comparing the experimental data.

To obtain the performance characteristics of the LSEV, typical driving cycles are to be applied to the test vehicle. At present, these drive cycles can only be applied manually by operating the vehicle. A direct input of the driving cycle to the motor controller can automate the process, improve accuracy and ensure test consistency. This has been implemented to our electric bicycle test station by Richard Stackhouse [1]. A similar system needs to be implemented or the same system needs to be applied to the electric scooters. Further improvement includes the design and implementation of a "closedlooped speed controller" can be incorporated into the dynamometer system. This device automatically controls the speed of the test vehicle and would be necessary to apply drive cycles. It obtains feed back from the RPM sensor on the dynamometer and adjusts the throttle of the vehicle to meet the set point value provided by the drive cycle (Figure 71).

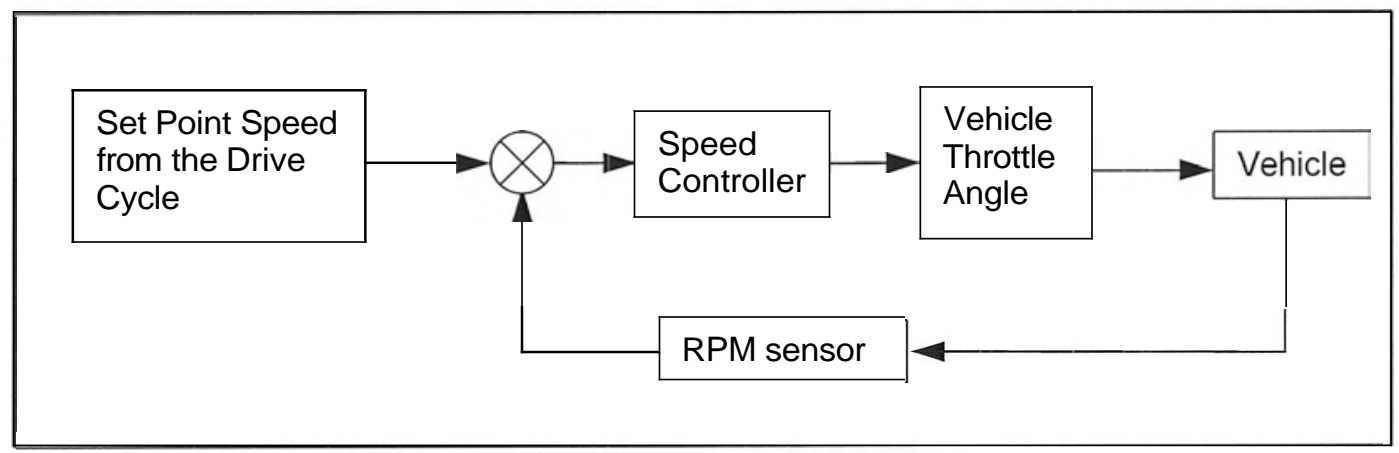

Figure 7-1 Speed control flow diagram

Another area of improvement is the forced air cooling of the ECA to allow high load to be continuously applied by the system, especially for prolonged operation. Enough space is left inside the platform to install a cooling fan. The size of the cooling fan can be determined upon the amount of heat created by the ECA. 


\section{REFERENCES}

1. R. Stackhouse, "Modeling, Design, and Testing of Electric Bicycles", MASc Thesis, University of Victoria, 2002.

2. Z. Dong, "A Generic Test Bed for Fuel Cell Powered Low-speed Electric Vehicles", University of Victoria, 2003.

3. F. Ramherdi, "Demand for Clean Fuel Car in Norway" http://www.tft.lth.se/kfbkonf/1 ramjerdirand.pdf, last accessed Sep 2004.

4. 0. Peksoy and S. Irhayem, "Powering a gator by fuel cell", University of Victoria, Fuel Cell Technology Project, March 2004.

5. Fuel Cell Tech, Hydrogenics Corporation website - http://www.hydrogenics.com, last accessed Feb 2005.

6. Montana State University, Fuel Cell Background website http://www.physics.montana.edu/sofc/bground.htm, last accessed Oct 2004.

7. Fuel Cells 2000, the online fuel cell information resource - http://www.fuelcells.org, last accessed Dec 2004.

8. Transportation - Energy and Environment, Transport Canada website http://www.tc.gc.ca/pol/en/Report/anre1999/tc9905ce.htm,last accessed Feb 2005.

9. E-power technologies presentation, John Deere Co. website - http://www.deere.com, last accessed March 2005.

10. Z. Dong, "Palcan - UVic Fuel Cell - Battery Hybrid Electric Scooter", University of Victoria, Nov 2004.

11. B. Lin, "Conceptual Design and Modeling of a Fuel Cell Scooter for Urban Asia", Princeton University, 1999.

12. Hybrid Electrical Vehicle Program, NREL (National Renewable Energy Laboratory) website - http://www.nrel.gov/vehiclesandfbels/hev,last accessed July 2004.

13. Z. Dong, "Customized hydrogen fuel cell battery hybrid electric scooters for lowspeed fuel cell hybrid electric vehicle research", University of Victoria, Feb2004.

14. U.S. Department of Energy Office of Transportation Technology website http://www.eere.energy.gov/vehiclesandfuels,last accessed May 2005. 
15. Advanced Vehicle Testing Activity, Idaho National Laboratory website http://avt.inl.gov/index.shtml, last accessed June 2005 and direct e-mail communication with James Francfort from INL, tel: 1(208) 526-6787.

16. B. Lin, "Taipei Driving Cycle", Personal Website http://www.spinglass.net/scooters/poster-content.pdf, Last Accessed Jan 2005.

17. K. Lees, "Fuel Cell Powered Electric Vehicle Testing", Technical Report, University of Victoria, Dec 2003.

18. Dynomite ${ }^{\mathrm{TM}}$ Dynamometers product catalogue and website - http://www.land-andsea.com, last accessed June 2005.

19. Muscle Car Club website - http://www.musclecarclub.com/library/dictionary, last accessed May 2005.

20. Designing with DC Motors, Massachusetts Institute of Technology - Center for Innovation in Product Development website http://lancet.mit.edu/motors/motors3.html\#top, last accessed May 2005.

21.2. Dong, "Concept design of the low-speed vehicle dynamometer and key components from Land \& Sea Inc", University of Victoria, Jan 2004.

22. Motorcycle Dyno Models, Dynojet Inc. Website - http://www.dynojet.com/, last accessed Dec,2004

23. Wikipedia Encyclopedia - http://en.wikipedia.org/wiki, last accessed May 2005.

24. O. Keskin, "Design of a Fuel Cell Scooter", Quantitative analysis, reasoning and optimization methods in CAD/CAM and concurrent engineering project, University of Victoria, Dec 2001.

25. Machinery's Handbook, $25^{\text {th }}$ edition, Industrial Press Inc.

26. Dyno-max2000 Help - Copyright (C2004 - Land \& Sea, Inc.

27. J. Larminie and A. Dicks, "Fuel Cell Systems Explained", John Willey \& Sons Ltd., England, 2003. 


\section{APPENDIX A: TECHNICAL SPECIFICATIONS OF VARIOUS LOW-SPEED ELECTRIC VEHICLES}

\section{Electric Scooters [10]}

\section{AGILTY:}

Maximum Speed : $45 \mathrm{~km} / \mathrm{h}$

Vehicle Weight : $<60 \mathrm{~kg}$

Carrying Weight : $75 \mathrm{~kg}$

Climbing Ability: $\geq 8^{\circ}$

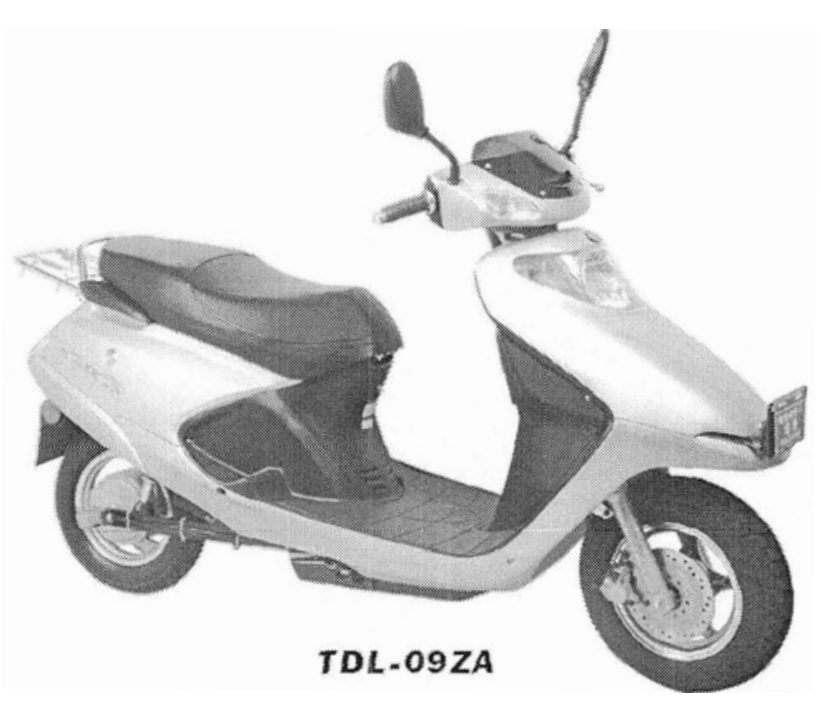

Rated Rotation Speed: 390r/min (323r/min)

Rated Power0300W 600W (maximum efficiency 88\%)

Rated Output Torque $\square 1$ ON.m (6.5 N.m); 12 N.m

Voltage (minimum) $\square 42 \mathrm{~V}(31.5 \mathrm{~V})$

Maximum Current $\square 22 \mathrm{~A}$ (14A)

Type of Motor: Hub Motor ( $\square 3000$ hours)

Power Use per Kilometer $\square 1 \mathrm{kw} / \mathrm{h}$

Battery $\square 12 \mathrm{~V} / 17 \mathrm{Ah} \times 4$

Type of Battery: Sealed Lead Acid

Charging Time $14-8 \square \square$

Charger $\square \mathrm{AC} 220 \mathrm{~V} 50 \mathrm{~Hz}$

Maximum Operation Noise $\square$ 62dB (A)

Range of One Full Charge $\square 45 \sim 60 \mathrm{~km} \square$ Normal Operation - flat, paved road, no wind,

$75 \mathrm{~kg}$ carrying weight and constant speed at $80 \%$ of maximum speed ). 
Electric scooters are defined in this report as a sit-down vehicle with a maximum motor power between $3 \mathrm{~kW}$ and $6 \mathrm{~kW}$. Common small sized battery powered electric scooters have the following specifications:

Table 7 Electric Scooter Specifics

\begin{tabular}{||l|l||}
\hline \hline SPECIFICS & VALUE \\
\hline Continuous Power & $1.5 \mathrm{~kW}$ \\
\hline Continuous Current & $63 \mathrm{~A}$ \\
\hline Maximum Power & $3 \mathrm{~kW}$ \\
\hline Peak Current & $180 \mathrm{~A}$ \\
\hline Gradeability & $8-10 \%$ \\
\hline Maximum Speed & $45 \mathrm{~km} / \mathrm{h}$ \\
\hline Acceleration $(0-45 \mathrm{~km} / \mathrm{h})$ & $8 \mathrm{~s}$ \\
\hline Range & $50 \mathrm{~km}$ \\
\hline Mass & $-100 \mathrm{~kg}$ \\
\hline \hline
\end{tabular}

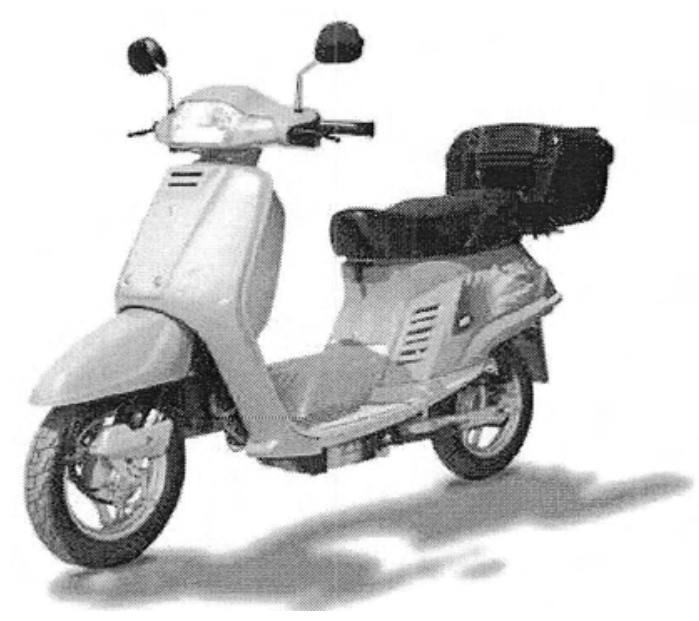

Figure A-0-1 A small sized E-Scooter

\section{Fuel Cell Powered Electirc Scooters}

PEM fuel cells are currently being adapted to power large electric scooters. For example, the ZES IV Fuel Cell demonstration scooter has been developed through collaboration with Asia Pacific Fuel Cell Technologies Ltd. (USA), Kwang Yang Motor Co., Ltd. (Taiwan), the Taiwan Institute of Economic Research (Taiwan), and the W. Alton Jones Foundation (USA).

The PEM fuel cell stack used to power the electric motor is rated at $6 \mathrm{~kW}(8 \mathrm{HP})$. It has a power density of $0.9 \mathrm{~kW} / \mathrm{L}$, a specific power of $1.0 \mathrm{~kW} / \mathrm{Kg}$, operates at atmospheric pressure at a temperature of 60 degrees Celsius, and uses pure hydrogen as fuel. The fuel cell engine produces $5.1 \mathrm{~kW}(6.8 \mathrm{HP})$ of traction power, is water-cooled, uses metal hydride fuel storage, and has a fuel capacity of 2400 liters of hydrogen. 


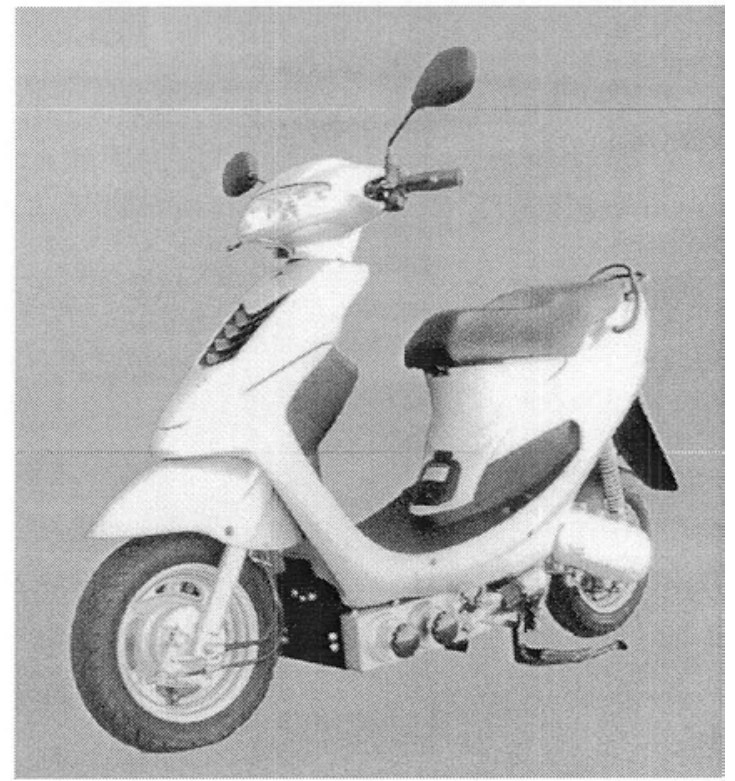

Figure A-2 ZES IV Fuel Cell Scooter

The ZES IV scooter has a mass of $95 \mathrm{~kg}$, a driving range of $160 \mathrm{krn}$, a refueling time of 2 minutes, and can achieve a maximum speed of $75 \mathrm{~km} / \mathrm{h}$. The scooter uses a DC brushless clcctric motor, and can climb grades of $18^{\circ}$.

\section{YAMAHA Golf Car (http://www.yamahagolfcar.com)}

\section{Specifications}

Overall Length Overall Width

Wheel Base

Min. Ground Clearance

Dry Weight

Seating Capacity

Maximum Speed

Max. Turning Radius

Transmission Type

Engine (G-MAX 4-

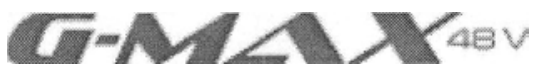

93.9 in. $(2385 \mathrm{~mm})$

47.2 in. $(1200 \mathrm{~mm})$

$64.3 \mathrm{in} .(1632 \mathrm{~mm})$

$3.8 \mathrm{in.}(97 \mathrm{~mm})$

549 lbs. (249 KG) (w/out Batteries)

2

$12 \sim 15 \mathrm{mph}(19.3 \sim 24.1 \mathrm{~km} / \mathrm{h})$

$65 \%$ Reverse Speed

$114.2 \ln .(2.9 \mathrm{M})$

Direct coupled high efficiency transmission designed for maximum performance.

Type of Engine: Yamaha low-emission, single-cylinder, overhead valve, 
$\begin{array}{ll}\text { Stroke only) } & \text { four-stroke. } \\ & \text { Total Displacement: } 357 \\ & \text { Output Rating: } 11.4 \text { HP @ } 3500 \text { RPM } \\ & \text { Cooling System: Forced Cooling } \\ & \text { Air Cleaner: Foam urethane pre-filter and automotive-type, high } \\ & \text { capacity pleated paper cartridge. } \\ & \text { Lubrication System: Splash }\end{array}$

Electric Motor/Speed

Type of motor: 48-Volt high-efficiency, shunt-wound GE motor with Controller (G-MAX 48V only) internal solid-state tachometer.

Output Rating: $2.5 \mathrm{kw}$ (3.4 HP) at $3540 \mathrm{rpm}$ for 30 minutes.

Speed Controller: GE solid-state micro-processor with high-efficiency MOSFET switching. 270-amp armature output, 20 amp field output.

\section{Additional Features found on all G-MAX Models}

Front

Suspension/Steering

Rear Suspension

Brakes

Frame

Seating

Body

Bumpers
Yamaha's Tru-Trak precision suspension and steering provides a comfortable, responsive ride via automotive style front struts linked to a fast ratio, self adjusting, greaseless rack and pinion steering system. With Tru-trak, minimal camber and toe changes result in a virtually adjustment free lifetime alignment.

Mono-link rear suspension with coil springs and hydraulic shock absorbers.

Mechanical with self adjusting, individual drum shoe brakes on each wheel. The all new, top, left parking brake with automatic release provides the driver with a better overall brake feel.

Engineers have minimized welds to provide a seamless tubular steel frame providing optimum strength and rigidity. Yamaha frames are protected by a three step anti-corrosive process which includes a full emersion phosphate coating, electro-deposition epoxy base coating and an electrostatically applied polyester/urethane powder top coat.

The largest seat in the industry has soft, comfortable virgin-foam seat cushions. Wrapped in seamless, durable fabric-backed vinyl and mated to the industries only warp and moisture resistant polypropylene seat bottom, this seat is not only built for comfort, but designed to withstand the abuse of high pressure washings.

Custom formulated color matched thermoplastic olefin, painted with a two part topcoat of high luster automotive grade polyurethane.

Yamaha's $5 \mathrm{mph}$ energy absorbing front and rear bumpers are the same height to minimize damage to the body and the frame during a collision. 


\section{ELECTIRC UTILITY VEHICLE John Deere E-Gator}

\section{FEATURES}

- Powerful $3.8 \mathrm{hp}(2.8 \mathrm{~kW})$ motor powered by a 48V system with 8 Trojan T-105 batteries accelerates faster, climbs hills better, and performs evenly until recharge

- Golf-cart-style drivetrain prevents need for engine re-start

- Tight, 24.1-ft. turn clearance circle

- Directional change control feature slows machine to a stop before changing directions to prevent whiplash and stress on the drive train

- 15.5-mph ground speed

- Separately excited controller provides overspeed control, dynamic braking, roll-away control, and regeneration

- Wide flotation tires, especially designed for turf applications, minimize ground compaction, provide good traction in mud, and flex over bumps for a smooth ride

- Wide wheel stance and low center of gravity offer passenger and operator superb stability

- Quiet, electric operation

- 16-gauge-steel, $11.2 \mathrm{cu}$. ft. capacity cargo box hauls up to $500 \mathrm{lb}$.

- Available at Golf and Turf distributors only.

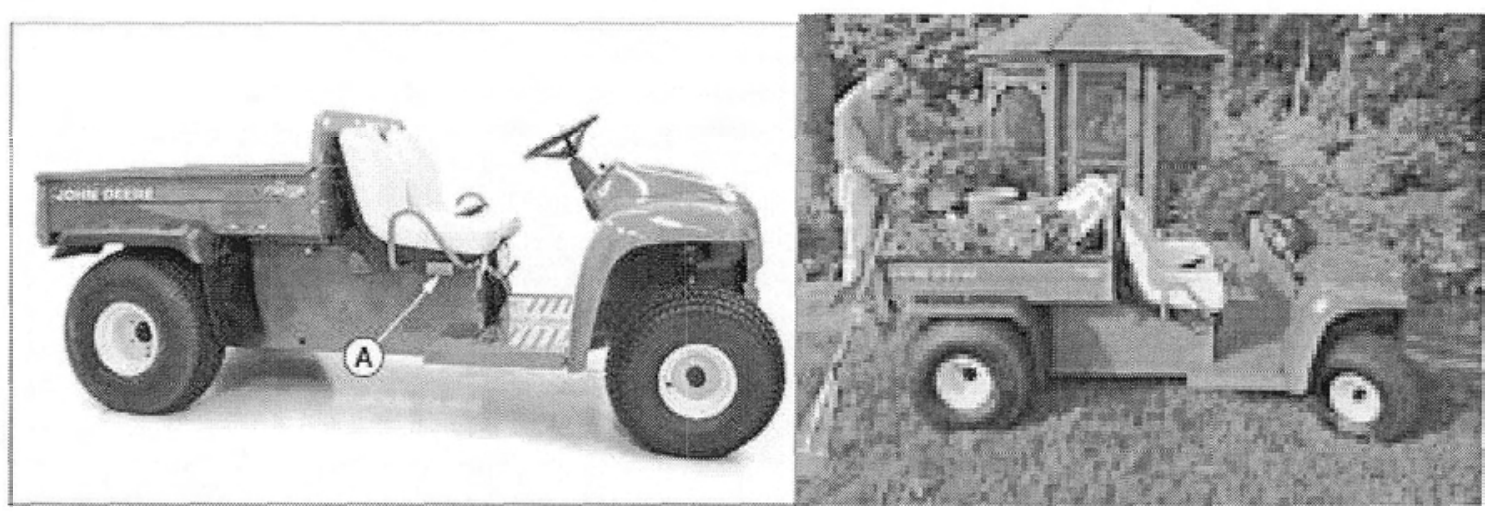

Figure A-3 John Deere ${ }^{\mathrm{TM}}$ E-Gator

\section{Drive System}

Motor

Horsepower

Controller

Transaxle

Electrical System

Brakes

Park Brake

Speed

Torque Converter

Battery
Separatley Excited DC Motor

3.8

Separatley Excited

Dana with Helical Gearing

$48 \mathrm{~V}$ with 8 Trojan T-105 Batteries

Dual Rear Wheel Mechanical Drum Self Adj

Hand Operated, Multi-latch

$15.5(25 \mathrm{~km} / \mathrm{h})$ Typical

N/A

Trojan T-105 or T-145 
Headlights Two 37.5 Watt Halogen

Tires

Front $\quad 22.5 \times 10.00-8$ 2PR Hi-Flotation Turf

Rear 25X12.00-92PR HiI-Flotation Turf

Steering Rack-and-Pinion

Suspension

Front Ind, Spring Over Shock, Single A-arm

Rear 2 Hi-Flotation, Low Pressure Tires

Dimensions

Height $\quad 44.5$ im. $(1130 \mathrm{~mm}) 44.5$ in. (1130 mm)

Width $\quad 60.0$ in. $(1524 \mathrm{~mm})$

Length $\quad 104.9$ in. $(2664 \mathrm{~mm})$

Vehicle Weight $1322 \mathrm{lb} .(600 \mathrm{~kg})$ with T-105 Batteries

Ground Clearance 7.3 in. $(185 \mathrm{~mm})$

Turning Clearance Circle $24.1 \mathrm{ft} .(7.3 \mathrm{~m})$

Wheelbase

69.5 IN. (1765 MM) 69.5 in. (1765 mm)

Payload Capacity

$900 \mathrm{lb} .(409 \mathrm{~kg})$

Towing Capacity $\quad 600 \mathrm{lb} .(272 \mathrm{~kg})$

Seats

Type

Tilt

High-Back Bucket

Restraint

Forward

Cargo Box

Length

Width

Hip Restraints

Depth

Capacity

Volume

Material

Tailgate

Power Lift

44 in. $(1118 \mathrm{~mm})$

49 in. $(1245 \mathrm{~mm})$

9 in. $(229 \mathrm{~mm})$

$500 \mathrm{lb}(227 \mathrm{~kg})$

11.2 cu. ft. $(0.32 \mathrm{~m})$

16-Gague Steel

Removeable, Hinged At Bottom REMOVABLE,

Ground Pressure $\quad 8.6$ psi (Fully Loaded)

Frame Mig Welded, Uni-Body

Fenders High Density Polyethylene

Charger

Type

Input Voltage

Ferroresonant Transformer

Input Current $120 \mathrm{VAC}+/-10 \% 60 \mathrm{HZ}$

12 amps AC (AC Start)

True RMS Power 1200 Watts

Estimated Full Recharge Time 12 hr. (Dep. Depth, Age, Temp, of Batt.) 


\section{APPENDIX B： SAMPLE POWER CALCULATION}

Having assumed the "torque" applied to the rollers from the wheels of the vehicle, and the "angular velocity" of the rollers are known, those values are substituted in the formulation below to obtain the power value. Torque is found from the product of the force (from the load cell, described in Chapter 4 and 5) and the torque arm length, and the angular velocity is obtained from the RPM reader (discussed in Chapter 5) or a calculation via speed and the wheel dimensions.

Power $(W)=\mathrm{T}(N m) \times$ a (radls)

For a scooter with $400 \mathrm{~mm}$ wheel diameter which is traveling at $30 \mathrm{~km} / \mathrm{h}$, rpm of the wheel calculated as;

$$
\begin{aligned}
& \mathbf{a}^{\mathrm{rev} / \mathrm{min}}=\frac{30 \frac{\mathrm{km}}{\mathrm{h}}\left(\frac{10^{6} \mathrm{~mm}}{400 \pi}\right)\left(\frac{1 \mathrm{~h}}{60 \mathrm{~min}}\right)=398 \mathrm{rpm}}{1 \mathrm{~mm}} \\
& \omega=398 \mathrm{rev} / \min \left(\frac{2 \pi \mathrm{rad}}{\mathrm{rev}}\right)\left(\frac{\mathrm{lmin}}{60 \mathrm{~s}}\right)=41.65 \mathrm{rad} / \mathrm{s}
\end{aligned}
$$

Assuming the torque value as $55 \mathrm{Nm}$, the power equals to;

$$
P=(55 \mathrm{~N} \cdot \mathrm{m})\left(41.65 \frac{\mathrm{rad}}{\mathrm{s}}\right)=2290 \frac{\mathrm{N} \cdot \mathrm{m}}{\mathrm{s}}=2.29 \mathrm{~kW}, 2.29 \mathrm{~kW}\left(1.341 \frac{\mathrm{Hp}}{\mathrm{kW}}\right)=3.07 \mathrm{Hp}
$$

or with the formulation; Power $(\mathrm{Hp})=$ Torque $(l b s$-feet $) \times \mathrm{RPM} / 5,252$

$$
=(55 \mathrm{~N} \cdot \mathrm{m})\left(\frac{1 \mathrm{lb} \cdot \mathrm{ft}}{1.356 \mathrm{~N} \cdot \mathrm{m}}\right)\left(\frac{398 \mathrm{rpm}}{5252}\right)=3.07 \mathrm{Hp}
$$

This formulation above is the result of combining several formulas into one. "1 horsepower" is defined as 550 foot-pounds per second. The units of torque are poundfeet. Thus, to get from torque to horsepower, we need the "per second" term. We get that 
by multiplying the torque by the engine speed. But engine speed is normally referred to in revolutions per minute (RPM). Since we want a "per second," we need to convert RPMs to "something per second". Then we divide by 60 to convert minutes to seconds.

A "radian", which we need a dimensionless unit for revolutions, is actually a ratio of the length of an arc divided by the length of a radius, so the units of length cancel out and we are left with a dimensionless measure.

A revolution can be thought as a measurement of an angle. One revolution is 360 degrees of a circle. Since the circumference of a circle is $2 \pi \mathrm{r}$, there are $2 \pi$ radians in a revolution. To convert revolutions per minute to radians per second, we multiply RPM by $2 \pi / 60$, which equal 0.10472 radians per second. This gives us the "per second".

We need to calculate the horsepower, which is 550 foot-pounds per second, using torque (pound-feet) and engine speed (RPM). If we divide the 550 foot-pounds by the 0.10472 radians per second (engine speed), we get 55010.10472, which equals 5,252. So if we multiply torque (in pound-feet) by engine speed (in RPM) and divide the product by 5,252 , RPM is converted to "radians per second" and we can get from torque to horsepower from "pound-feet" to "foot-pounds per second". 


\section{APPENDIX C: THE BRUSHLESS DC MOTOR}

The figure below describes the operation of brushless DC motor. The rotor consists of a permanent magnet and the switches direct the current from a DC source through a coil on the stator [27].

a)

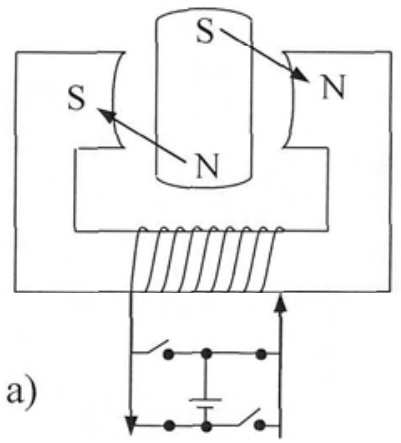

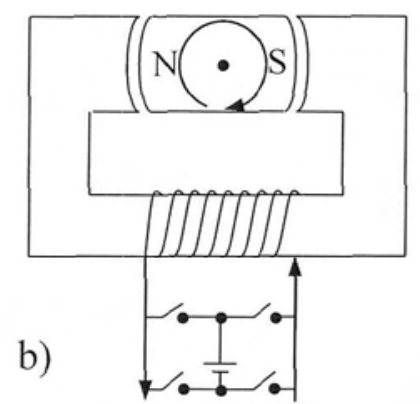

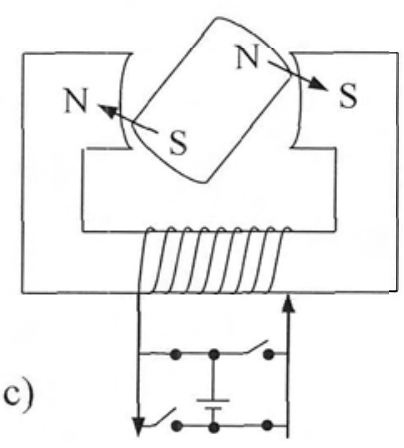

Figure C-1 The operation of brushless DC motor

a) The current flows in the direction that magnetizes the stator, thus the rotor is turned clockwise.

b) The rotor passes between the poles of the stator, and the stator current is switched off. Momentum carries the rotor on.

c) The stator coil is re-energized, but the coil (and hence the magnetic field) are reversed, so the rotor is pulled on round in a clockwise direction.

The switching of the current is synchronized with the position of the rotor by using sensors. Electric circuits, inverters, are used to drive and control the coil currents.

Torque is inversely proportional to the speed of the output shaft; it reduces as the speed increases. The rotating magnet generates a back electro magnetic field (emf) in the coil that is approaching. This back emf is proportional to the speed of the rotation and reduces the current flowing in the coil. The reduced current reduces the magnetic field strength (and hence the torque). Consequently, the size of the induced back emf equals the supply voltage, and at this point the maximum speed is reached. 


\section{APPENDIX D: TECHNICAL DRAWINGS}

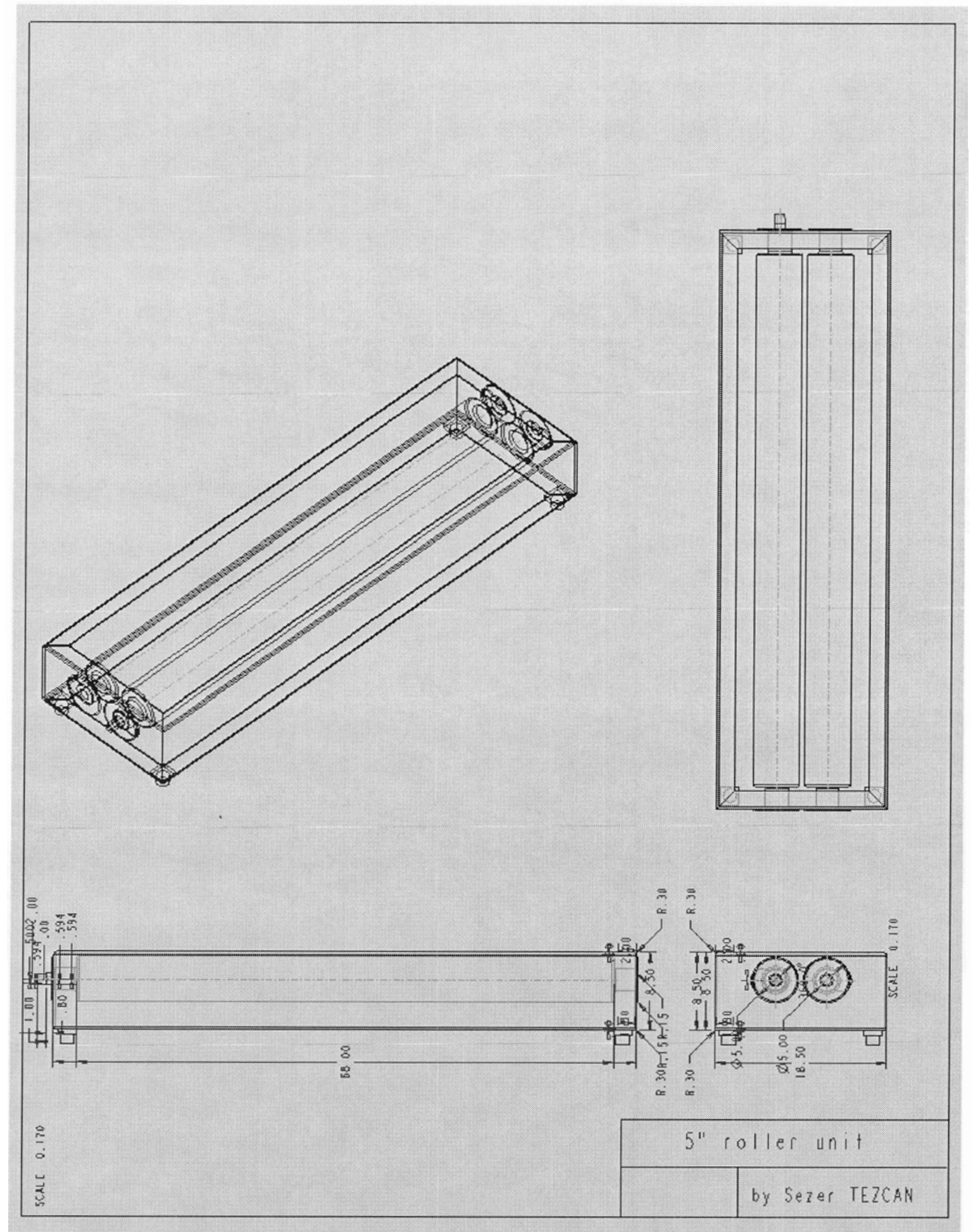

Figure D-1 5" Roller Unit 


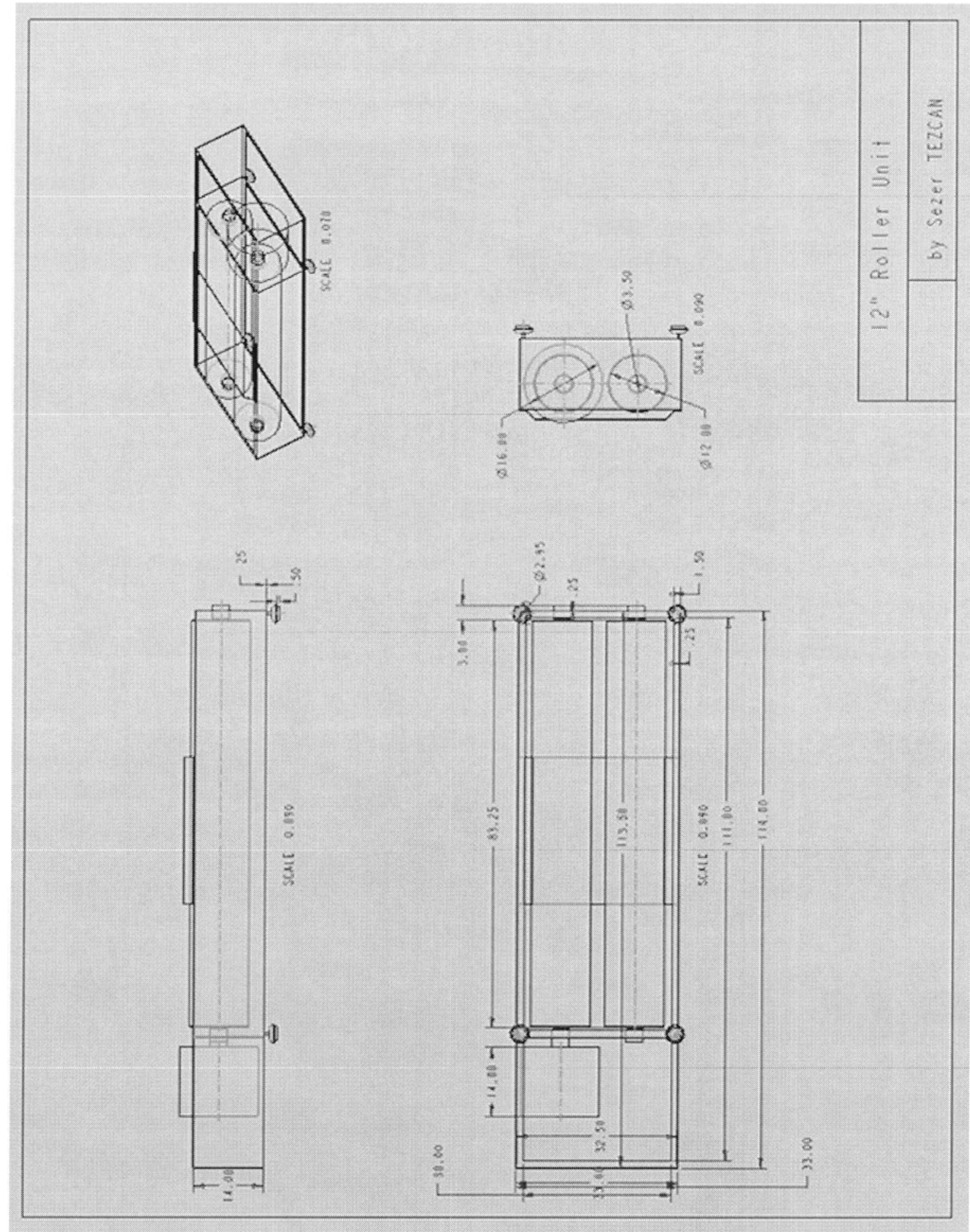

Figure D-2 12' ' Roller Unit 


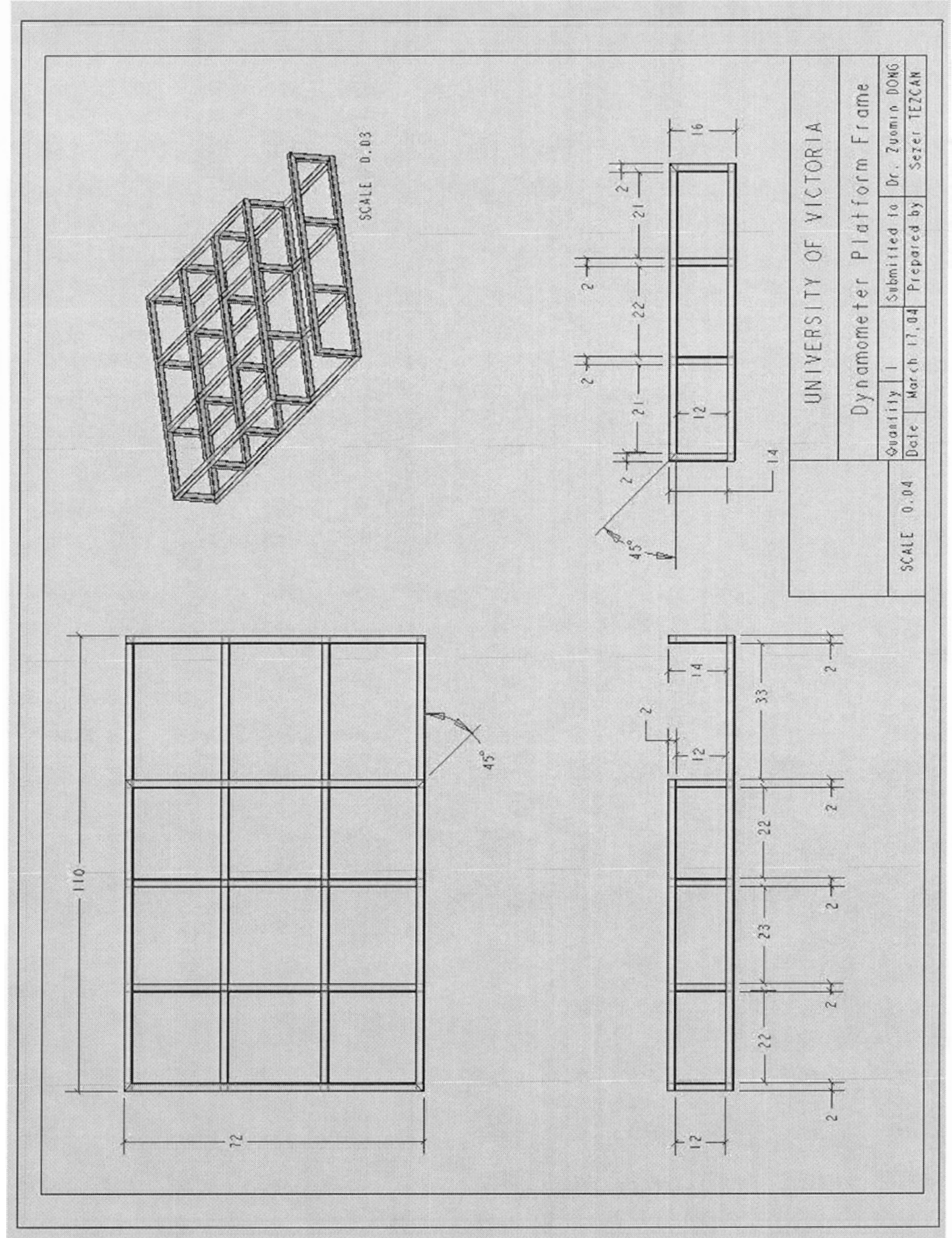

Figure D-3 Dynamometer Platform Main Frame 

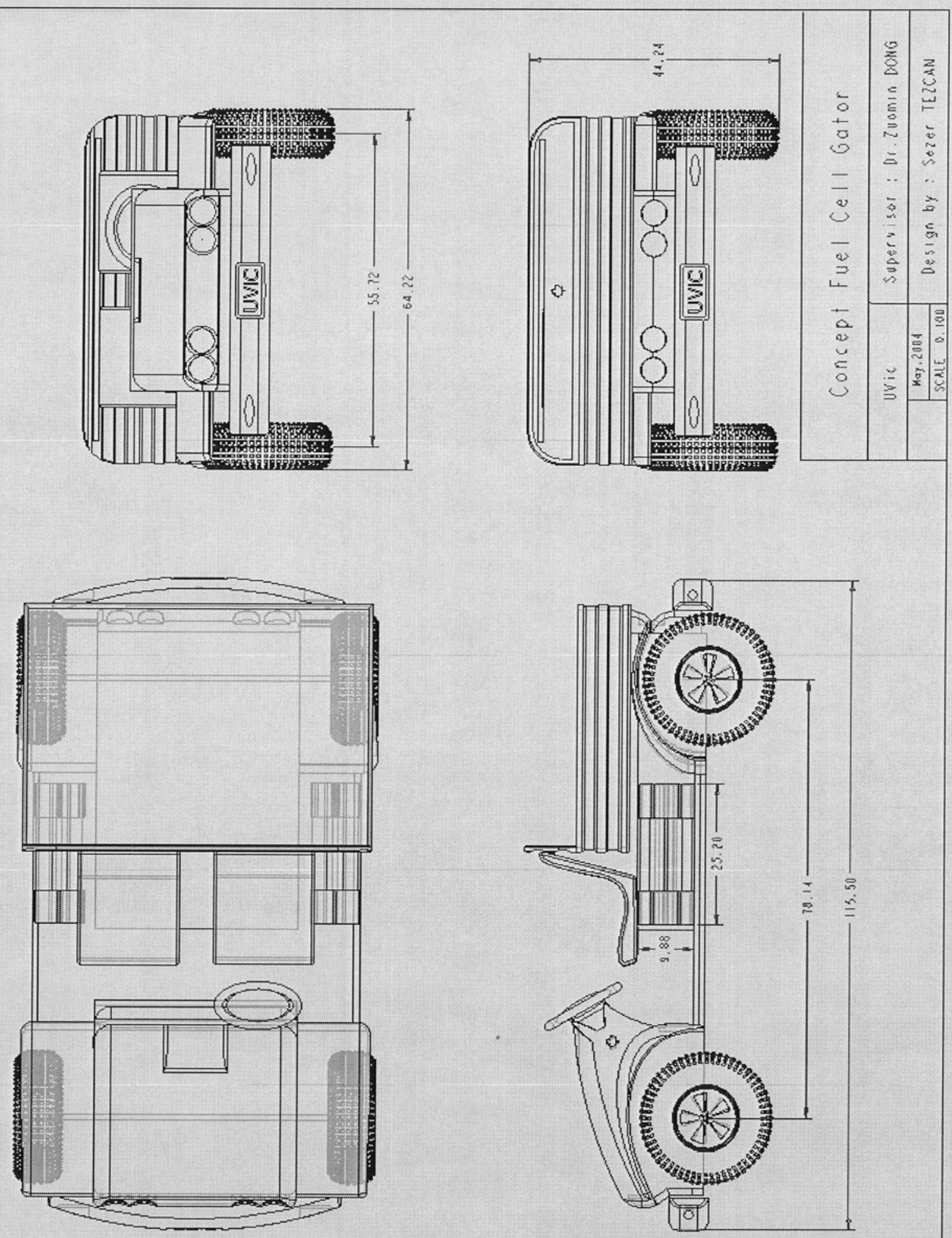

Figure D-4 Concept fuel cell powered E-Gator 


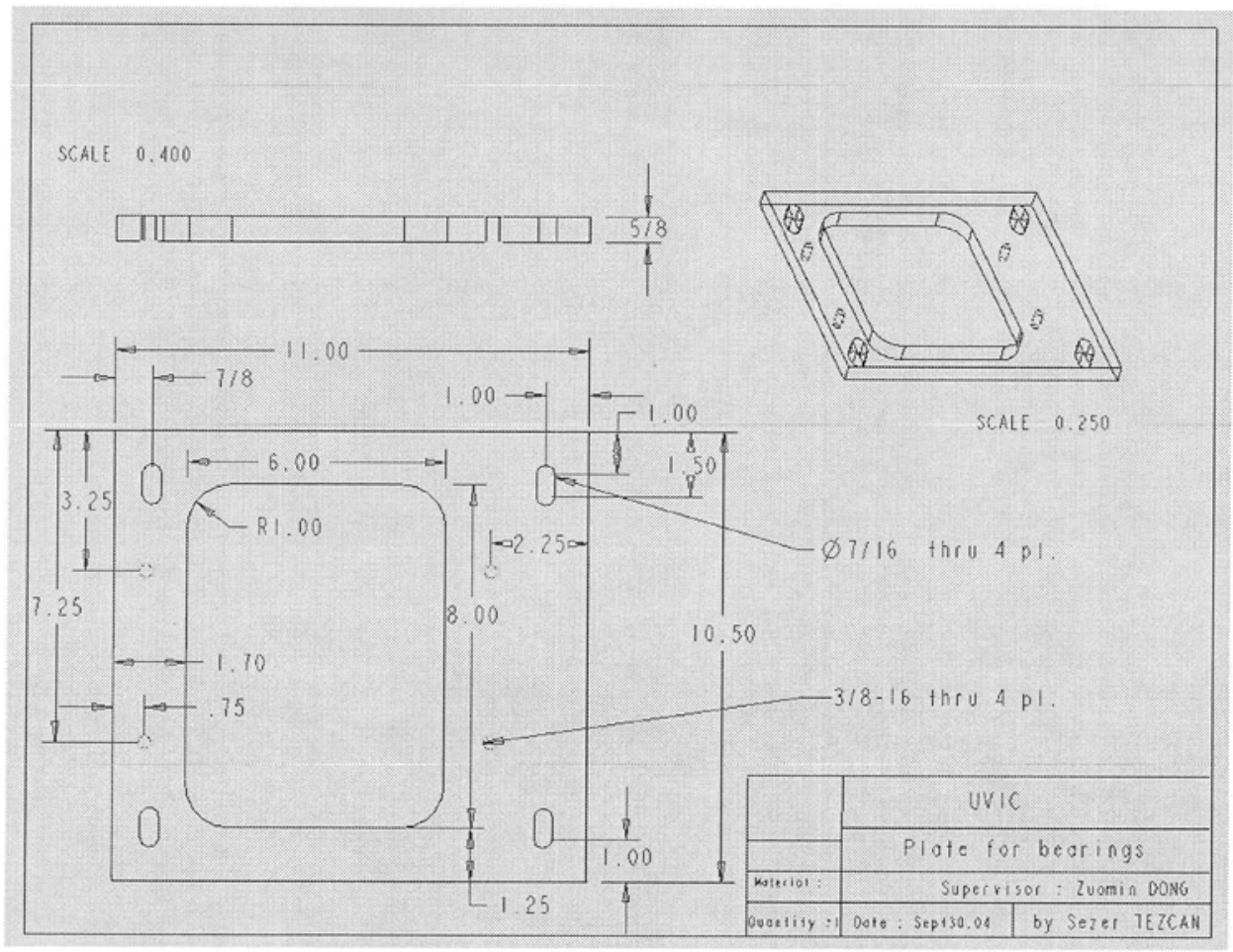

Figure D-5 The Alignment Plate for the Eddy Current Absorber

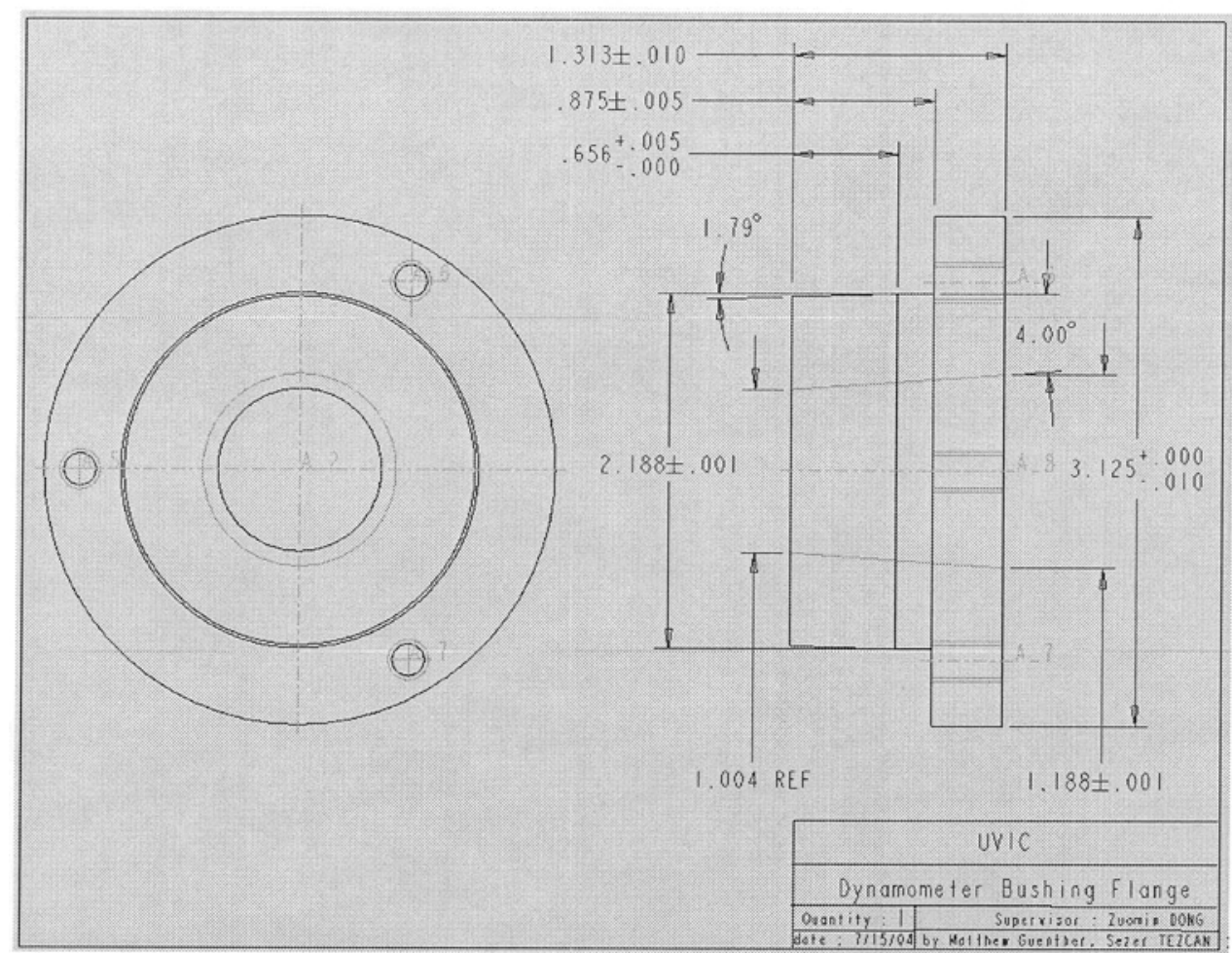

Figure D-6 The Bushing Flange for the Roller-Belt Connection 


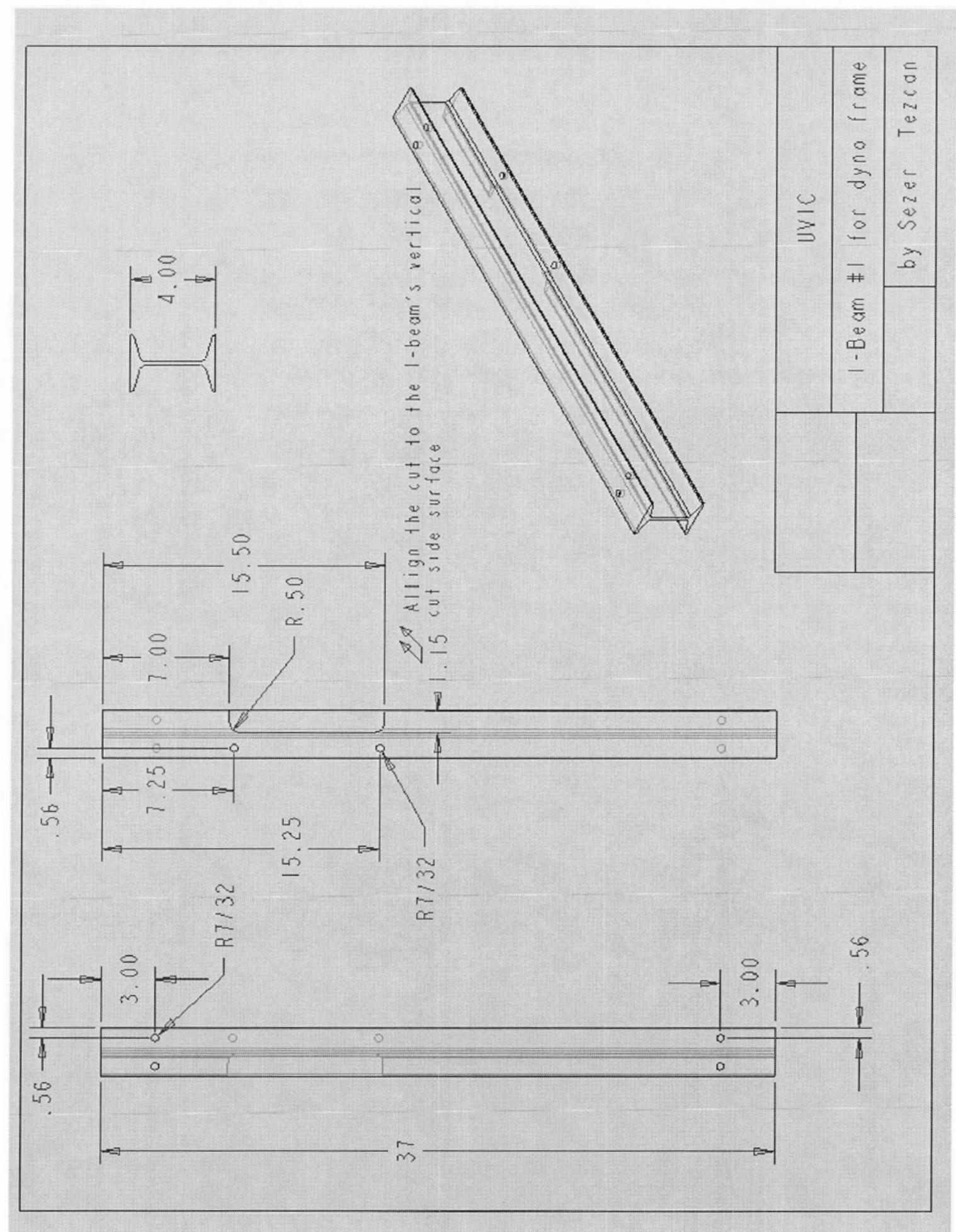

Figure D-7 I-Beam with the cut 


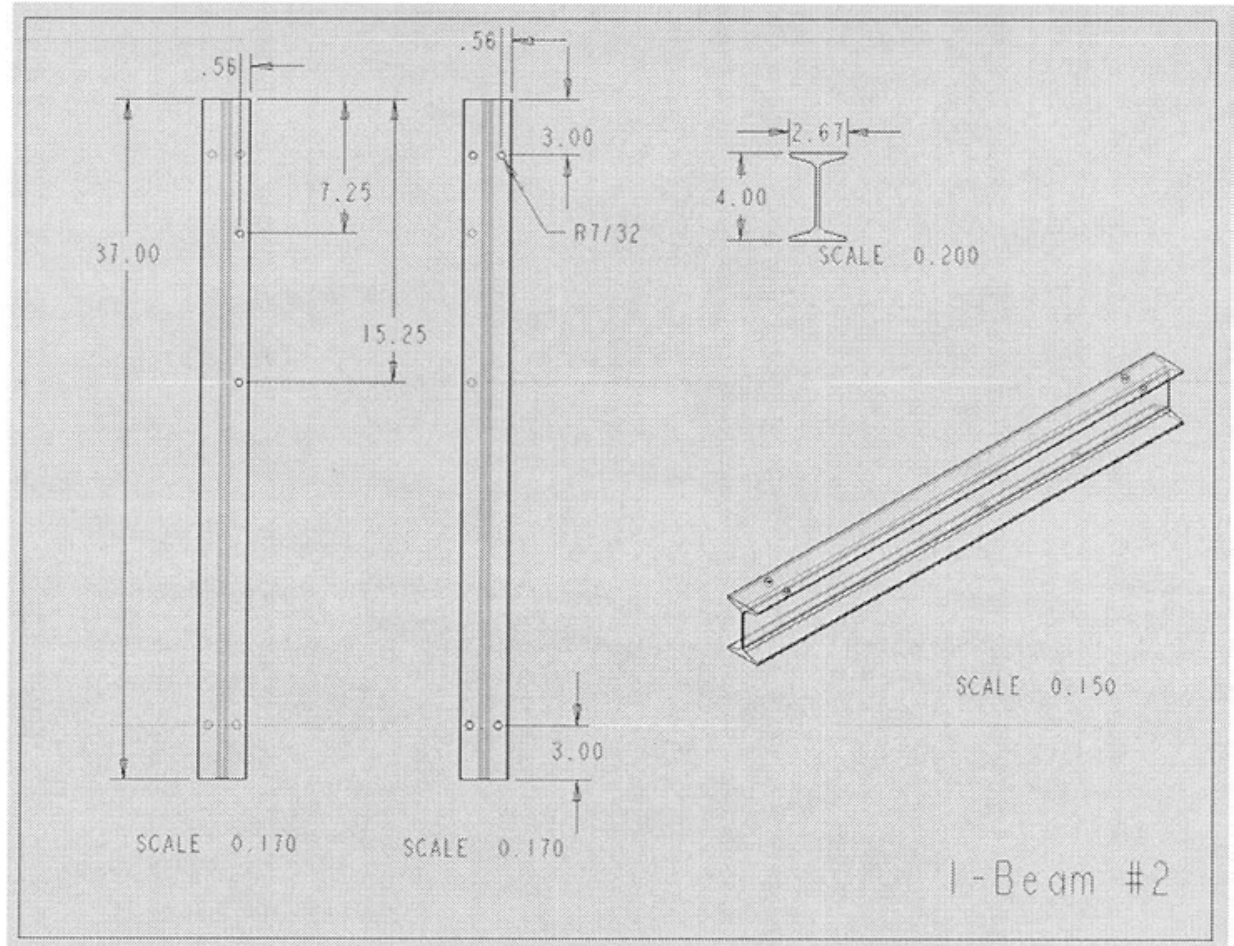

Figure D-8 I-Beam \#2

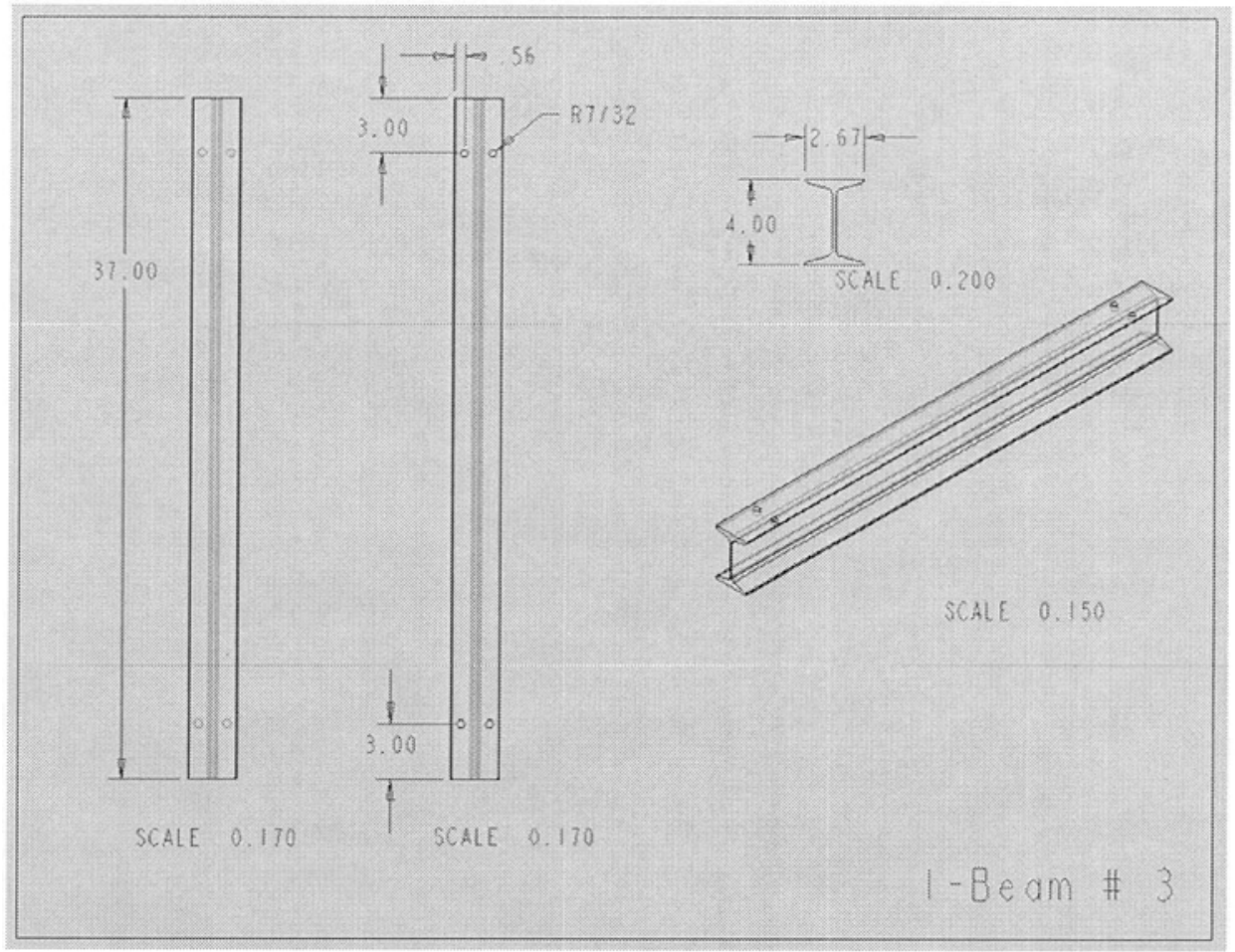

Figure ID-9 I-Beam \#3 


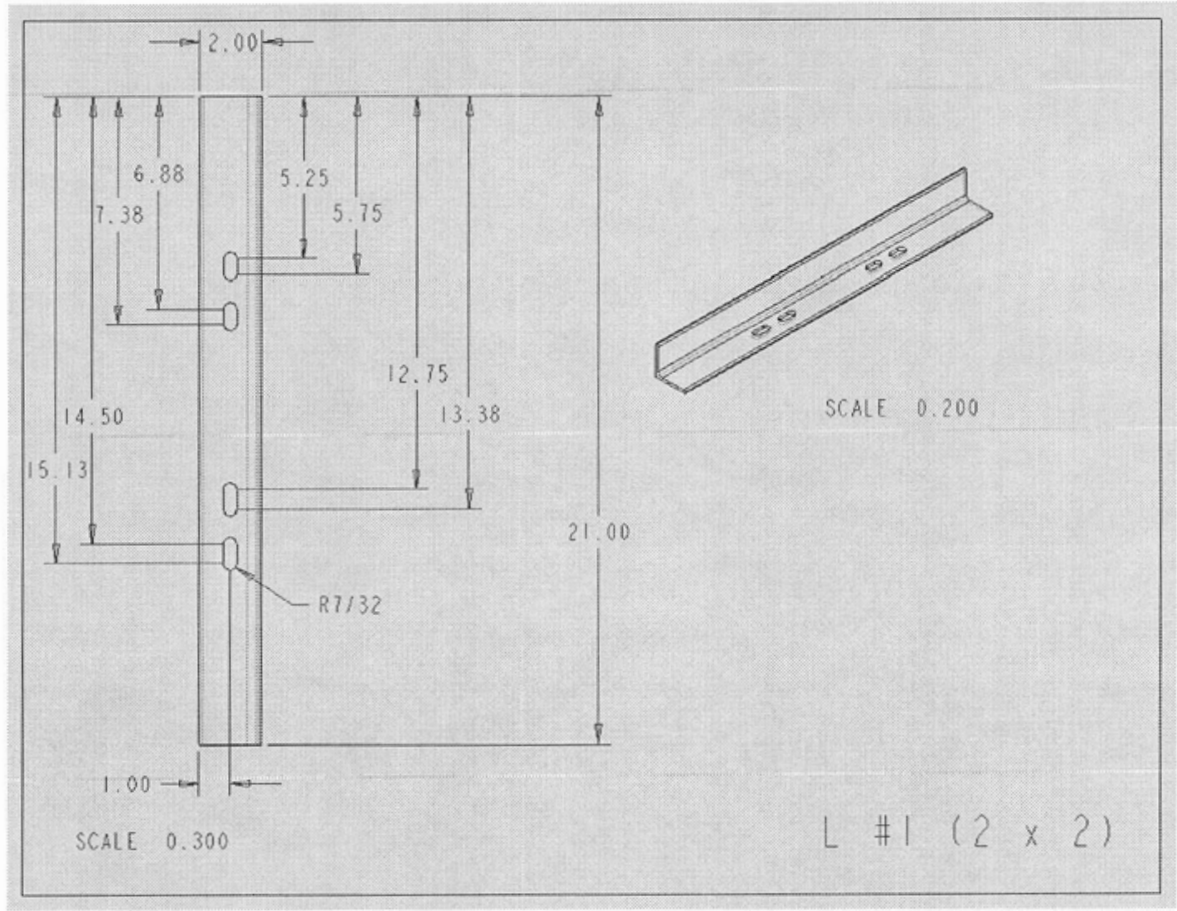

Figure D-10 I-Beam Mounting Brackets

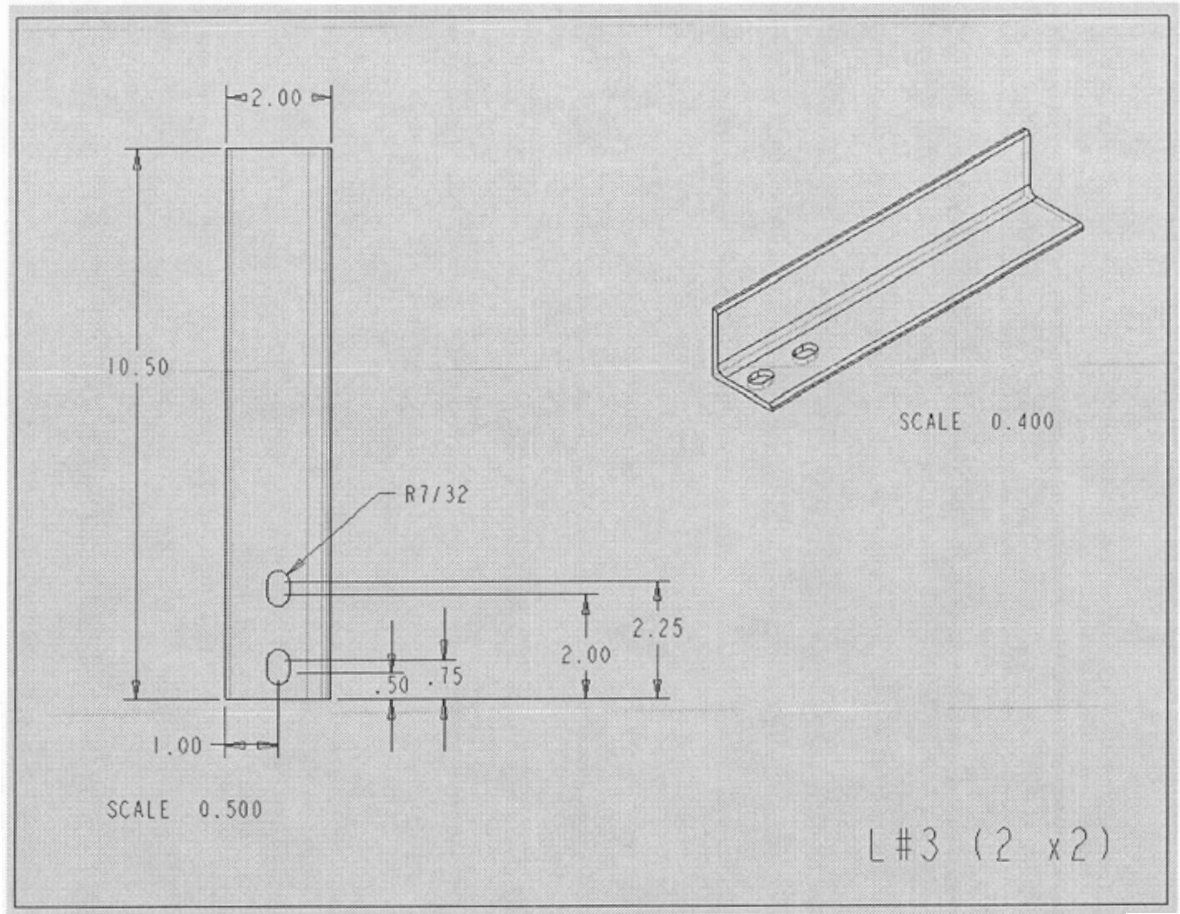

Figure D-11 I-Beam Mounting Brackets 


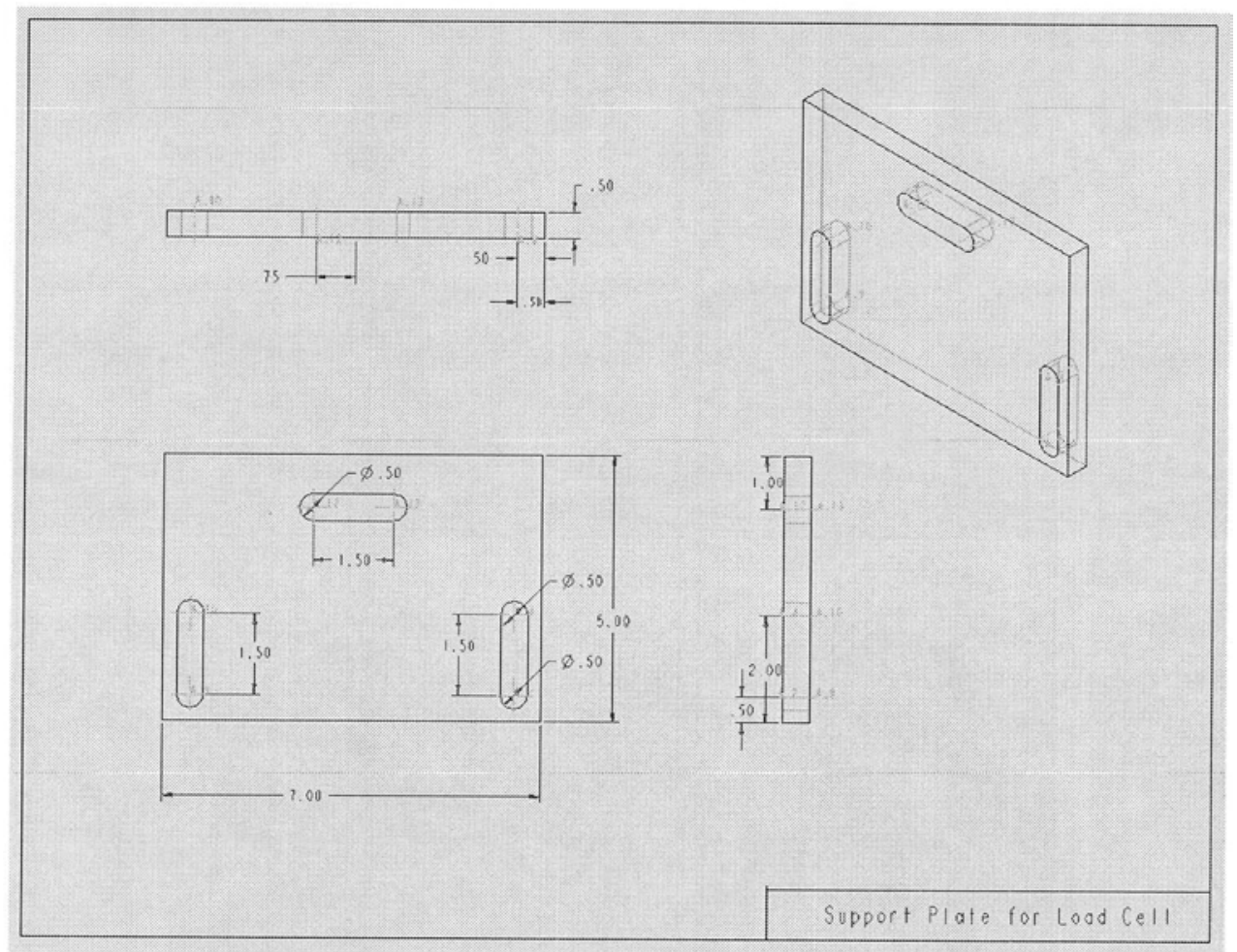

Figure D-12 The Support Plate for the Load Cell

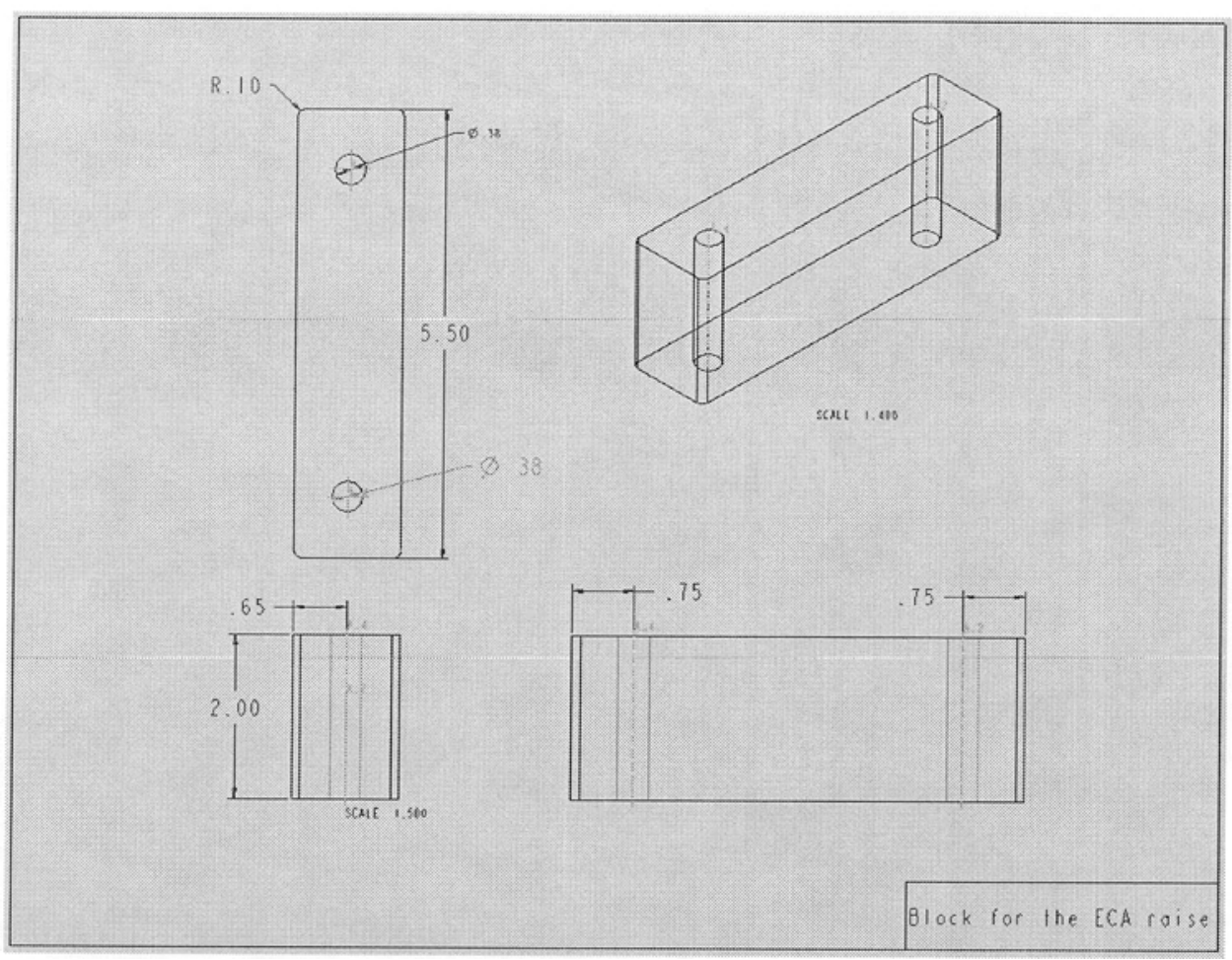

Figure D-13 The Metal Block for ECA raise 


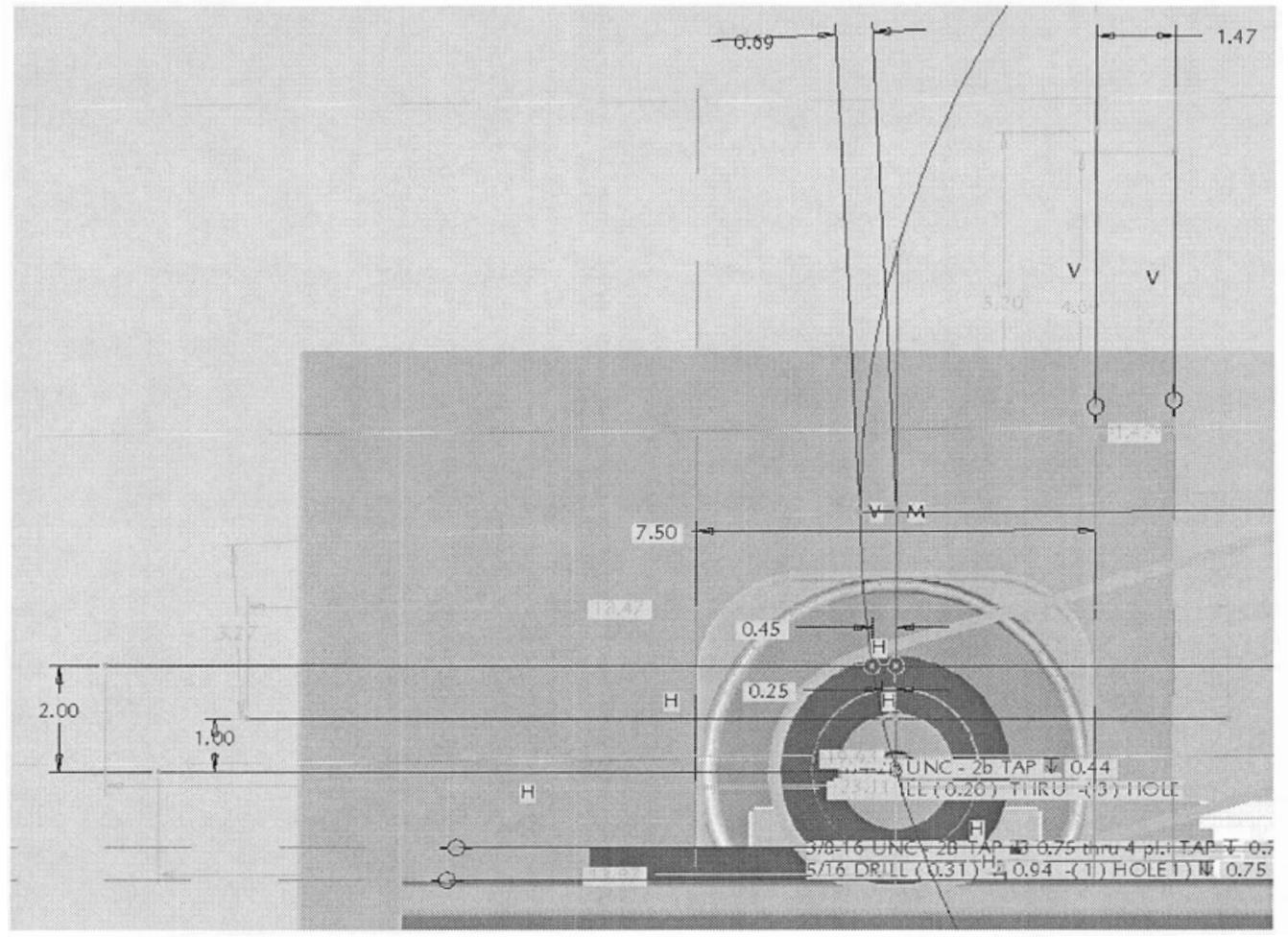

Figure D-14 The study of raising ECA for rollers wide positions 


\title{
APPENDIX E: SOFTWARE INSTRUCTIONS
}

\author{
(Dyno-max2000 Help - Copyright $\mathbb{O} 2004$ - Land \& Sea, Inc.)
}

1) If DYNO-MAX 2000 is not already running, go to your Windows Start button and select Programs DYNO.MAX 2000

2) Each time DYNO-MAX 2000 starts it automatically opens (and minimizes) the last session's Enwironment Initially that will be the default env file The Enironment "points" to the seven active Configuration files from the last test session

To Restore (expand) the minimized Envlronment window, select

Window - 1 ENVIRONMENT: Default env

Leave things alone for now, but understand that you could change any of the displayed configuration file pointers by browsing to a different (appropriate) configuration file

Next, hook-up the appropriate cable (s) between your PC's serial port(s) and (each of) your DYNOmite Data Acquisition computer's board sets

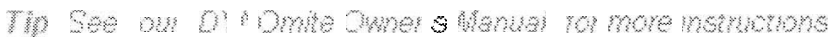

4) Power up the DYNOmite Data Acquisition computer

Important: If you are using a DYNOmite-Basic model with an LCD and 4-button panel, make sure it is in RS-232 Mode \# 16.

Tip: See your "DYwomite Owher's Manus?" for more inathutions.

5) Select Electronics m Communication Ports Setun and verify that "Board: 11 ID: \#1 Type:

DYNOmite-Basic Board..." is the first Board on the list*. If you have multiple boards, the second listing must be "Board: \#2 ID: \#2 Type: DYNOmite-Basic Board..." If your listing is different, use the Replace, Add, ar Delete buttons (as required) to Open the appropriate combination of DYNOmite-Basic Board ID \#.daq files.

"Important If you are using a DYNOmite-Pro (or -Lite) board set, select the matching type of board (instead of -Basic as in the above example).

6) For each board listed, check that its Corn Port \# is assigned to same PC Com Port \#that you have plugged your DYNOmite board sets into Also make sure that the default DYNOmite-Basic Baud Rate af 57,6000 (or 115,200 for DYNOmite-Pro and -Lite board sets)

7) Before trying to capture your own data, click File - Open Run to load the demo test Run Information file Small Block sample run By default, it's located in your c \{Program Files:DYNO-MAX 2000Runs folder

8) The Run Information panel opens to display the Small Block sample test header data. Spend time examining the Run Information window's many tabs and fields. Much of the displayed data is just optional information, but several required fields must always be correctly filled in for accurate test results.

Tip: See the Help (use your PC's F1 Function Key) under Bur lintormation for delsils about each panel tab.

9) Whenever a Saved Run is open like this, you can examine its test data. Select View - Graph (or press your PC's F5 Function Key) to display the Run's (current default format) graph.

Tip: Graphing may take several seconda depanding on your PC's sweed the length of the Pun, the complexty of its displayed Formula hes, and the maxmum amount of damening set for anv one chanrel.

10) The Graph's window has special Toolbar Icons (and right click menu choices) for zooming, panning, clipping segments, examining data points, print previewing, and Graph Set Up.

Tip. Click on the Eyeglass icon button and then left-chich on a Graph he (using the Eyeglass cursor). A yellow infomstion ballow appears whth information about that point on the graph.

11) To modify the Graph's design, select View - Graph Set Up to open the Graph Set Up Editor. Important: For access to most menu choices in DYNO-MAX 2000 you must have a Run open. This is because DYNO-MAX2000 sores most configuration parameters whin each Fun file, thus allowing Puns to 
to retain their last settings!

12) The Graph Set Up Editor has one or more tabs, each representing the available Graph layouts (currently stored within this Run). You can modify, add, and subtract layout tabs as needed. Right now, click on the " $\mathrm{Hp}$ us. Time Averaging" layout tab (making it the active graph tab).

13) Notice the window listing several Formula Lines. Each is labeled with its data channel Formula's Short Line Name (i.e. RPM, Hp, etc.). By selecting other Formula's (from the Formula: drop down list) and then clicking on Insert Line, you can modify the information shown in any Graph layout. You can also change the axis scaling, axis legends, averaging method, and much more.

14) Next, click on the "Hp vs. RPM Steps" tab, and then click on "OK." Notice that the Graph redraws - but with Engine RPM as its Xaxis. For more information on graphing, review this Help system's Graphing topics.

15) Try clicking the Graph's Print Preview toolbar icon [3. (or select File - Print Preview) to see a close representation of how the Graph will look when output to your printer You can click on the Preview 'window' s Print.. button to actually print this Graph now, or click Close to exit

16) Click on the Small Block sample Run Information panel again (to give that window the focus). To review its full Bun Inommation fevont, select File - Print Preview. After several seconds (while your PC graphs and formats the data), the pages of the Report preview. Examine each page of this Report using the Preview's Next Page and Prev Page buttons.

Tip: If your Preview is too small, use the Preview menu's Zoom in buton.

17) Notice that the Report has several Group boxes (General, Weather, Inertia, etc.) Each displays information about the Run's test conditions. The next step will show wot how to turn any Run Information Group off (in Reports). Close the Preview for now.

18) Click back in the Small Elock sample's Run Information panel Perhaps you do not want every tab's information (say the Vehicle tab) on your own printed reports To hide thrs tab, first click on the Yehicle tab Notice that a Checkbox is checked next to Show an Run Information Report click on that check to toggle it off (un-checked)

19) Use the Print Preview feature again to verify that the Vehicle Group section is gone from the Run Information Report! Click Close to exit the Preview again.

20) Return to the Small Block sample Run Information panel Toggle the Vehicle group back on (if you want it to print out on future reports)

21) Each of the Run Informatron's tabs also has a similar Show on Quick Report Checkbox These toggle the respective Report Group sections in the same way, but "Quick" selections apply only to Reports printed while the Console has the focus (I e using the Console's Quick Print button)! (As opposed to Reports printed while your are within the Run Information panel )

Tip: What appropriste set up, you can have a long repot for use gt the end of a test sessioni, and a short "quick and dirty" report with just the essentials (for printing curing testing). If you have the "Pro" veraion of DYNO-MAX 2000, you will eventually want to experment with its Report Designer to customize the individual Groun fielis:

22) Select Console - Dyno Cell... (or click the Dyno Cell toolbar icon Wl or just press your PC's F11 Function key) to open up the Console. This is DYNO-MAX 20IO's mission control center Click on the Console's Replay Mode button (or press your PC's letter "M" key) to prepare for play-back.

Tip. You can press any Console Button's underined letter to actwate it (whthou using the mouse) from your PC's keyboand. This is much faster then the mouse ciung actulal testing

23) Because the Console was started from the Small Block sample Run Information panel, that run's test file is already loaded. 
23) Because the Console was started from the Small Block sample Run Infarmation panel, that run's test tile is already loaded.

Tip Notre that Small Block sample shows as the suffix on the Console winchow's blue Titie Bar

24) The Console uses VCR like buttons to control recording and playback. Press you PC's "P" key to push-in the Play button (or click it with the mouse) to revrew the Small Block sample run Since you have not modified the Console's Gauge and Alarm Properties, everything displays as it did durng its original RPM Sweep Test recording A Trace Chart also graphs selected Channel Formulas

25) Notice that a WAn Tachometer gauges change color near the end of the sweep test. This is because the Thermocouple and RPM exceed preset Alarm Limits. Different Alam Limis and Actibis can be programmed by you for any test session. Depending on you current preference settings, you may even hear the tachometer and audible voice alarms, or see a small video window showing the engine running in the cell.

Tip: All of the Console Geuge's, Tites, Rangea Scaling, Resolution, Unit, Chan Axis, Alam Limits and Actions can be reconfigured to sut your ow tesing

26) When the Run is finished re-playing, the Console's Test Run Time clock and the \# of Recs (Records Counter) stops Its Status message also changes from "

27) The Console has a Freeze button to temporarily halt playback, a Rewind button to return to the beginning of the run (ready to play again), and a Ouick Print button to print the currently defined Quick Print Report. Lastly, the Open Run button loads a different mu (from your PC's Hard Disk) ready for reviewing within the Console.

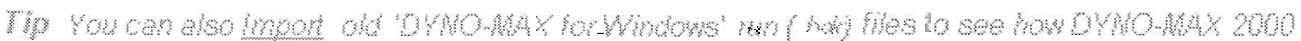

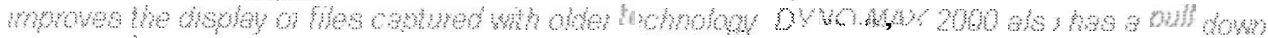

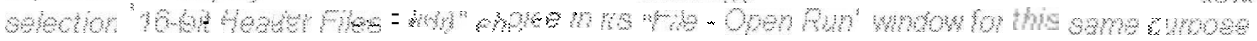

28) Prepare the Console for Real Time data collection by clicking on its Testing Mode button. If your DYNOmite Data Acquisition Computer is actively communicating with DYNO-MAX, the Status message will display ready

29) Several items on the Console change between Replay and Testrng modes For example The Play button becomes a Record button (for capturing data), the Freeze button becomes a Pause button [to pause recording), and the Rewind button swrtches to an Erase button (that deletes any unsaved test recording) The nine Relay Control buttons change from gray to colors, indicating they're available to operate assigned hardware options Five new Servo Mode buttons appear These toggle between Manual, Servo, and Auto Testing mode for both the Electronic Laded vake and Thatwle Gear options

30) The Real Time Console's New Rum button initiates closure of the last test recording (if one made in this sessron) and then opens a New Run tile

Finish exploring all of DYNO-MAX 2000's basics, before coming back to the Real Time Console to capture data from a running engine.

Important: After you have looked over more of DYNO-MAX 2000 on your own, we suggest reviewing this Getting Started Help topic a second time, spending more time reviewing each screen's individual Help Topics (which explain individual field functions).

Tip: Be sure to review all the required fields in the Run Information panel, as these settings influence test resuts! 